US Army Corps of Engineers ${ }_{\circledast}$

Engineer Research and

Development Center

\title{
Prototype Test of a Water Jet System to Mitigate the Transport of Asian Carp by Barges
}

Duncan B. Bryant, Jarrell Smith, Richard Styles, Benjamin

November 2019

Burnham, Christopher Callegan, Jonathan Marshall,

and Mary Claire Allison

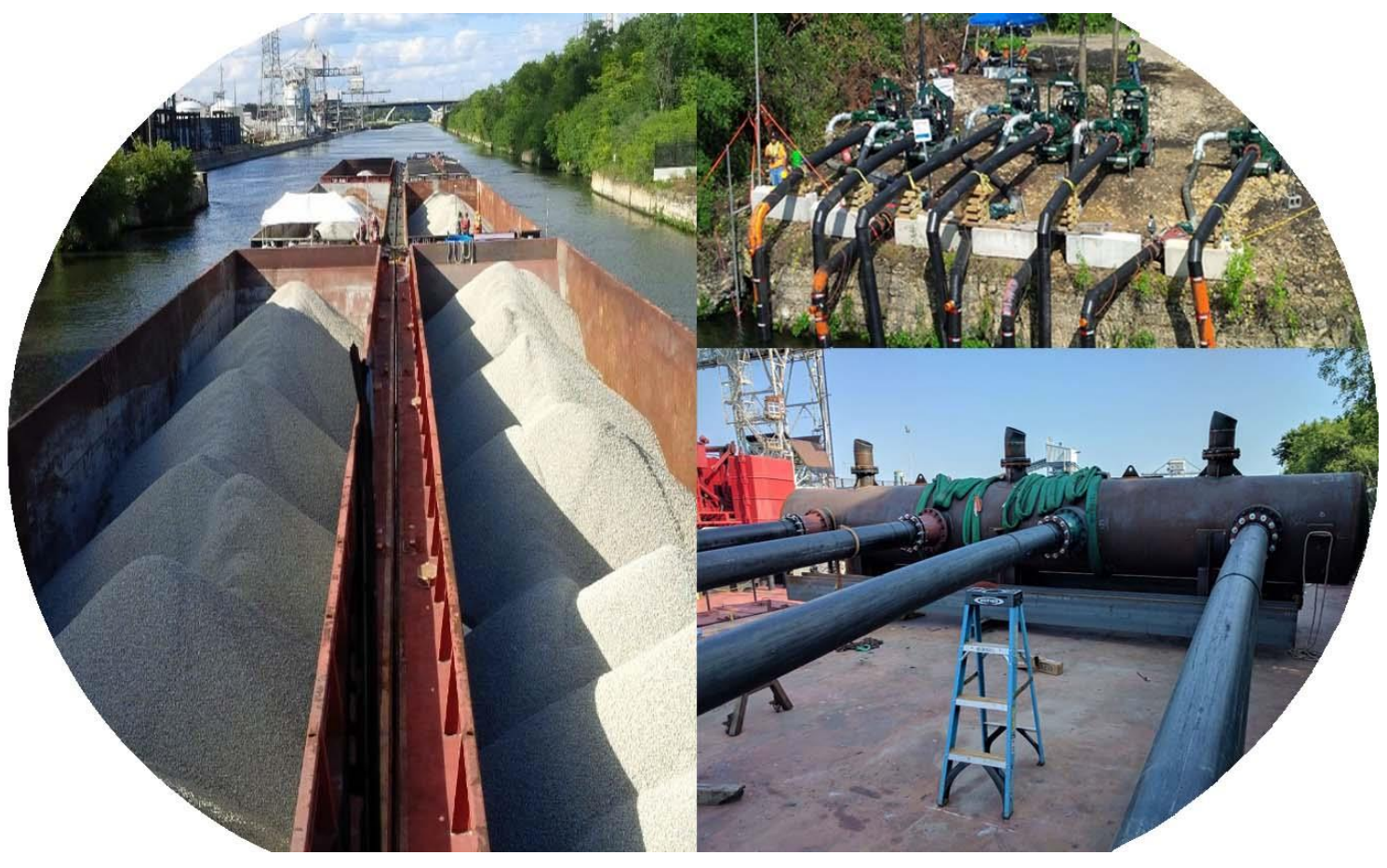


The US Army Engineer Research and Development Center (ERDC) solves the nation's toughest engineering and environmental challenges. ERDC develops innovative solutions in civil and military engineering, geospatial sciences, water resources, and environmental sciences for the Army, the Department of Defense, civilian agencies, and our nation's public good. Find out more at www.erdc.usace.army.mil.

To search for other technical reports published by ERDC, visit the ERDC online library at http://acwc.sdp.sirsi.net/client/default. 


\section{Prototype Test of a Water Jet System to Mitigate the Transport of Asian Carp by Barges}

Duncan B. Bryant, Jarrell Smith, Richard Styles, Benjamin Burnham, Christopher Callegan, Jonathan Marshall, and Mary Claire Allison

Coastal and Hydraulics Laboratory

US Army Engineer Research and Development Center 3909 Halls Ferry Road

Vicksburg, MS 39180-6199

Final report

Approved for public release; distribution is unlimited.

Prepared for US Army Corps of Engineers, Chicago District

111 North Canal Street, Suite 600

Chicago, IL 60606-7206

Under Project W81G6672098667, "Prototype Flushing Jet Array" 


\section{Abstract}

The potential migration of Asian carp through the Illinois River, Des Plaines River, and Chicago Area Waterway System is one risk factor facing the Great Lakes today. In an effort to mitigate this risk, the US Army Corps of Engineers has installed a series of electric dispersal barriers within the Chicago Sanitary and Ship Canal (CSSC) near Romeoville, IL, to deter fish from using the canal as a pathway to enter the Great Lakes. Previous laboratory studies have shown that tows produce residual currents and forces that can entrain and potentially transport fish across the barrier. The US Army Engineer Research and Development Center was tasked by US Army Corps of Engineers, Chicago District, to investigate mitigation measures to remove entrained fish from the recesses between barges. A full-scale prototype jet manifold was constructed and tested in the CSSC to determine the degree to which the jets could dislodge or remove fish during passage. Similar to previous laboratory studies, the jets were most effective for slow tow speeds $(<1$ meter per second $[\mathrm{m} / \mathrm{s}]$ ) and higher jet velocities $(4.9 \mathrm{~m} / \mathrm{s})$. For higher vessel speeds, the barges passed more quickly over the array, which reduced the exposure time and the number of tracers flushed.

DISCLAIMER: The contents of this report are not to be used for advertising, publication, or promotional purposes. Citation of trade names does not constitute an official endorsement or approval of the use of such commercial products. All product names and trademarks cited are the property of their respective owners. The findings of this report are not to be construed as an official Department of the Army position unless so designated by other authorized documents. 


\section{Contents}

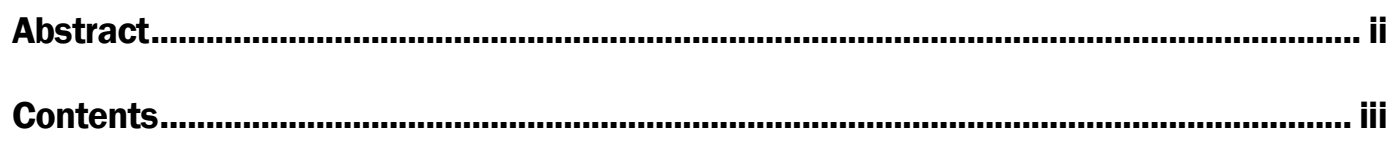

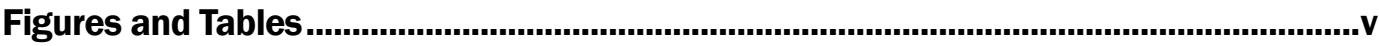

Preface .................................................................................................................................viii

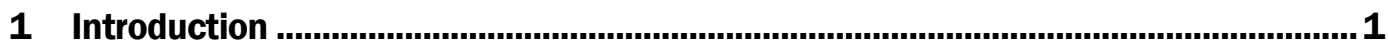

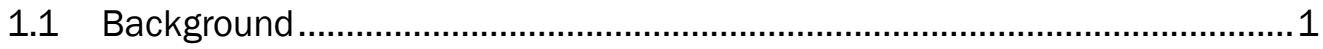

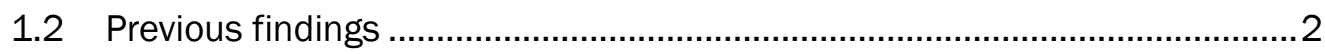

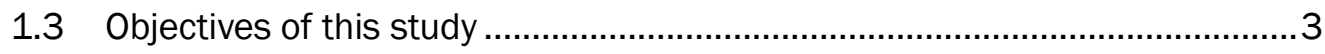

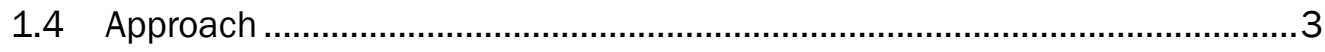

1.5 Other agency involvement.................................................................

2 Environmental and vessel parameters.................................................................... 5

2.1 The Chicago Sanitary and Ship Canal (CSSC)............................................

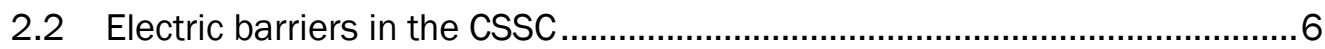

2.3 Vessel speed during barrier passage ......................................................... 8

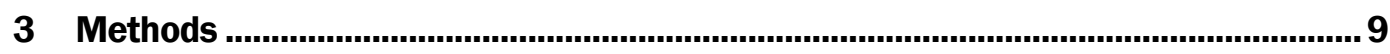

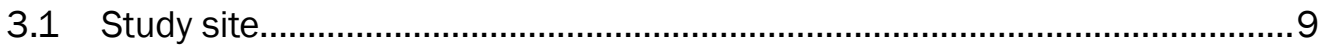

3.2 Jet manifold construction.......................................................................... 10

3.3 Pump selection and discharge requirements ..........................................14

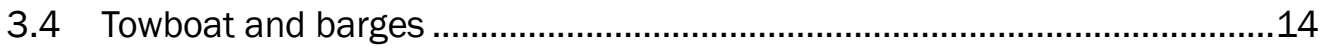

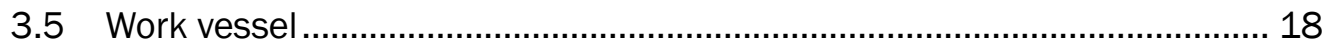

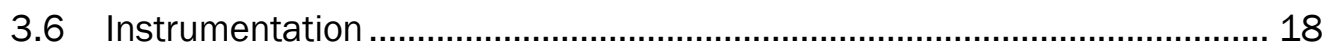

3.6.1 Acoustic Doppler velocimeters (ADVs)........................................................ 18

3.6.2 Acoustic Doppler current profiler (ADCP) surveys ............................................20

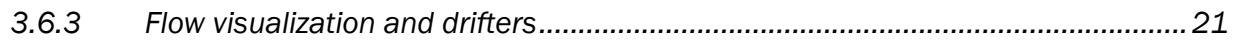

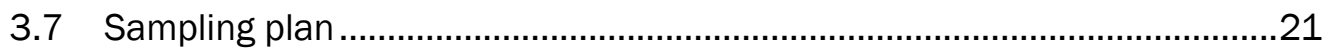

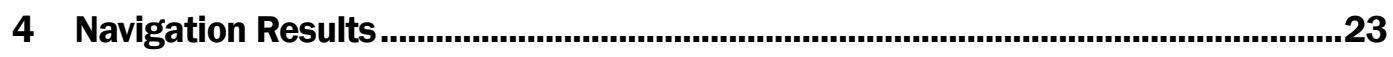

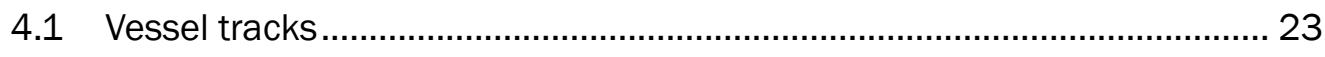

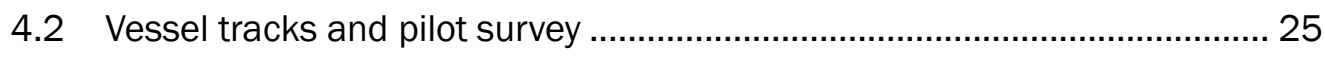

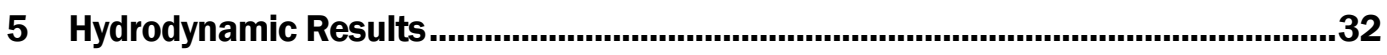

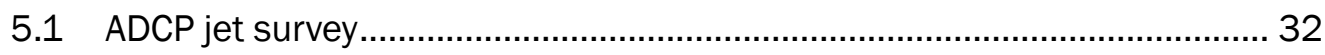

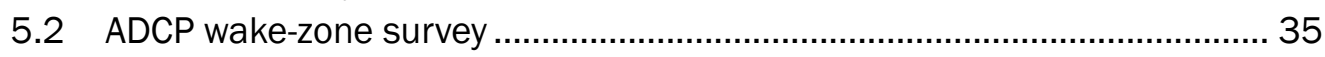

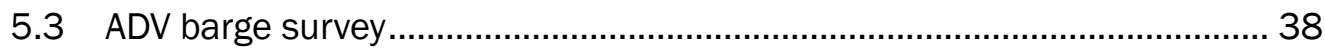

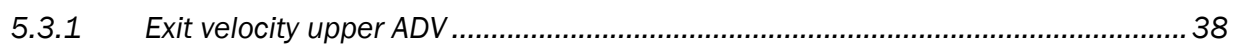

5.3.2 Exit velocity lower ADV .......................................................................... 41

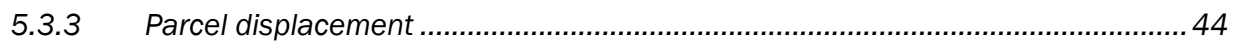

5.3.4 Correlation with different metrics ................................................................... 46 


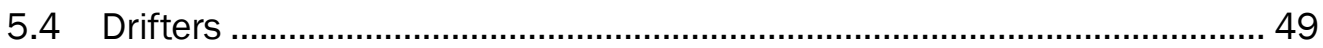

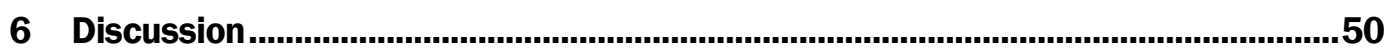

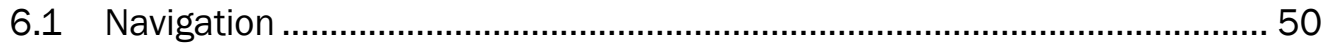

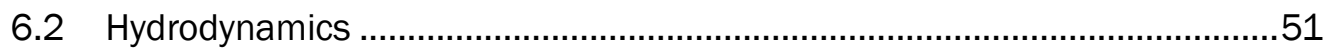

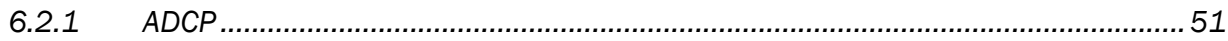

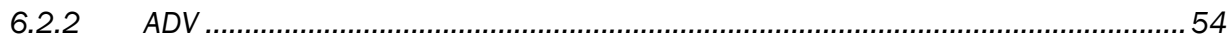

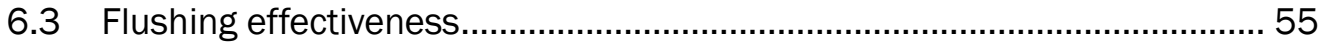

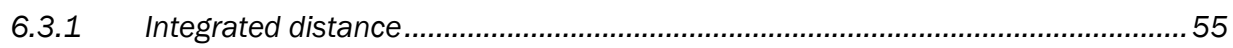

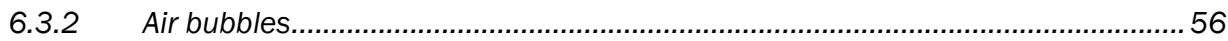

6.4 Recommendation for further study ..................................................... 58

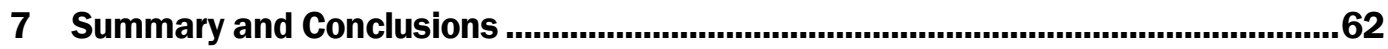

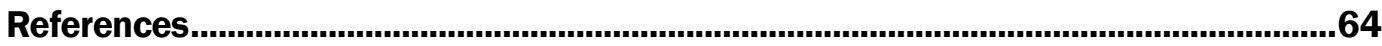

Appendix A: Test Matrix …...................................................................................65

Appendix B: Vessel Metrics for Each Test .........................................................69

Unit Conversion Factors........................................................................................

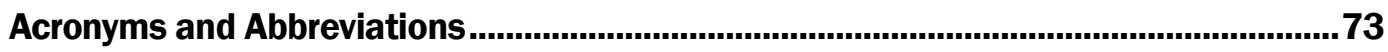

Report Documentation Page 


\section{Figures and Tables}

\section{Figures}

Figure 1-1. Aerial photograph depicting the location of the electric barriers within the CSSC.

Figure 2-1. Estimated discharge from USGS site 05536890 on the CSSC near Lemont, IL. Note: At the time of publication, these data were indicated as "provisional" by the USGS and subject to revision.

Figure 2-2. Estimated cross-sectionally averaged velocity from USGS site 05536890 on the CSSC near Lemont, IL. Note: At the time of publication, these data were indicated as "provisional" by the USGS and subject to revision.

Figure 2-3. Electric barriers on the CSSC.

Figure 2-4. Distributions of AIS-LPMS resolved passages from 01 January 2013 to 31 December 2015. A) Northbound tugs ( $N=2247)$; B) Southbound tugs $(\mathrm{N}=2428)$.

Figure 3-1. Study site near Romeoville, IL. The manifold was deployed in the CSSC south of the electric barriers. The manifold was approximately $22 \mathrm{~m}$ from the east bank, where the pumps were deployed. The east bank was cleared prior to installation to accommodate the field equipment needed to operate the jet manifold. All trials were conducted south of the E. Romeo road bridge. North is up on the map.

Figure 3-2. Jet manifold awaiting deployment in the CSSC. The photograph shows the $0.3 \mathrm{~m}$ diameter fused HDP pipe connected to the four $0.41 \mathrm{~m}$ side ports through a reducer. The three $0.3 \mathrm{~m}$ jet nozzles are visible on the top of the manifold. Steel bridge piers were mounted on the manifold feet to provide anchor support. One is visible beneath the side ports. When placed in the canal, the jets are oriented upstream.

Figure 3-3. Jet manifold schematic.

Figure 3-4. Jet manifold schematic.

Figure 3-5. East bank operations area depicting the pump setup. There are six intake lines and four discharge lines that supply water pressure to the jets. The six intakes are set on top of the Jersey barriers and supported by the wooden slats. The four discharge pipes are set between the Jersey barriers. The strobe lights are visible on four of the pipes. A light plant (top, center, left) was also deployed to illuminate the site at night.

Figure 3-6. View from the wheelhouse of the MV Derek $E$ showing the $2 \times 3$ barge configuration. The leading barge is about to pass over the manifold.

Figure 3-7. Schematic illustrating barge configurations used during the field test. The ovals denote the testing region where fish and drifters were released. Although not pictured, there is a $0.76 \mathrm{~m}$ gap between the barges at the testing region. The three crossed yellow circles denote the location of the USACE GPS units.

Figure 3-8. Pilot survey form

Figure 3-9. Final pilot survey. This survey was administered at the end of the field program. 
Figure 3-10. Photograph depicting the ADVs with mounting hardware and a schematic illustrating the location of the ADVs once deployed. The view is looking towards the east bank, and the cameraman is standing on the box barge. The ADVs are in a vertically stacked configuration awaiting deployment. The ADVs were placed at $1 \mathrm{~m}$ and $2 \mathrm{~m}$ depths below the water surface.

Figure 3-11. M/V Garcia measuring the flow between the aft barge and the towboat. The ADCP mounting system is visible behind the open door on the starboard side. This photograph was taken at the start of a trial, so the towboat is at rest. As the towboat moves forward, the region monitored by the ADCP develops eddies and becomes turbulent.

Figure 4-1. Schematic illustrating the coordinate system and definitions of offset for a $2 \times 3$ barge. The blue rectangle denotes the manifold (not to scale). For the $1 \times 3$ configuration the offset is measured from the centerline of the barge.

Figure 4-2. Vessel tracks indicating the off-center approach to the jets. The yellow rectangle denotes the approximate profile of the jet manifold.

Figure 4-3. Vessel position showing the off-center approach and veering towards the east bank after passing over the jet manifold.

Figure 4-4. Tow tracks for the $2 \times 3$ barge configuration subdivided by vessel speed. (A) $0.4 \mathrm{~m} / \mathrm{s}$; (B) $0.9 \mathrm{~m} / \mathrm{s}$; and (C) $1.3 \mathrm{~m} / \mathrm{s}$.

Figure 4-5. Tow tracks for the $1 \times 3$ barge configuration. (A) $0.4 \mathrm{~m} / \mathrm{s}$; (B) $0.9 \mathrm{~m} / \mathrm{s}$; (C) $1.8 \mathrm{~m} / \mathrm{s}$; and (D) $2.2 \mathrm{~m} / \mathrm{s}$.

Figure 5-1. Depth-averaged currents in the vicinity of the manifold obtained from the ADCP mounted on the MV Garcia. (A) Without the jets operating; (B) with the jet velocity of $2.4 \mathrm{~m} / \mathrm{s}$.

Figure 5-2. Depth-averaged currents for (A) jet velocity of $3.7 \mathrm{~m} / \mathrm{s}$ and $(B)$ jet velocity of $4.9 \mathrm{~m} / \mathrm{s}$.

Figure 5-3. Vertical profiles of the current near the manifold. Dashed line denotes standard error for the case without jets and provides a measure of the natural variability of the ambient current.

Figure 5-4. Vertical profiles of the current in the region between the aft barge and the starboard side of the towboat. A, C, and E give streamwise velocity; B, D, and F give cross-stream velocity. Vessel speeds (A-B) 0.57 $\mathrm{m} / \mathrm{s}$; (C-D) $0.49 \mathrm{~m} / \mathrm{s}$; and (D-E) $1.6 \mathrm{~m} / \mathrm{s}$. The white areas denote poor data quality, typically over the jet array. The solid black line indicates the bottom of the canal.

Figure 5-5. (A) Streamwise and (B) cross-stream currents derived from averaging the ADCP profiles over the top $3 \mathrm{~m}$ of the water column. The zero crossing of the $x$-axis denotes when the ADCP passes over the manifold.

Figure 5-6. Exit velocity representing the flow perpendicular to the box-rake junction near the starboard side of the barge. Tow speed is $0.45 \mathrm{~m} / \mathrm{s}$. Positive values denote flow exiting the junction. The ADV is mounted on the vessel and is positioned $1 \mathrm{~m}$ below the water surface. The horizontal axis denotes the displacement of the ADV from the center of the jet manifold.

Figure 5-7. Exit velocity for the upper ADV with a tow speed of $1 \mathrm{~m} / \mathrm{s}$................................40

Figure 5-8. Exit velocity for the upper ADV with a tow speed of $2 \mathrm{~m} / \mathrm{s}$.

Figure 5-9. Exit velocity measured from the lower ADV for a tow speed of 0.45 $\mathrm{m} / \mathrm{s}$. 
Figure 5-10. Exit velocity measured from the lower ADV for a tow speed of $1 \mathrm{~m} / \mathrm{s}$. ..........43

Figure 5-11. Exit velocity measured from the lower ADV for a tow speed of $2 \mathrm{~m} / \mathrm{s}$. ..........44

Figure 5-12. Net displacement due to the exit velocity as a function of the jet velocity. Legend denotes the three tow speeds in meters per second. The dashed line is the half-width of a single-wide standard barge. A parcel initially located at the center of the barge must travel $5.4 \mathrm{~m}$ before it is clear of the barge.

Figure 5-13. Correlation matrix to determine relationships between variables that may influence flushing efficiency. Redline denotes the best fit based on linear regression analysis. Numeric values indicate $r^{2}$ [p-value].

Figure 5-14. Integrated distance (displacement) and percentage of drifters flushed as a function of vessel speed. Legend denotes the two highest jet velocities. Dashed line is the half-width of a single-wide standard barge. The * denote percentage of drifters that were flushed, and open circles denote integrated distance...

Figure 6-1. Manifold configuration for successful jet tests in the laboratory. The barge approaches from the top of the photograph. The nozzle angle increases in an alternating pattern along the manifold axis, thereby directing the flow farther from the centerline of the barge as it passes over the array.

Figure 6-2, Photograph depicting a fish swimming in the barge boundary layer near the box-rake junction. The dashed line denotes the general path the fish follow. They are initially forced out of the recess and then approach the side of the barge away from the junction. Then, they swim along the side of the barge in the boundary layer to return to the junction.

Figure 6-3. Photograph depicting air bubbles issuing from beneath the barge. Bubbles were seen rising to the surface along the hull for several minutes after the tow had cleared the manifold.

\section{Tables}

Table 4-1. Vessel passage statistics. Each row denotes different vessel speeds. 


\section{Preface}

This study was conducted for the U S Army Corps of Engineers, Chicago District, under Project W81G6672098667, "Prototype Flushing Jet Array. The work was performed at the US Army Engineer Research and Development Center (ERDC), Coastal and Hydraulics Laboratory (CHL), during the time period April 2017 through September 2018.

This research was conducted under the general direction of Dr. Jacqueline S. Pettway, Chief, Navigation Division, CHL; Dr. Cary A. Talbot, Chief, Flood and Coastal Protection Division, CHL; Ms. Ashley Frey, Chief, Coastal Processes Branch, CHL; Mr. William Butler, Chief, Field Data Collection Branch, CHL; Ms. Lauren Dunkin, Chief, Coastal Engineering Branch, CHL; and Mr. Ben Burnham, Chief, Navigation Branch, CHL.

At the time of publication of this report, Mr. Jeffrey R. Eckstein was the Deputy Director of CHL, and Dr. Ty V. Wamsley was the Director.

COL Teresa A. Schlosser was the Commander of ERDC, and the Director was Dr. David W. Pittman. 


\section{Introduction}

\subsection{Background}

The potential migration of Asian carp through the Illinois River, Des Plaines River, and Chicago Area Waterway System (CAWS) is a severe risk factor facing the Great Lakes. Asian carp were originally imported into the southern United States in the 1970s to help maintain wastewater treatment facility retention ponds and to provide fresh fish for human consumption (Chick and Pegg 2001). Of the four species of Asian carp, bighead and silver carp pose the most ecological risk to US waters. They are voracious eaters and thus are in direct competition with native planktivores, juvenile fishes, and mussels.

To help prevent Asian carp from entering the Great Lakes, the US Army Corps of Engineers (USACE) erected a dispersal barrier system on the Chicago Sanitary and Ship Canal (CSSC). The CSSC is a man-made hydrologic connection between the Great Lakes and Mississippi River basin that was completed in the early twentieth century to improve water quality in southern Lake Michigan and to provide a navigation connection between the Great Lakes and Mississippi River. The electric barriers in this system operate by creating an electric current in the water, which deters fish from swimming through the CSSC and into Lake Michigan.

The Electric Dispersal Barriers are located near Romeoville, IL, in the CSSC within the more extensive CAWS (Figure 1-1). The barriers are constructed of steel electrodes that are secured to the bottom of the CSSC. The electrodes are connected to a raceway consisting of electric connections to a control building. Equipment in the control building generates a direct current pulse through the electrodes, creating an electric field in the water that serves as a barrier to certain species of fish.

As of October 2014, bighead and silver carp had not been seen at the electric barriers; however, a single bighead carp was captured in the Lockport pool approximately 8.9 kilometers $(\mathrm{km})$ south of the barriers in December 2009. 
Figure 1-1. Aerial photograph depicting the location of the electric barriers within the CSSC.

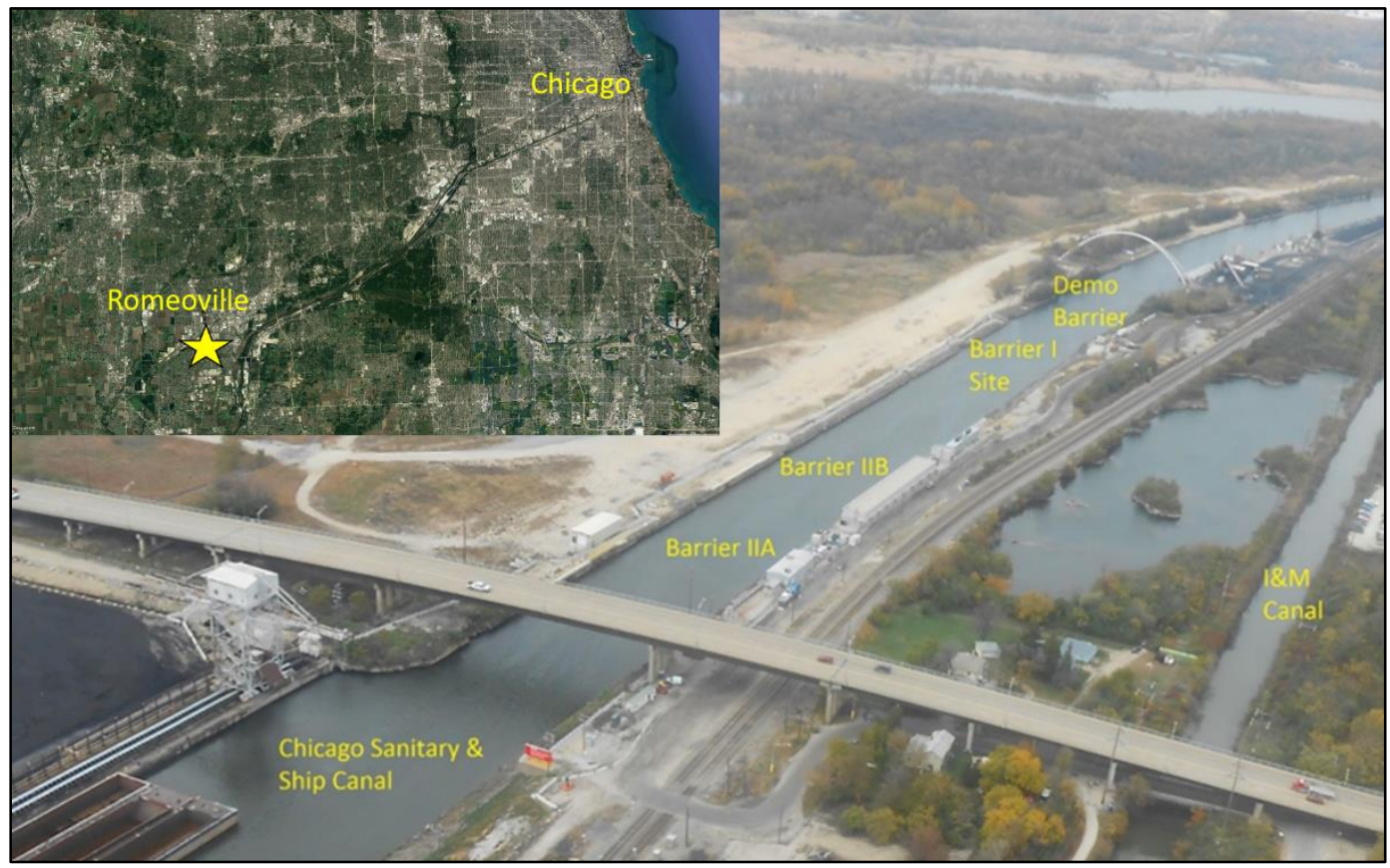

\subsection{Previous findings}

In 2011, the USACE, Chicago District (LRC), requested the US Army Engineer Research and Development Center (ERDC), Coastal and Hydraulics Laboratory (CHL), to determine if commercial navigation could cause or facilitate transport of Asian carp past the protective electric barriers at some time in the future. It was hypothesized that currents generated by moving vessels or the vessel structure itself could inadvertently entrain fish, where they would be carried along with the vessel across the electric dispersal barriers. Once past the barriers, the fish would be free to swim farther upstream and potentially on to Lake Michigan. ERDC recommended that a physical model of the CSSC and a remote control model towboat and barges would enable evaluation of the potential for barge traffic to transport Asian carp past the barrier.

The results of the 2011 laboratory test indicated that barges were capable of entraining and transporting Asian carp distances greater than the width of the dispersal barriers (Bryant et al. 2016). Furthermore, it was determined that under certain barge configurations and vessel speeds, southbound tows could produce a return current that could transport fish across the electrical barriers. These findings led to a second laboratory study in 2015 to evaluate mitigation measures to remove Asian carp from 
barges before crossing the electrical barrier and to explore methods to reduce the magnitude of the return current of southbound tows (Bryant et al. 2018).

This second laboratory study was carried out at ERDC using a submerged waterjet system to remove fish from barges as they passed over the jet array. Experiments were conducted using the same facility and remote control tow as the 2011 study. Model fish were seeded in the recess between barges prior to passing over the jet array. Flow visualization was used to evaluate the effectiveness of the jet array at removing fish under different vessel speeds, jet velocities, and jet configurations. Jet configurations included varying the number of jets, the nozzle angle (vertical or tilted), the nozzle diameter, and the jet array angle (parallel to the channel bottom, perpendicular to the canal bottom, and at an angle of 45 degrees). The results showed that slower tows with a total of 18 jets were successful at clearing fish from the barge-rake junction. The most successful jet configuration included 0.30 meter (m)-diameter nozzles oriented at an angle of 22.5 degrees off vertical facing in the direction of tow travel. Laboratory jet testing (Bryant et al. 2018) suggested that 12-18, 0.20 to $0.30 \mathrm{~m}$ diameter jets operating with $10-20$ meters per second $(\mathrm{m} / \mathrm{s})$ exit velocities were effective in flushing model fish from the boxrake junctions of two-wide barge rafts.

\subsection{Objectives of this study}

The goal of this study is to develop and test a prototype-scale jet system in the CSSC. This is a follow-on study of previous laboratory efforts that used submerged upward-looking jets to remove model fish from beneath a model remote control towboat and barges.

\subsection{Approach}

For this field test, a manifold consisting of three jets was constructed and installed in the CSSC downstream of the electric barriers to determine the degree and under what conditions the jets were effective at removing fish from between barges. This technical report focuses on the results of the field study, including the jet design, pump requirements, jet velocity, flushing effectiveness, and the impact of the jet array to navigation. 


\subsection{Other agency involvement}

This effort included coordination amongst three federal agencies including USACE, US Fish and Wildlife Service (USFWS), and US Geological Survey (USGS). USFWS was responsible for releasing the fish and tracking their numbers pre- and post-traversing the jets. They focused primarily on monitoring the number of fish that were removed after passing over the jet array. The USGS deployed current meters on the barges, a shore-based camera system to monitor surface roughness, and a shore-based acoustic current profiler to measure canal currents and return velocity. Their respective agencies should be consulted with questions regarding their methodologies, results, recommendations, and conclusions. This report focuses primarily on the results of the CHL component of the study, which includes the jet flushing and the potential effects to navigation due to the presence of the jet. 


\section{Environmental and vessel parameters}

The electric barriers are located near Romeoville, IL, in the CSSC within the CAWS (Fig. 1-1). This chapter provides background information about the canal, the electric barriers, vessel traffic in the canal, and the local water motions around the tow and barges while underway.

\subsection{The Chicago Sanitary and Ship Canal (CSSC)}

At the barrier, the CSSC is $49 \mathrm{~m}$ wide and has a rectangular cross section. Water depth varies from 6.1 to $8.5 \mathrm{~m}$ with $8.5 \mathrm{~m}$ being typical and $6.1 \mathrm{~m}$ only occurring when the canal is drawn down at Lockport Lock approximately $8.9 \mathrm{~km}$ downstream to prevent flooding in Chicago during heavy rainfall. The CSSC has a straight alignment for approximately $5.6 \mathrm{~km}$ south and $0.5 \mathrm{~km}$ north of the barrier. Flow in the channel is generally low. Discharge estimates between 2011 and 2015 (Figure 2-1) near Lemont, IL (USGS site 05536890, jointly operated by the USGS and the USACE), indicate that channel discharge is commonly between $460-$ 1100 cubic meters per second ( $\left.\mathrm{m}^{3} / \mathrm{s}\right)$, and greater than $1400 \mathrm{~m}^{3} / \mathrm{s}$ only 10 percent of the time. Less than one percent of the record indicates that lock and hydropower pump operations and/or wind can cause water to flow north toward Lake Michigan. These events are weak and short lived.

The flow estimates from Lemont were coupled with the typical crosssectional area of the CSSC at the barrier to generate estimates of average velocity at the barrier (Figure 2-2). The median cross-sectionally averaged velocity is $0.17 \mathrm{~m} / \mathrm{s}$, and the velocities exceeded at the 8oth, 90th, and $95^{\text {th }}$ percentiles are $0.27,0.33$, and $0.40 \mathrm{~m} / \mathrm{s}$, respectively. 
Figure 2-1. Estimated discharge from USGS site 05536890 on the CSSC near Lemont, IL. Note: At the time of publication, these data were indicated as "provisional" by the USGS and subject to revision.

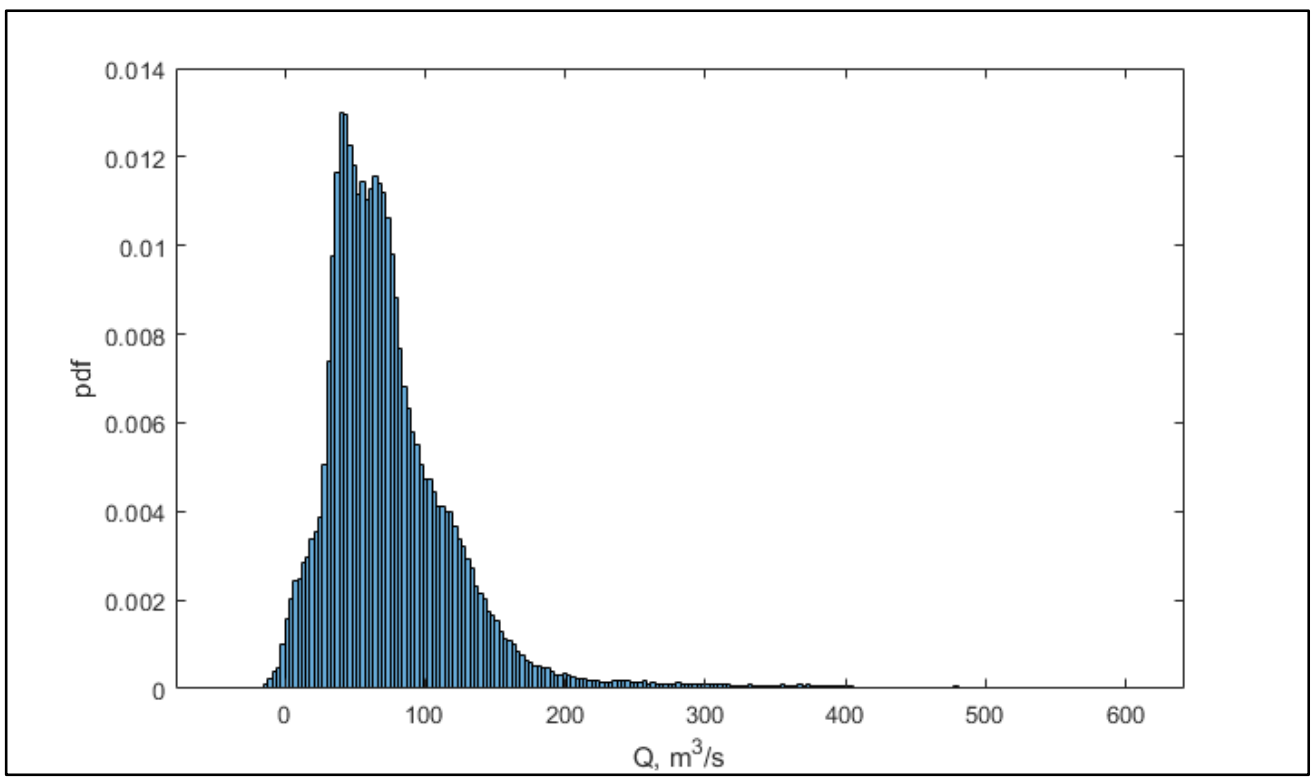

Figure 2-2. Estimated cross-sectionally averaged velocity from USGS site 05536890 on the CSSC near Lemont, IL. Note: At the time of publication, these data were indicated as "provisional" by the USGS and subject to revision.

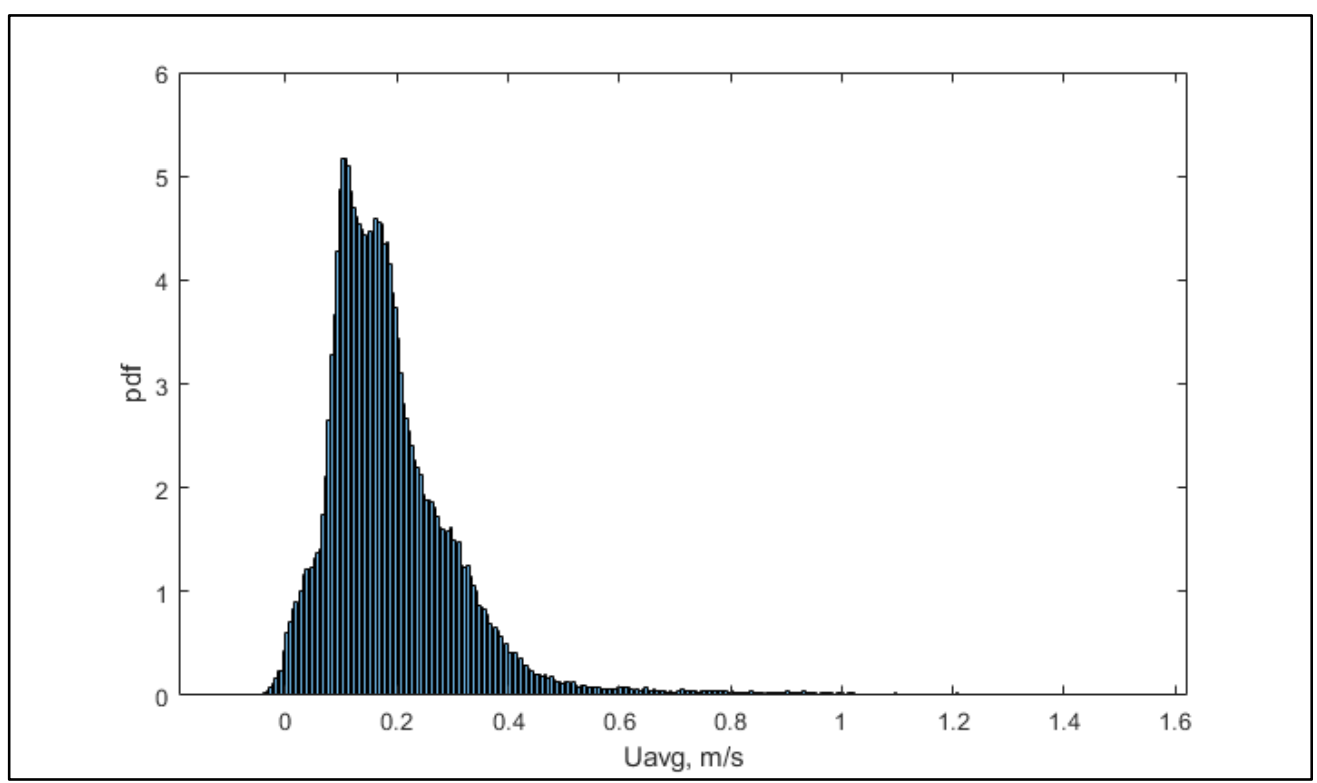

\subsection{Electric barriers in the CSSC}

The Electric Dispersal Barriers are located near Romeoville, IL, in the CSSC within the CAWS. The barriers are constructed of steel electrodes that are secured to the bottom of the CSSC. The electrodes are connected to a raceway consisting of electric connections to a control building, 
located adjacent to the canal. Equipment in the control building generates a direct current pulse through the electrodes, producing an electric field in the water that presents a barrier to certain fish.

There are three electric barriers: Demonstration Barrier, Barrier 2A, and Barrier 2B (Figure 2-3). The Demonstration Barrier has been operational since 2002. Due to its original demonstration status, it was designed and built with materials that were not intended for long-term use. Significant repairs were successfully completed in October 2008. In July 2013, USACE awarded a construction contract to build a permanent electric Barrier 1 between Barrier 2B and the Demonstration Barrier.

Figure 2-3. Electric barriers on the CSSC.

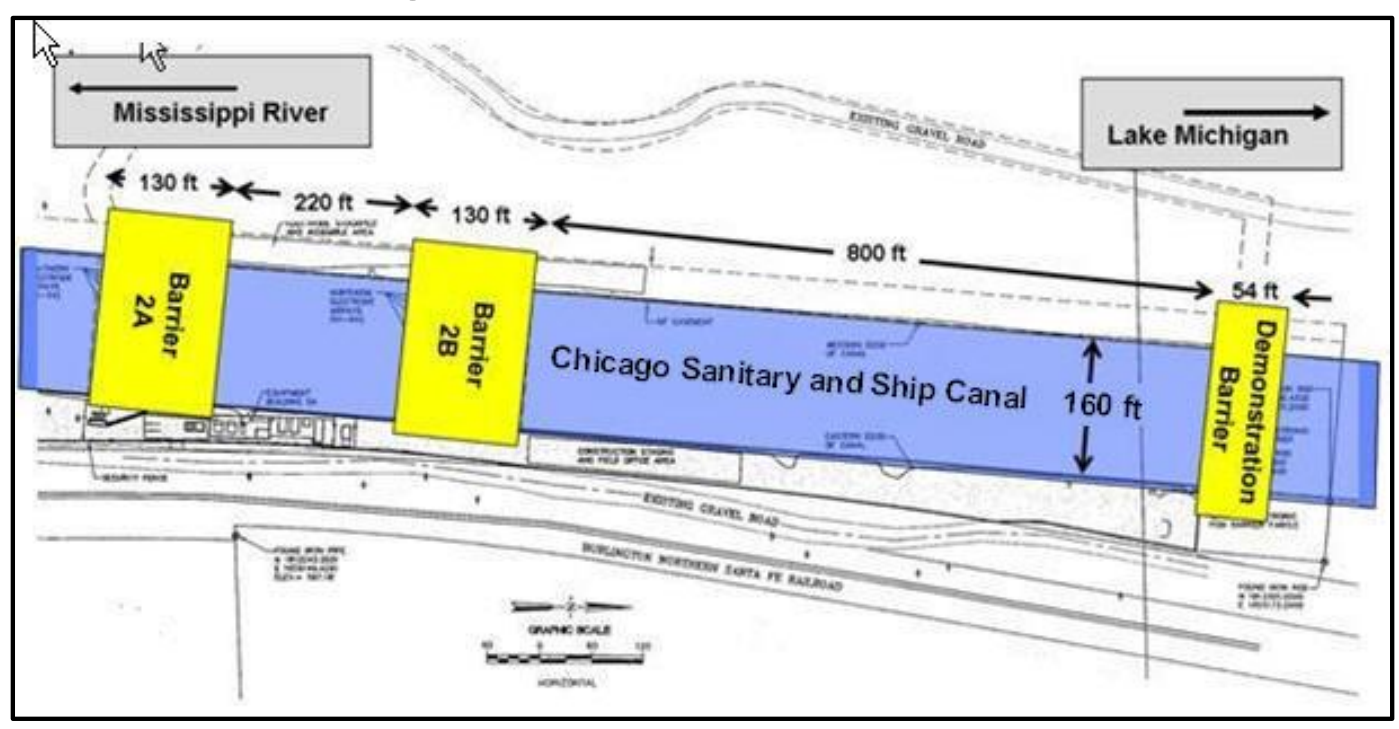

The Demonstration Barrier operates at 0.39 volt per centimeter (volt $/ \mathrm{cm}$ ), at a frequency of 5 hertz (Hz), with 4-millisecond (ms) pulse duration. Barrier 2A was placed into full-time operation in 2009. Barrier 2B was activated in April 2011 with the same operating parameters as Barrier 2A: 0.78 volts $/ \mathrm{cm}, 15 \mathrm{~Hz}, 6.5 \mathrm{~ms}$ pulse width. In the fall of 2011, the settings at Barrier 2 were increased from 0.78 volts $/ \mathrm{cm}, 15 \mathrm{~Hz}$, and $6.5 \mathrm{~ms}$ to 0.91 volts $/ \mathrm{cm}, 30 \mathrm{~Hz}$, and $2.5 \mathrm{~ms}$ pulse width. This increase was implemented after the completion of a study that suggested these settings would be more effective at preventing all sizes of fish, including very small juvenile fish, from crossing the electric barriers. 


\subsection{Vessel speed during barrier passage}

Bryant et al. (2018) conducted a towboat speed analysis by crossreferencing the Automatic Identification System (AIS) and the USACE Lock Performance Monitoring System (LPMS) databases. Vessel speed while passing through the barrier varies with the number of loaded barges (Figure 2-4). For both north- and southbound traffic, the fastest towboat passages were associated with unloaded towboats. With increasing load, the peaks and maxima of the velocity distributions over water generally decreased with increasing numbers of loaded barges. For the largest tows, with five to six loaded barges, although the vessel counts differed by direction, the normalized distributions were quite similar. The median, 90th, 95th, and 99th percentile speeds were 1.6, 2.0, 2.2, and $2.7 \mathrm{~m} / \mathrm{s}$ for southbound tows and 1.7, 2.0, 2.2, and $2.7 \mathrm{~m} / \mathrm{s}$ for northbound tows.

Figure 2-4. Distributions of AIS-LPMS resolved passages from 01 January 2013 to 31 December 2015. A) Northbound tugs ( $\mathrm{N}=2247)$; B) Southbound tugs $(\mathrm{N}=2428)$.

A)

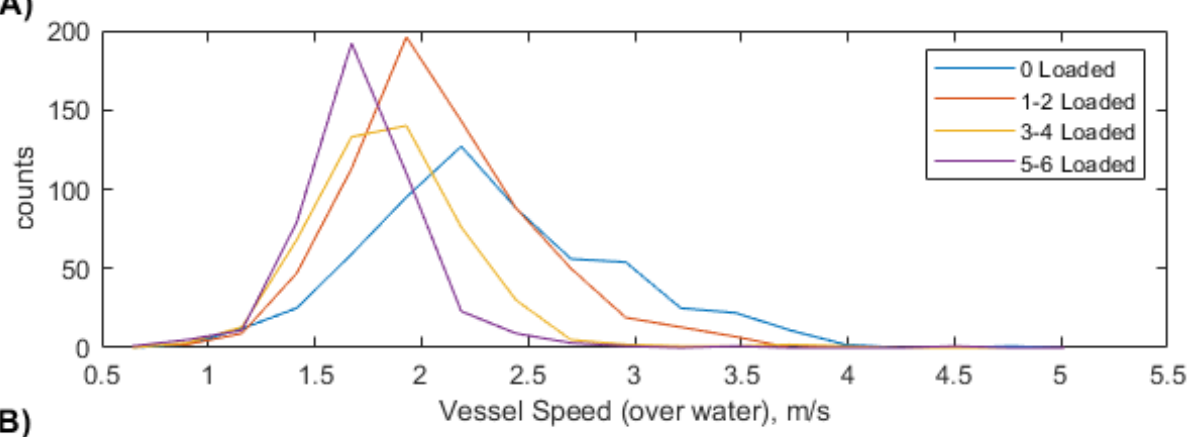

B)

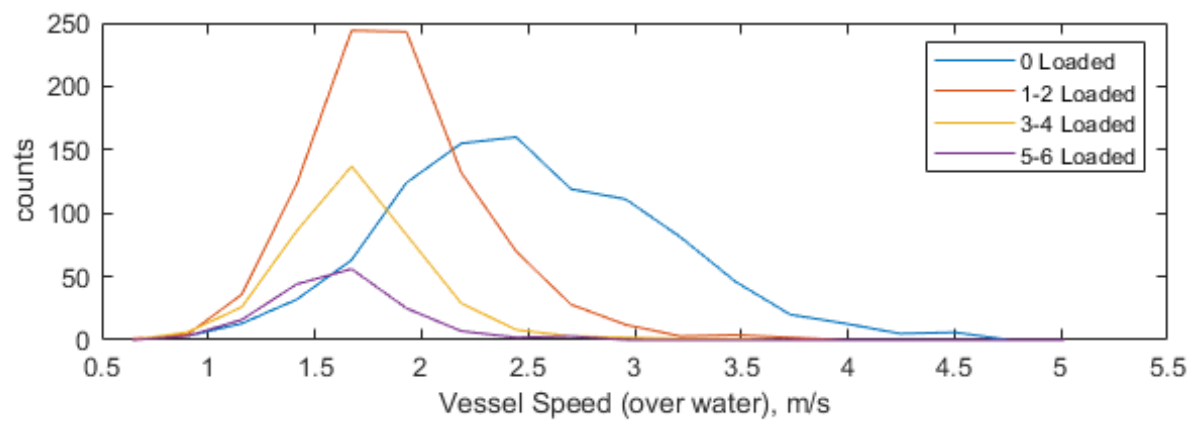




\section{Methods}

\subsection{Study site}

The study site was located near the electric barrier complex located on the CSSC near Romeoville, IL (Figure 3-1). The jet manifold was placed in the canal approximately $640 \mathrm{~m}$ downstream of Barrier $2 \mathrm{~A}$. The canal widens to $70 \mathrm{~m}$ south of the electric barriers to accommodate barge loading and unloading at the Will County Generating Station. The manifold was placed $23 \mathrm{~m}$ from the east bank, placing it off center of the canal. An approximately $24 \mathrm{~m}$ wide area was cleared on the east canal bank adjacent to the manifold to support an array of six pumps and piping that supplied the required water flow to operate the jet manifold. A service road from the north provided access to the site for unloading the equipment and setting up and monitoring the pumps.

The study was carried out between 7 August 2017 and 1 September 2017. During the first week (7-11 August), the jet manifold was transported from ERDC to Brandon Road Lock and Dam and loaded onto a crane barge. The crane barge arrived at the study site the following Monday (14 August). During the second week (14-18 August), the manifold and pumps were installed, and a multi-beam survey of the canal bottom with the manifold in place was carried out. The third week (21-25 August) consisted of jet tests and surveys of the jet-induced flow. The fourth and final week of the study included 3 days of jet testing (28-30 August) and 2 days of recovery of the manifold and pumps beginning the afternoon of 30 August. After the study was complete, the manifold was stored on the west bank of the CSSC at the electric barrier complex. 
Figure 3-1. Study site near Romeoville, IL. The manifold was deployed in the CSSC south of the electric barriers. The manifold was approximately $22 \mathrm{~m}$ from the east

bank, where the pumps were deployed. The east bank was cleared prior to installation to accommodate the field equipment needed to operate the jet manifold. All trials were conducted south of the E. Romeo road bridge. North is up on the map.

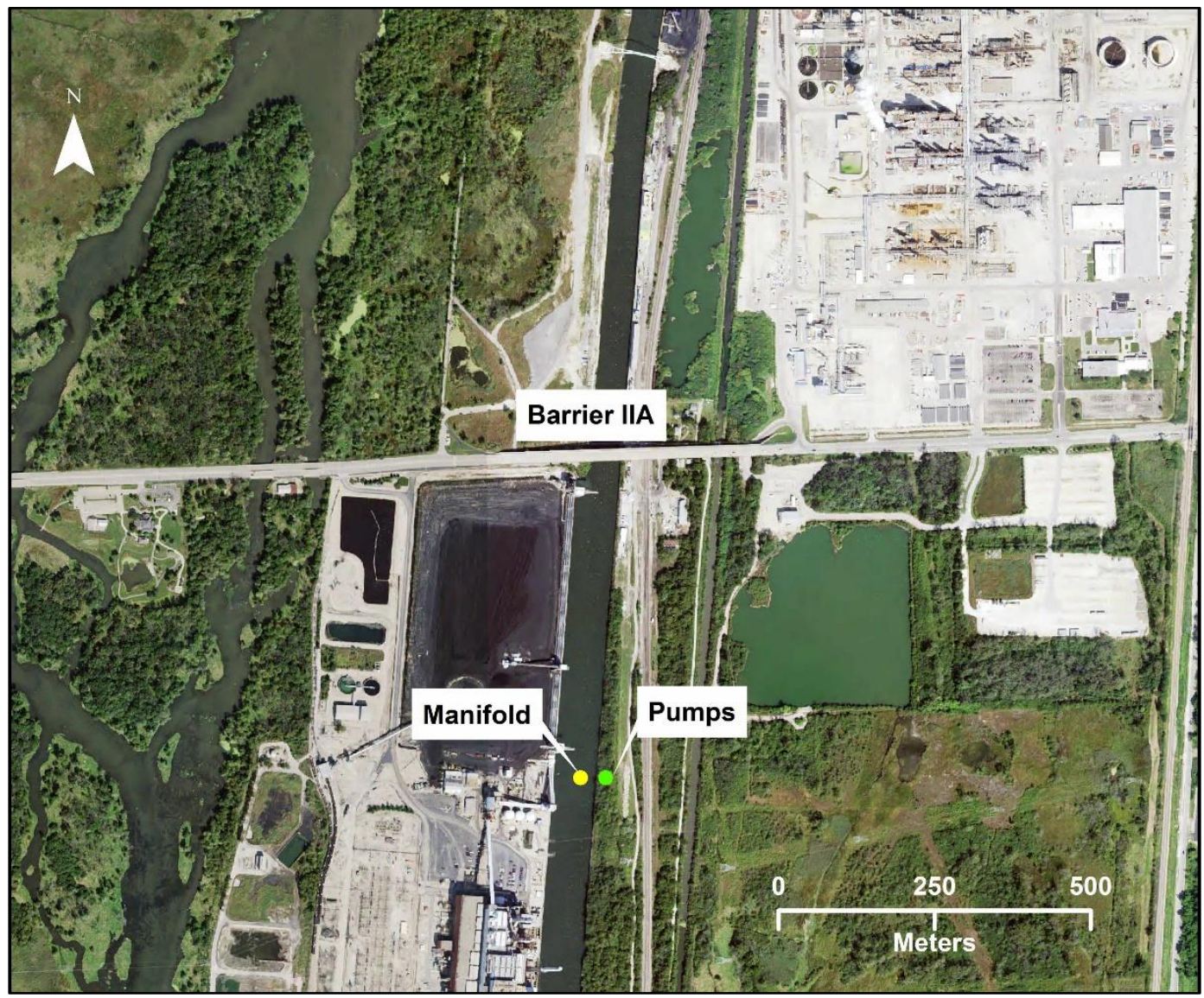

\subsection{Jet manifold construction}

The jet manifold was designed as a prototype model of the system used in the 2015 laboratory study. The previous physical model used up to 18 jets. The time and cost constraints of the field test plan prohibited construction of a full, 18-jet array. To demonstrate the jet array operation, but still remain within budget constraints, the manifold was constructed using three jets.

The prototype array was constructed out of $0.64 \mathrm{~cm}$ thick carbon steel by the ERDC Welding Shop (Figure 3-2). The highest point on the array was approximately $2.7 \mathrm{~m}$ off of the bottom, allowing for $3.0 \mathrm{~m}$ of clearance for a fully loaded barge (2.74 $\mathrm{m}$ draft) to pass overhead during a 1-in-25-year low water event. The jets were angled at 22.5 degrees off of the vertical facing upstream, which is the configuration that had the best flushing effectiveness 
in the physical model. The jet nozzle was $0.30 \mathrm{~m}$ in diameter and was welded to a $0.30 \mathrm{~m}$ diameter carbon steel pipe that extended at a downward angle approximately $0.61 \mathrm{~m}$ (Figure 3-3 and Figure 3-4). The jet angle transitioned to vertical using a 22-degree elbow connected to a vertical pipe that extended downward an additional $0.91 \mathrm{~m}$ to the manifold. The other jets were installed in tandem with the first jet at equally spaced distances of $3.0 \mathrm{~m}$. The manifold consisted of a $1.22 \mathrm{~m}$ diameter by $9.14 \mathrm{~m}$ long vessel. The manifold was capped at both ends and equipped with bottom drain valves to allow the manifold to drain/fill when being raised/lowered into the water. The manifold also contained four $0.41 \mathrm{~m}$ diameter flanged side ports to connect to the pressure hoses. A man-access port was installed on the opposite side of the vessel to permit the welders to complete the final welding and inspect the inside of the vessel.

The manifold was anchored to the bottom using two $7.92 \mathrm{~m}$ steel bridge piers $(2,976$ kilograms $[\mathrm{kg}]$ each) that were attached to the manifold's feet. Initially, there was concern that the manifold might move due to the lateral forces generated by the angled jets, but the manifold remained in place during the tests. The four side ports were connected to $0.30 \mathrm{~m}$ diameter high-density polyethylene (HDP) fusible pipe using a reducer. The pipes ran along the bottom of the canal to the east bank and were anchored using two steel bridge piers (12 m, 4,427 kg; $11 \mathrm{~m}, 4105 \mathrm{~m}$ ) placed perpendicular to the pipes at approximately equal intervals between the manifold and the wall. At the canal wall, the pipes were connected to vertical risers that extended approximately $2.4 \mathrm{~m}$ above the water surface. Elbow connectors and splitters were used to connect the risers to the six pumps. Intakes ran from the pumps to the edge of the east bank and down the canal wall to a depth of approximately $3.0 \mathrm{~m}$ below the water surface. (Figure 3-5). 
Figure 3-2. Jet manifold awaiting deployment in the CSSC. The photograph shows the $0.3 \mathrm{~m}$ diameter fused HDP pipe connected to the four $0.41 \mathrm{~m}$ side ports through a reducer. The three $0.3 \mathrm{~m}$ jet nozzles are visible on the top of the manifold. Steel bridge piers were mounted on the manifold feet to provide anchor support. One is visible beneath the side ports. When placed in the canal, the jets are oriented upstream.

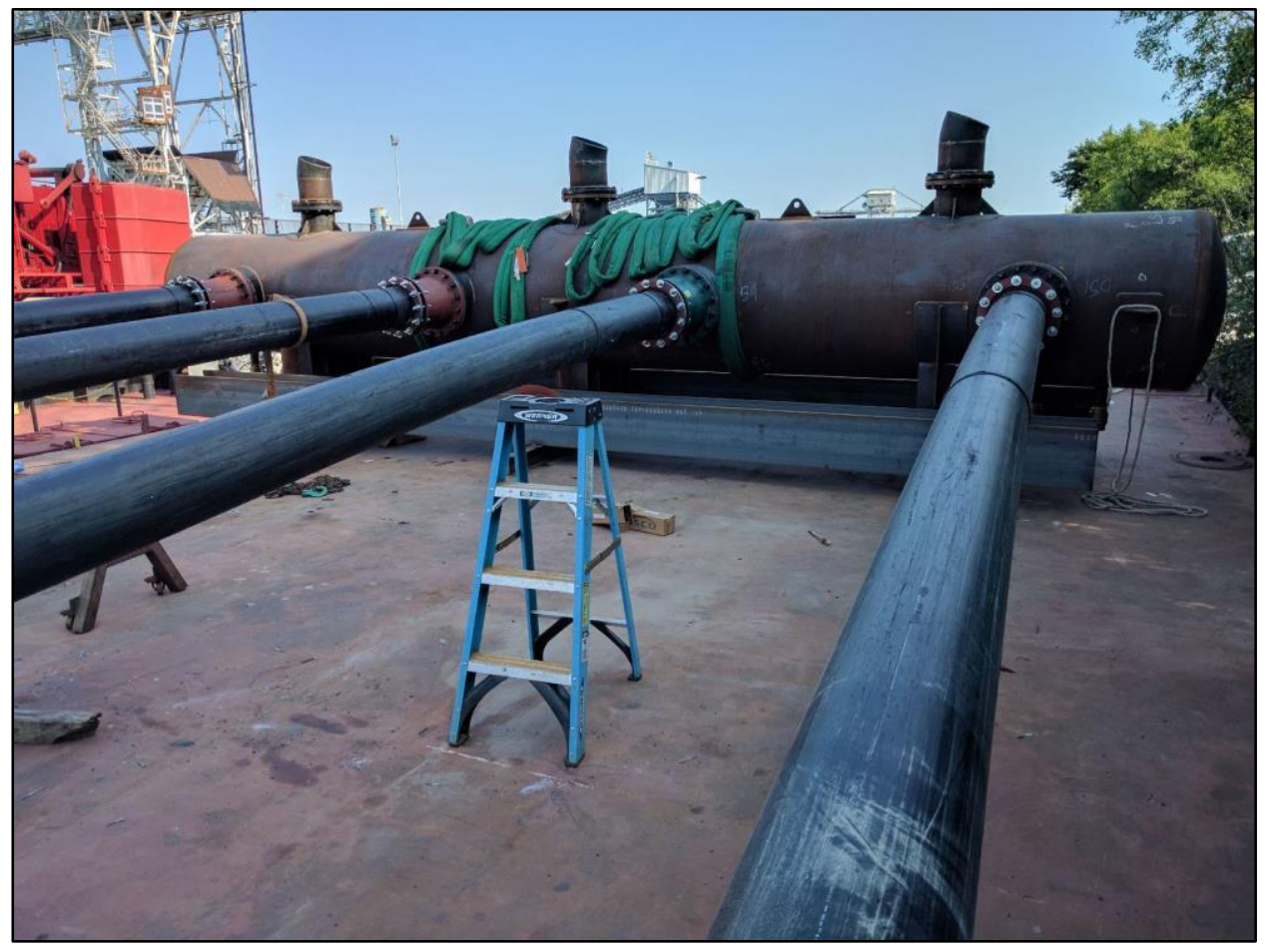

Figure 3-3. Jet manifold schematic.

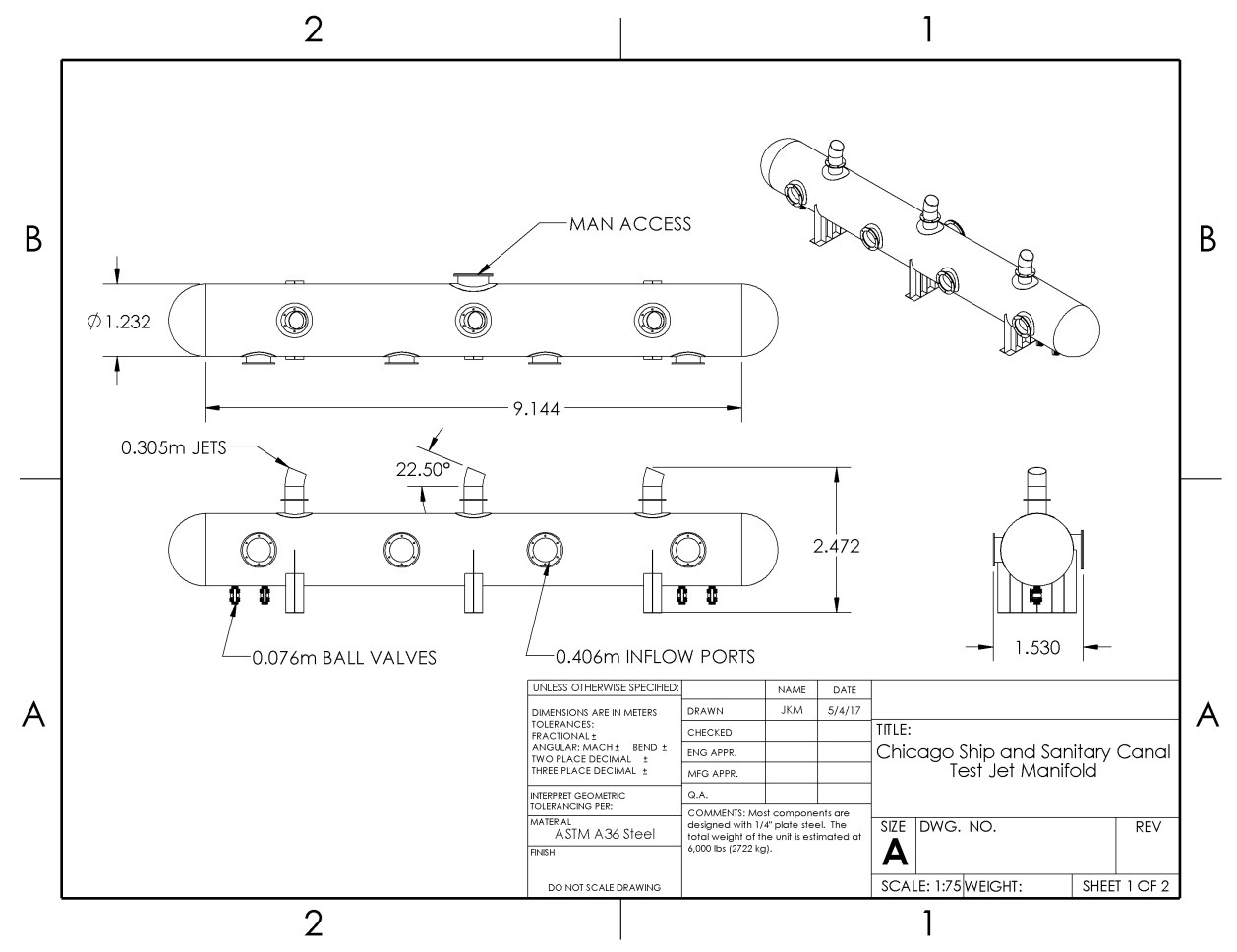


Figure 3-4. Jet manifold schematic.

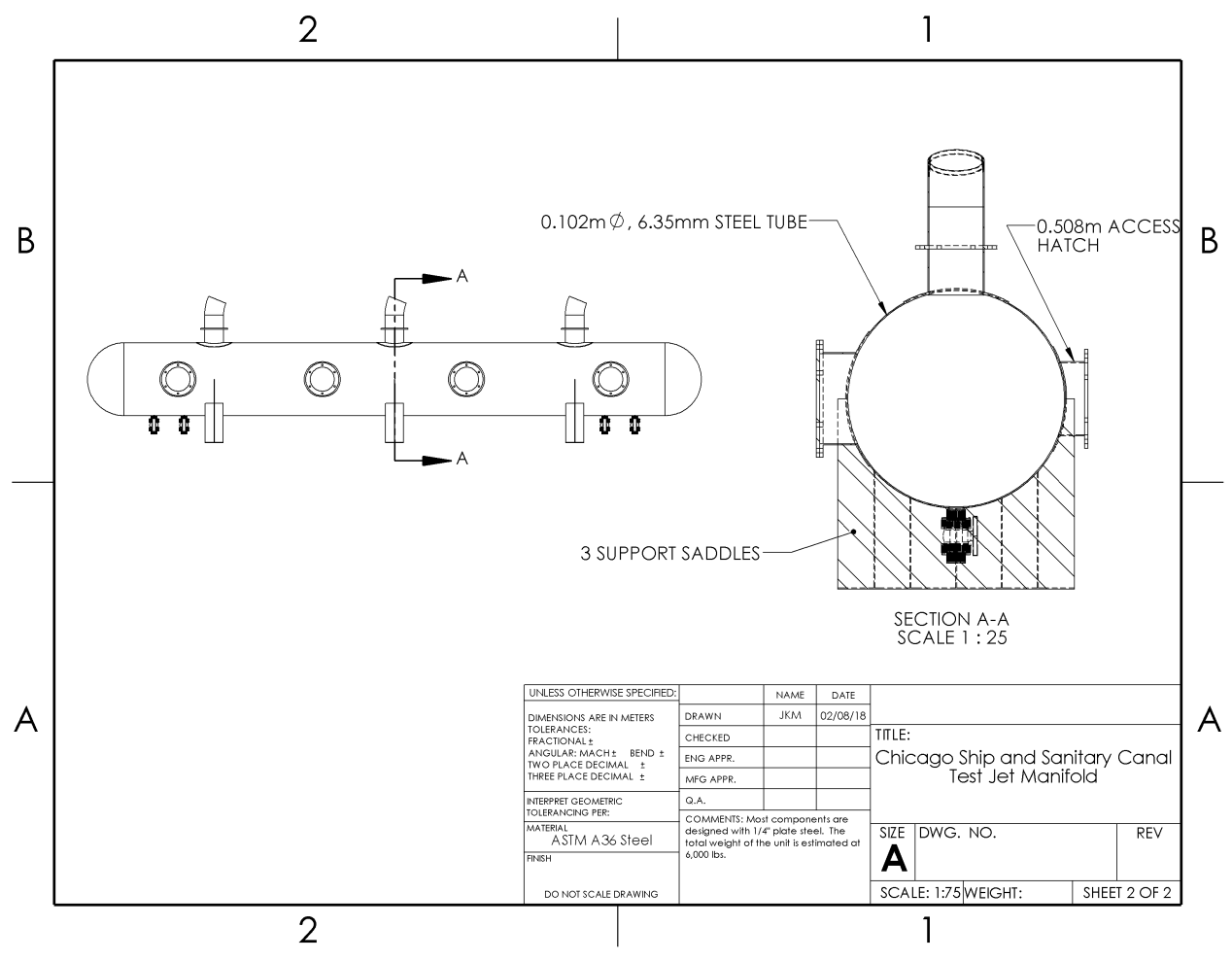

Figure 3-5. East bank operations area depicting the pump setup. There are six intake lines and four discharge lines that supply water pressure to the jets. The six intakes are set on top of the Jersey barriers and supported by the wooden slats. The four discharge pipes are set between the Jersey barriers. The strobe lights are visible on four of the pipes. A light plant (top, center, left) was also deployed to illuminate the site at night.

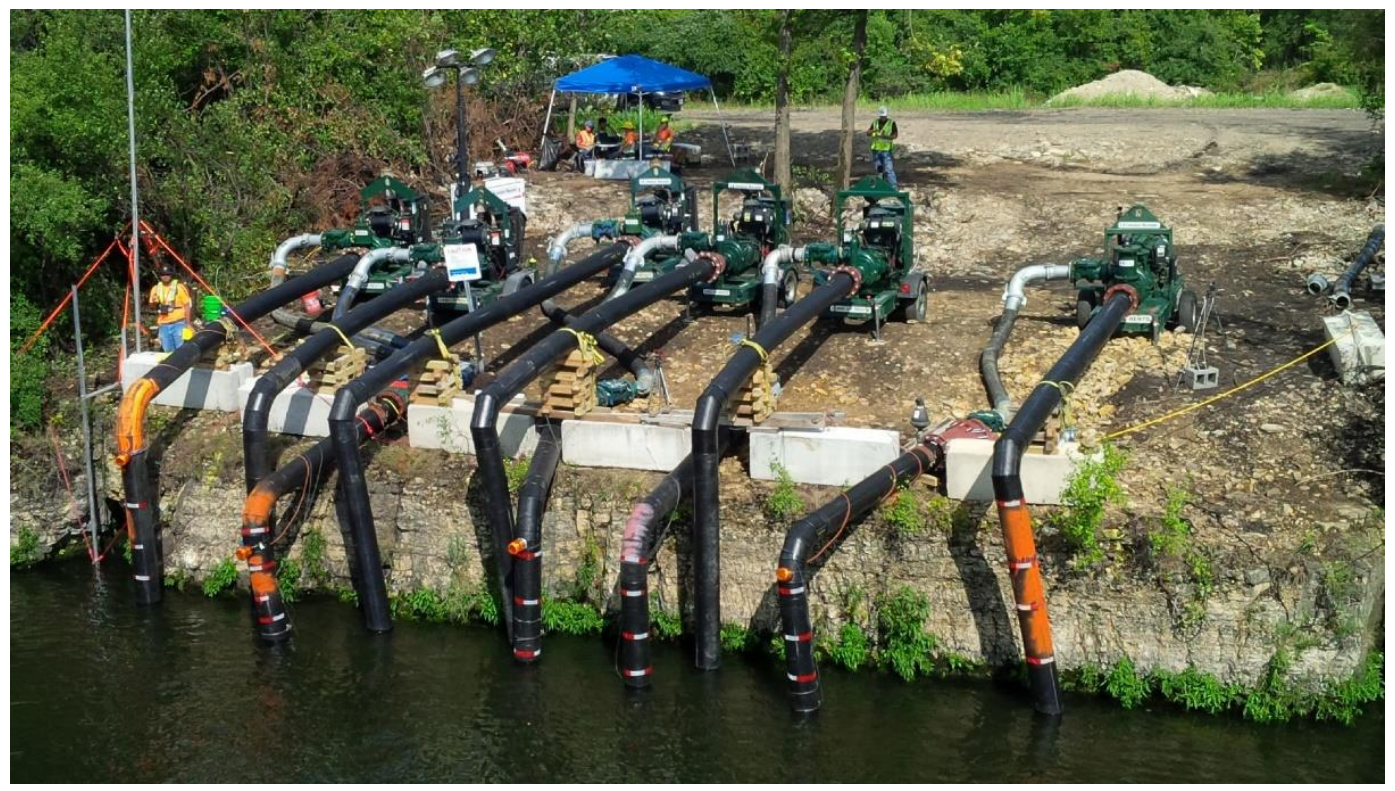


The manifold and underwater piping were installed by USACE operations personnel from US Army Corps of Engineers, Rock Island District (MVR). The team arrived Monday morning (14 August) via crane barge carrying the manifold and steel bridge piers. The MVR personnel consisted of a lift team to operate the cranes and a dive team to conduct underwater operations. The manifold was installed on Tuesday (15 August), and all underwater pipe connections were completed by Thursday (17 August). The team returned on 30 August to recover the manifold and pipes. The recovery took approximately 1.5 days to complete.

\subsection{Pump selection and discharge requirements}

Laboratory jet testing (Bryant et al. 2018) suggested that 12-18, 0.20 to $0.30 \mathrm{~m}$ diameter jets operating with $10-20 \mathrm{~m} / \mathrm{s}$ exit velocities were effective in flushing model fish from the box-rake junctions of two-wide barge rafts. The first jet prototype was much more modest in scale, with three $0.30 \mathrm{~m}$ diameter jets that were to be operated at a maximum of $6 \mathrm{~m} / \mathrm{s}$ exit velocity. These operating parameters require a flowrate of $1.3 \mathrm{~m}^{3} / \mathrm{s}$ discharge to the jet manifold.

Under contract with ERDC, United Rental provided six Pioneer PP88S12 pumps and all required pipe to supply the jet manifold. Four of the pumps were joined in pairs into single supply lines to the jet manifold. The remaining two pumps were singly connected to the remaining two supply lines (Figure 3-5). United Rental arrived onsite on 14 August to install the pumps and piping. The installation was complete by 18 August, allowing the sampling to begin on schedule the following Monday (21 August). CHL personnel installed ultrasonic flow meters on the four discharge pipes to record the flow rate from the variable speed pumps. The installed pumps generated a maximum discharge of $1.1 \mathrm{~m} 3 / \mathrm{s}$, resulting in a maximum jet exit velocity of $4.9 \mathrm{~m} / \mathrm{s}$. CHL personnel also installed four strobe lights on the risers as a safety measure to alert vessel traffic at night. The variable-speed pumps allowed the operators to set the discharge prior to each trial to maintain the required jet velocity. Operation of the pumps was conducted by CHL personnel, and there were no operational issues with the pumps.

\subsection{Towboat and barges}

The vessel used in this study (MV Derek $E$ ) was contracted by USFWS and was operated and owned by Egan Marine Corporation of Lemont, IL (Figure $3-6$ ). The towboat was $23.8 \mathrm{~m}$ long by $7.9 \mathrm{~m}$ wide with twin 
engines and a combined thrust of 1,000 horsepower. The flotilla included the towboat Derek $E$ and six fully loaded (2.7 m draft) barges (59.4 m long by $10.7 \mathrm{~m}$ wide). The barge configuration included two rake barges in the front, two box-end barges in the middle, and two rake barges at the rear connected to the towboat. Five of the barges were filled with gravel and one chemical barge was filled with water. For the first 3 days of the study, the barges were arranged in a $2 \times 3$ configuration (Figure 3-7). On the fourth day of testing (24 August), the barge configuration was changed to a $1 \times 3$. This reduced the flotilla width and the effective lateral distance that fish had to be transported to become free of the barge. The $1 \times 3$ barge configuration decreased the mass of the flotilla, which increased towboat response time so that more tests could be conducted each day.

Figure 3-6. View from the wheelhouse of the MV Derek $E$ showing the $2 \times 3$ barge configuration. The leading barge is about to pass over the manifold.

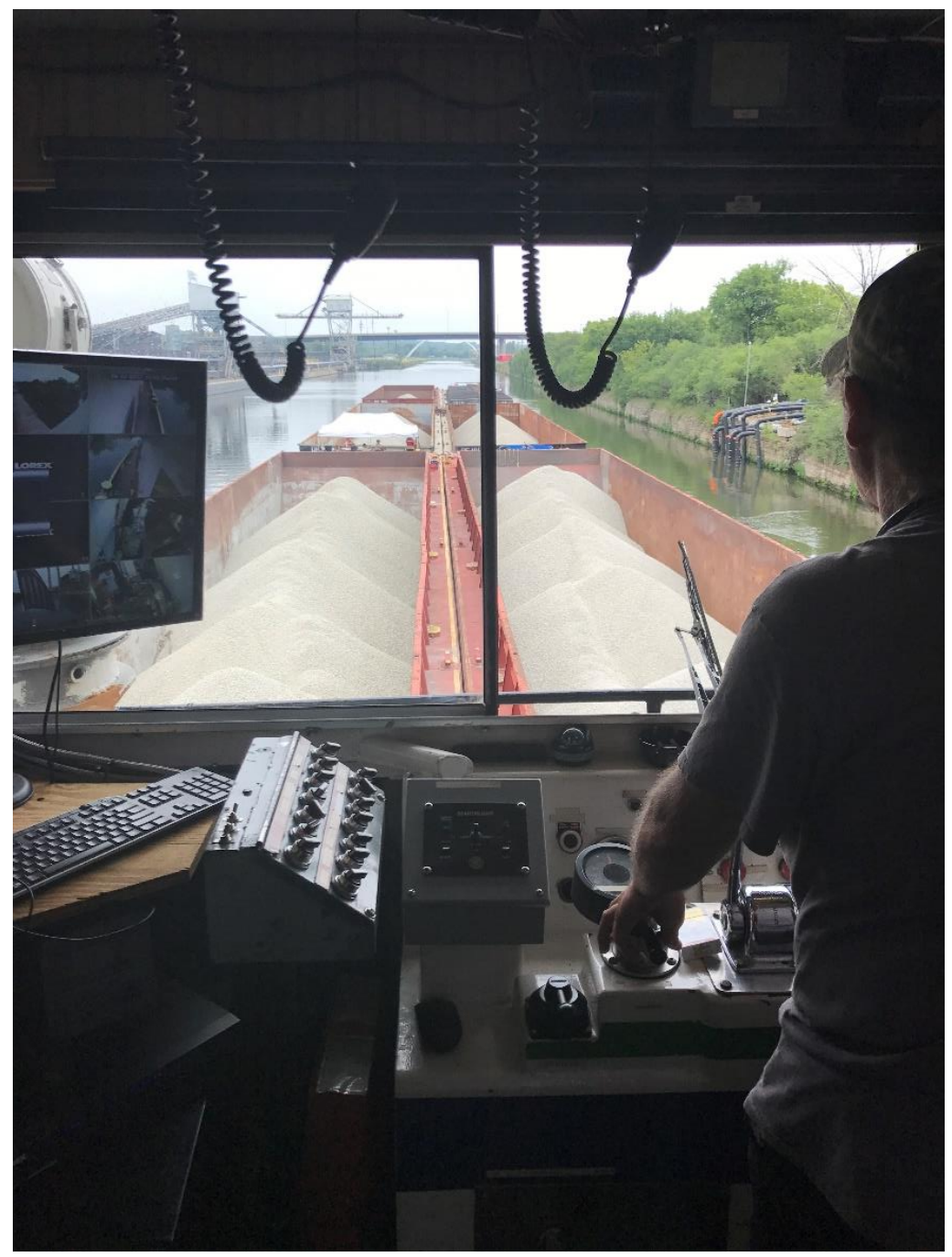


One focus area based on previous findings was between the middle boxend barges and the trailing rake barges. Push knees on the rake produced a $0.76 \mathrm{~m}$ gap separating the box barge allowing for fish release by USFW. Aluminum poles were mounted to the barges near the gap to support sensors deployed in the gap below the water surface.

The potential effect of the jets to navigation was investigated using pilot surveys and Global Positioning System (GPS) to measure precise tow position and heading. After each trial, the pilot was asked a set of questions to determine if the jets had any noticeable influence on the tow including whether the pilot needed to make any steering corrections or other navigation adjustments (Figure 3-8). A final survey was conducted at the end of the field study to obtain the pilot's overall assessment regarding the potential effect of a jet array to maneuvering and navigation (Figure 3-9). The results of the pilot surveying are provided in Section 4.2.

LRC provided three GPS units to monitor the position of each barge (Figure 3-7). The GPS units provided information to track the position of the flotilla as well as determine lateral movement of the barge relative to the canal axis including yaw.

Figure 3-7. Schematic illustrating barge configurations used during the field test. The ovals denote the testing region where fish and drifters were released. Although not pictured, there is a $0.76 \mathrm{~m}$ gap between the barges at the testing region. The three crossed yellow circles denote the location of the USACE GPS units.

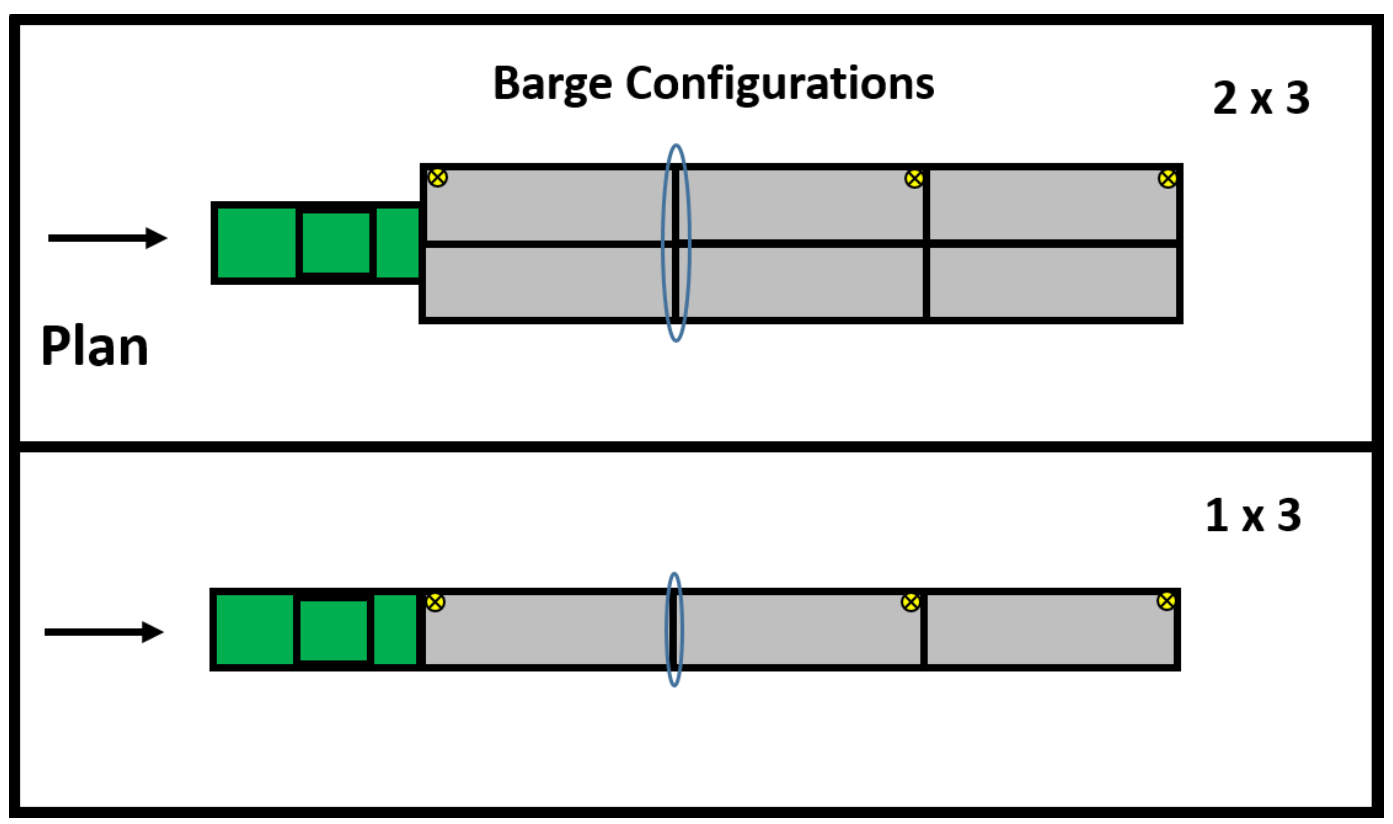


Figure 3-8. Pilot survey form.

Pilot Questionnaire - Field Test of Water Jets to Dislodge Entrained Fish from Barges, Chicago Sanitary and Ship Canal

Date:

Jet Velocity:

Tow Speed:

Tow Configuration:

Canal CFS:

1) What are your first thoughts that come to mind when passing over the jets?

2) Did you have to change normal operating procedures when passing over the jets? If so, specifically, what did you change? Heading, throttle, etc.

3) Did the tow move in the left or right direction as you passed over the jets?

a) If so, on a scale 1-10, 1 being not at all affected and 10 being highly affected, how would you rate the jets effect on the tow in the left or right direction?

4) Did the tow move in the up or down direction as you passed over the jets?

a) If so, on a scale 1-10, 1 being not at all affected, and 10 being highly affected, how would you rate the jets effect on the tow in the up or down direction? 
Figure 3-9. Final pilot survey. This survey was administered at the end of the field program.

Final Pilot Questionnaire - Field Test of Water Jets to Dislodge Entrained Fish from Barges, Chicago Sanitary and Ship Canal

1) What is the maximum velocity or discharge that you can still navigate within the canal?

2) If the flow within the canal is slow, was a recommended speed provided? If so, what concerns do you have about the speed?

3) Referring to the turn just upstream of the barrier, to maintain navigation, what speed are you concerned with around the turn in both the upstream and downstream directions?

4) What are your overall thoughts of the jets?

5) With just 3 jets being used during the field test, how do you feel a total of 18 jets used in the field would affect Navigation?

\subsection{Work vessel}

CHL trailered a small workboat (MV Garcia) from ERDC to ferry researchers to and from the barge for the daily testing and to serve as a safety vessel to prevent unauthorized vessels from entering the control area during testing. The workboat was also used to conduct a bathymetry survey with the manifold in place and to collect current measurements during the study. M/V Garcia is a $6.7 \mathrm{~m}$ long, $2.4 \mathrm{~m}$ wide, shallow-draft boat. It has a single 150 kilowatt $(\mathrm{kW})$ outboard engine and a 3000 watt generator. It is designed for data collection in turbulent riverine environments.

\subsection{Instrumentation}

\subsubsection{Acoustic Doppler velocimeters (ADVs)}

A pair of Nortek Vector ADVs were mounted between the rake and box barge (Figure 3-10). The first ADV was shipped from Vicksburg, MS, near 
the end of the week of 21 August and was mounted on the barge the following weekend. The first ADV started collecting data Monday morning, 28 August. The second unit arrived Monday morning and was installed approximately 12:00 $\mathrm{pm}$. The ADVs were mounted vertically approximately $1 \mathrm{~m}$ (first ADV) and $2 \mathrm{~m}$ (second ADV) below the water surface. While the ADVs were only deployed during the second week of the study, they provided direct measurements of the vertical distribution of the lateral exit velocity that is responsible for transporting fish out of the barge recess.

ADV measurements commonly included erroneous data in the form of data spikes, especially in the presence of bubbles. During steady state ADV measurements, a filter based on the work of Goring and Nikora (2002) and Wahl (2003) (GNW filter) can be applied to remove spikes from the time series. The GNW filter was applied to a moving $20 \mathrm{~s}$ window of the velocity time series. This was found to remove erroneous data spikes while maintaining the velocities induced by the water jet.

Figure 3-10. Photograph depicting the ADVs with mounting hardware and a schematic illustrating the location of the ADVs once deployed. The view is looking towards the east bank, and the cameraman is standing on the box barge. The ADVs are in a vertically stacked configuration awaiting deployment. The ADVs were placed at $1 \mathrm{~m}$ and $2 \mathrm{~m}$ depths below the water surface.

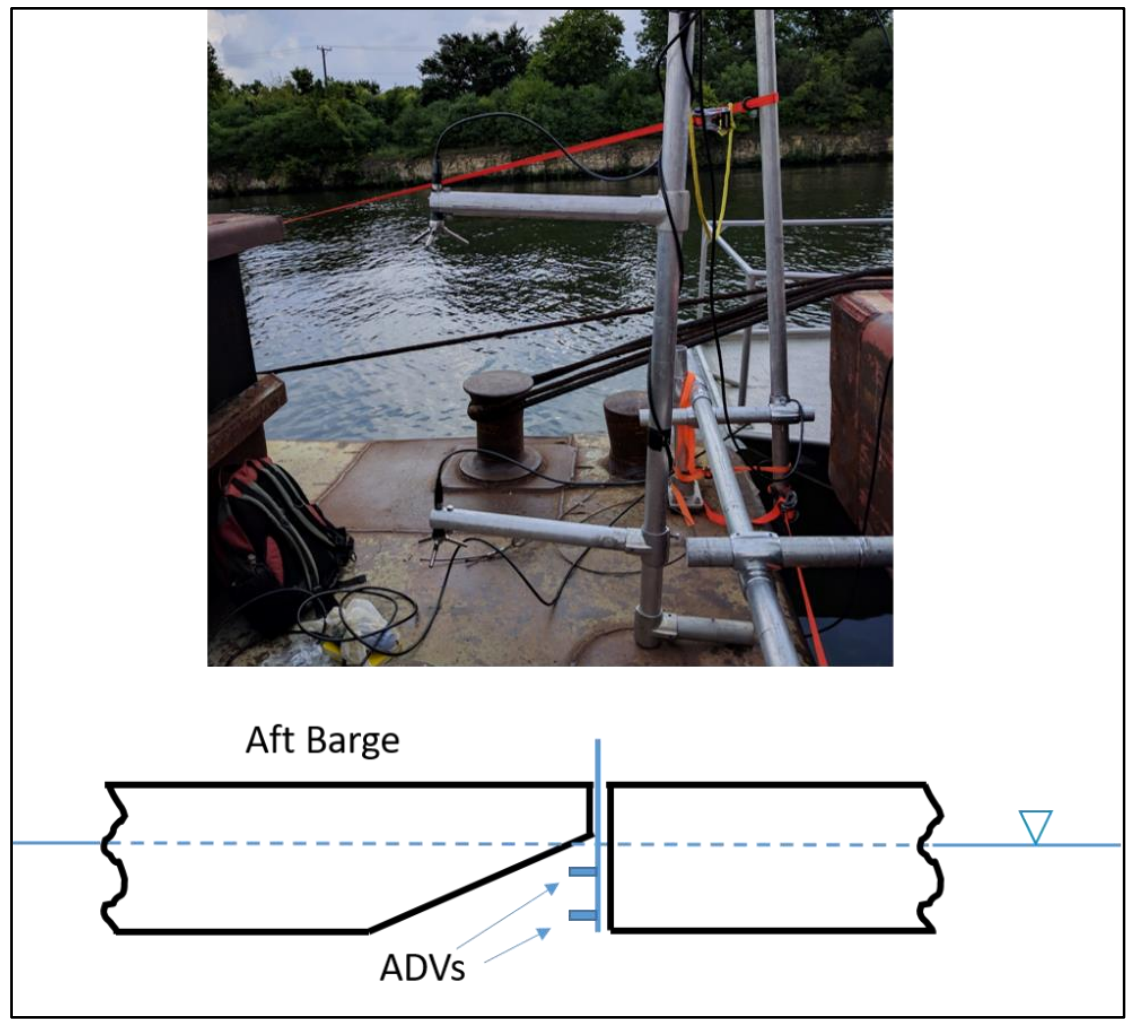




\subsubsection{Acoustic Doppler current profiler (ADCP) surveys}

A vessel-deployed ADCP was mounted to the MV Garcia to collect vertical profiles of currents over the jet array and near the tow. The initial ADCP survey occurred on Monday, 21 August, to map the jet-induced flow field. The vessel completed a grid survey starting downstream of the jets, moving northward over the manifold, and then upstream of the jets. The first survey was conducted without the jets operating to measure ambient flow in the canal. This was followed by repeat surveys for each of the three discharge velocities to map the magnitude and lateral extent of the jetinduced flow.

The previous laboratory experiments of Bryant et al. (2016, 2018) indicated that fish could become trapped in the flow separation region between the aft barge and the towboat. A second ADCP survey was conducted in this region by mooring the MV Garcia to the aft starboard barge and the towboat (Figure $3-11$ ). The survey was conducted during the afternoon test on 23 August with a $2 \times 3$ barge configuration.

Figure 3-11. M/V Garcia measuring the flow between the aft barge and the towboat. The ADCP mounting system is visible behind the open door on the starboard side. This photograph was taken at the start of a trial, so the towboat is at rest. As the towboat moves forward, the region monitored by the ADCP develops eddies and becomes turbulent.

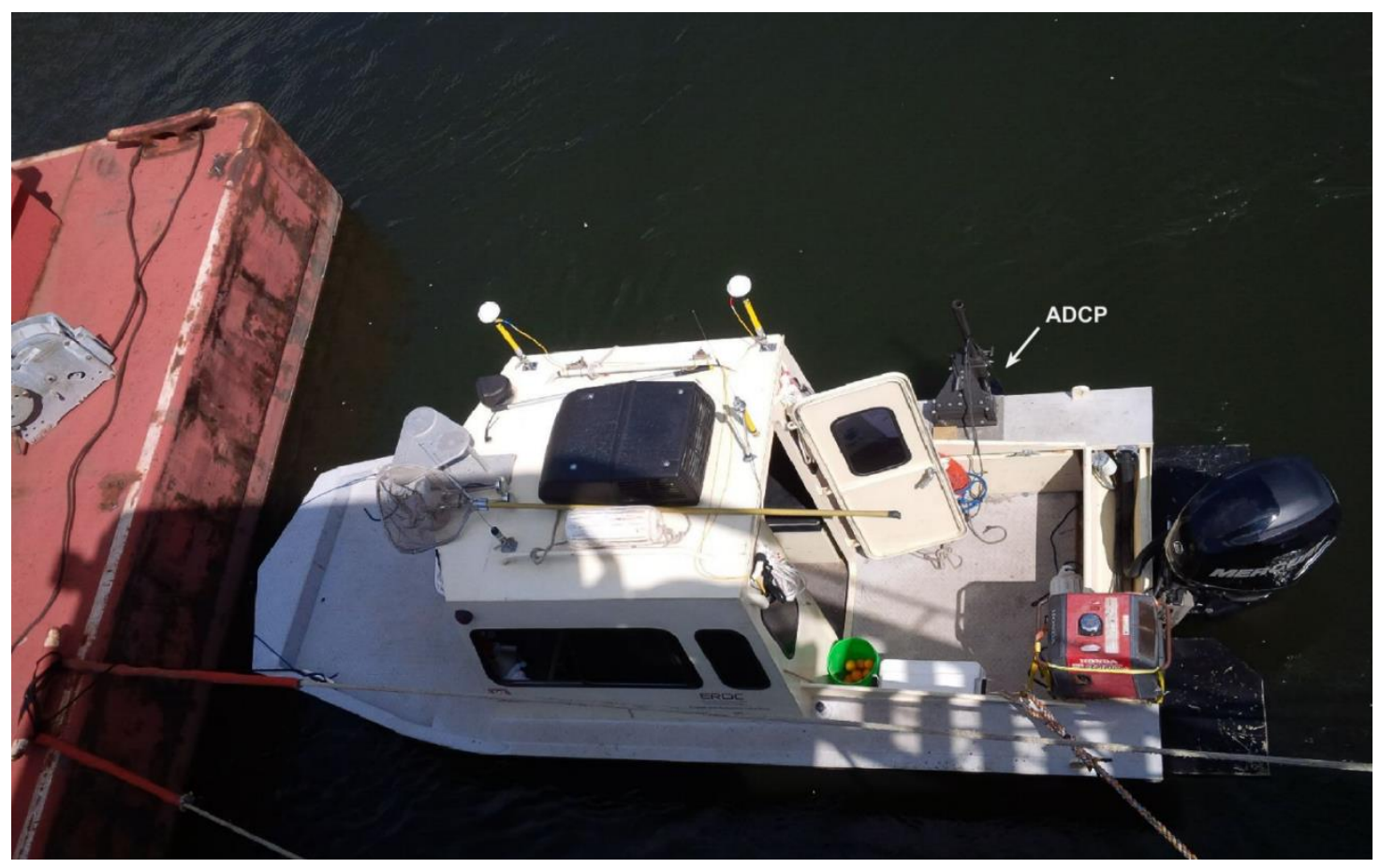




\subsubsection{Flow visualization and drifters}

Flow visualization included fish monitoring and surface drifters. The fish monitoring was conducted by USFWS personnel from the Carterville Fish and Wildlife Conservation Office located in Wilmington, IL. That office should be consulted regarding fish delivery methodologies and sampling strategies (Davis et al. 2016). CHL personnel deployed oranges as particle tracers to determine the degree to which the jets were effective at removing buoyant objects floating on the surface. Oranges were chosen because they were inexpensive, highly visible, and reusable. A fixed number of oranges (typically 10) were released in the rake junction prior to passing over the jets and then recovered from the canal at the completion of each trial. The number of oranges flushed and/or retained were recorded during the tests. To separate the effect of the jet versus vessel-induced currents, observers noted the timing of when the oranges were flushed from the barge junction. Drifter tracking included tallying the number of oranges that were ejected prior to passing over the jets, the number of oranges that were ejected as the barge passed over the jets, and the number of oranges that were ejected after the barge had cleared the jets.

\subsection{Sampling plan}

The sampling strategy was to identify a range of test conditions that would demonstrate the effectiveness of the jets at removing fish from the recess between the leading box and trailing rake barge junction. Based on the laboratory results, the primary testing matrix included individual barge trials with the following configurations: (1) barge speed $(0.45,0.90$, and $1.8 \mathrm{~m} / \mathrm{s}),(2)$ jet velocities $(2.4 \mathrm{~m} / \mathrm{s}, 3.7 \mathrm{~m} / \mathrm{s}$, and $4.9 \mathrm{~m} / \mathrm{s})$, and (3) tow configuration $(2 \times 3$ and $1 \times 3)$. In addition, several secondary trials were conducted to explore extreme conditions outside the primary testing matrix to provide bounds on the standard set of tests: (1) maximum tow speed $(>1.78 \mathrm{~m} / \mathrm{s}$ ) over the jets at maximum jet velocity, (2) minimum tow speed $(0.22 \mathrm{~m} / \mathrm{s})$ with maximum jet velocity, and (3) variations in canal discharge. A total of 106 trials was conducted, and a matrix containing information on each trial is in Appendix A.

Daily trials were scheduled during two testing windows (o80o to 1200 and 1400 to 1800 Central Daylight Time) with a 2-hour break between 1200 and 1400 to open the canal to recreational and commercial vessel traffic. As a safety precaution, the canal was closed to all unauthorized traffic during the testing windows. 
A trial consisted of a single crossing of the jet array, and the majority of the cases were for upbound tows. The vessel would start south of the array at a sufficient distance to ensure the tow could reach the required testing speed before passing over the manifold. The tow was to maintain a straight course parallel to the canal wall with the barges centered over the manifold. Three trials were conducted for most configurations to permit a statistical analysis on the effect of deviations in vessel position. 


\section{Navigation Results}

\subsection{Vessel tracks}

The three GPS units mounted on the barges are used to track vessel position during each trial. The GPS information is processed to generate estimates of the speed, heading, tow's yaw rate (rate of heading change), and the offset distance between the manifold and the centerline of the barge (Figure 4-1). To avoid bias in maneuvering a heavier barge, the statistics are computed only for the $1 \times 3$ barge configuration. The actual speed of the tow when passing over the manifold matches the target speed with a high level of accuracy (Table 4-1). The standard deviation (STD) indicates low variability about the mean for all three testing speeds, which indicates that the vessel speed during the majority of trials is representative of the desired target speed. The canal is oriented 4.5 degrees from true north. The heading indicates a 7.5-degree average (towards the north-northeast), which is approximately 3 degrees clockwise from the orientation of the canal. On average, the tow tends to pass over the array at a small angle. The average yaw rate is relatively small compared to the STD, indicating that the vessel is slightly turning as it passes over the manifold. The offset distance indicates the tow tends to be slightly closer to the east bank when passing over the manifold. This means, on average, the jet velocities are not symmetric but are stronger on the portside of the barge. The offset STD indicates greater variability in the tow's position over the manifold such that there is a larger number of instances when the jets are not concentrating their flow on the centerline of the flotilla. The data used to generate Table 4-1 are listed in Appendix B. 
Figure 4-1. Schematic illustrating the coordinate system and definitions of offset for a $2 \times 3$ barge. The blue rectangle denotes the manifold (not to scale). For the $1 \times 3$ configuration the offset is measured from the centerline of the barge.

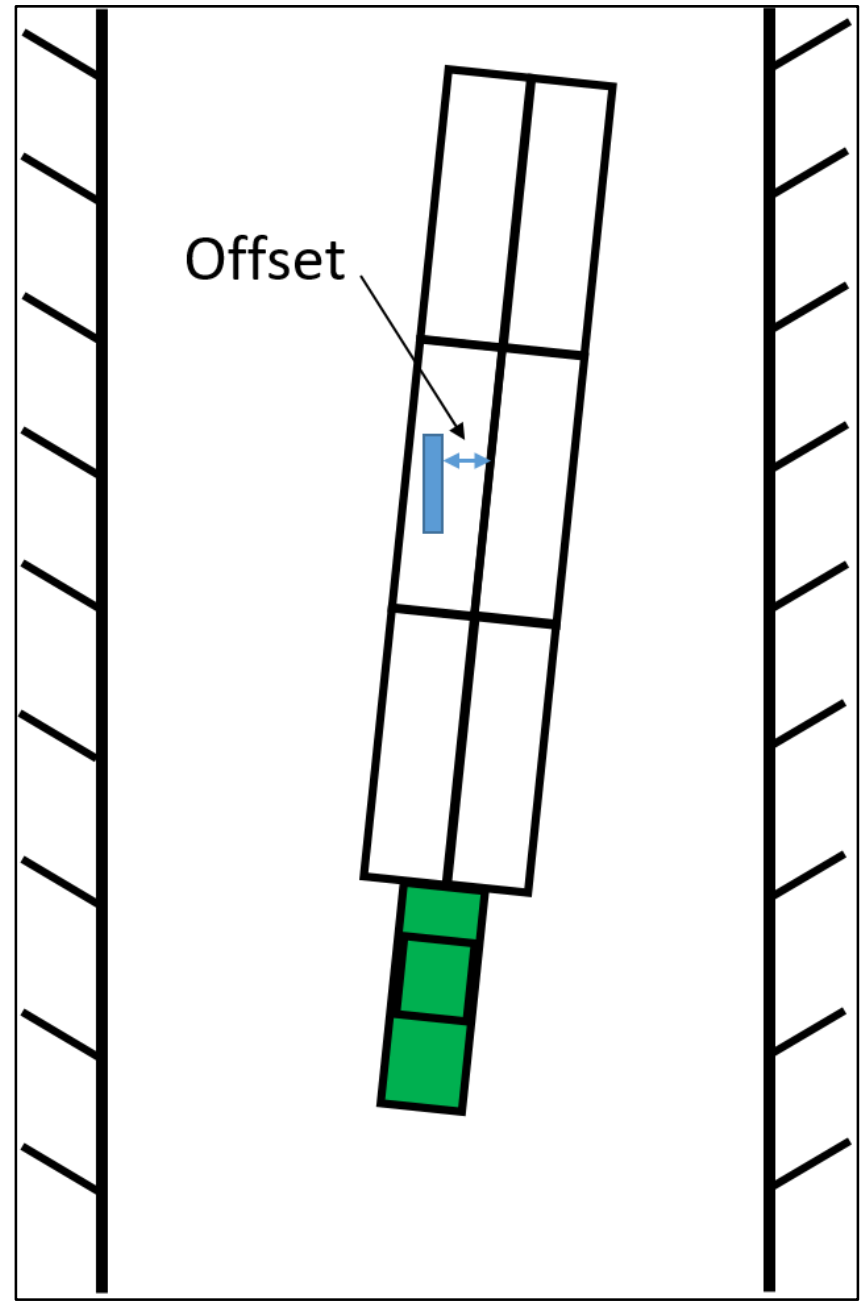

Table 4-1. Vessel passage statistics. Each row denotes different vessel speeds.

\begin{tabular}{|c|c|c|c|c|c|c|c|c|}
\hline $\begin{array}{c}\text { Target } \\
\text { Speed } \\
(\mathrm{m} / \mathrm{s})\end{array}$ & $\begin{array}{c}\text { Average } \\
\text { Speed } \\
(\mathrm{m} / \mathrm{s})\end{array}$ & $\begin{array}{c}\text { Speed } \\
\text { STD } \\
(\mathrm{m} / \mathrm{s})\end{array}$ & $\begin{array}{c}\text { Average } \\
\text { Heading } \\
\text { (degree) }\end{array}$ & $\begin{array}{c}\text { Heading } \\
\text { STD } \\
\text { (degree) }\end{array}$ & $\begin{array}{c}\text { Average Yaw } \\
\text { (degree/minute) }\end{array}$ & $\begin{array}{c}\text { Yaw STD } \\
\text { (degree/minute) }\end{array}$ & $\begin{array}{c}\text { Average } \\
\text { Offset } \\
(\mathrm{m})\end{array}$ & $\begin{array}{c}\text { Offset } \\
\text { STD } \\
(\mathrm{m})\end{array}$ \\
\hline 0.45 & 0.49 & 0.081 & 7.18 & 1.9 & 0.13 & 1.25 & 1.16 & 2.99 \\
\hline 0.89 & 0.91 & 0.025 & 7.66 & 1.9 & 0.04 & 1.02 & 1.94 & 4.42 \\
\hline 1.79 & 1.78 & 0.134 & 7.63 & 1.9 & 0.02 & 1.59 & 0.99 & 3.62 \\
\hline
\end{tabular}




\subsection{Vessel tracks and pilot survey}

The GPS data are used to generate vessel tracks to illustrate the vessel position during the trials. For the majority of the tests, the tow starts downstream of the jets with the towboat closer to the west bank of the canal and the barges oriented at a slight angle towards the east bank. As the tow accelerates, the captain maneuvers the flotilla to place the head of the tow towards the west until the tow is aligned with the canal axis. Once the tow passes over the jets, the pilot throttles back, and the head of the tow tends to drift towards the east bank. This is illustrated in Figure 4-2 and Figure 4-3.

The cumulative tow tracks subdivided by vessel speed and barge configuration illustrate the variability in vessel position for all trials. For the $2 \times 3$ barge configuration, there are a greater number of trials for the slowest speed and there is variability in the alignment with the manifold (Figure 4-4). At the higher speeds, there are fewer trials, and the tow tends to either pass over the manifold or slightly east of the manifold. For the $1 \times 3$ barge configuration, the variability is well illustrated due to the greater number of individual trials (Figure 4-5). The tendency for the centerline of the tow to pass just east of the manifold is best illustrated for the 0.4 and $1.8 \mathrm{~m} / \mathrm{s}$ speeds. 
Figure 4-2. Vessel tracks indicating the off-center approach to the jets. The yellow rectangle denotes the approximate profile of the jet manifold.

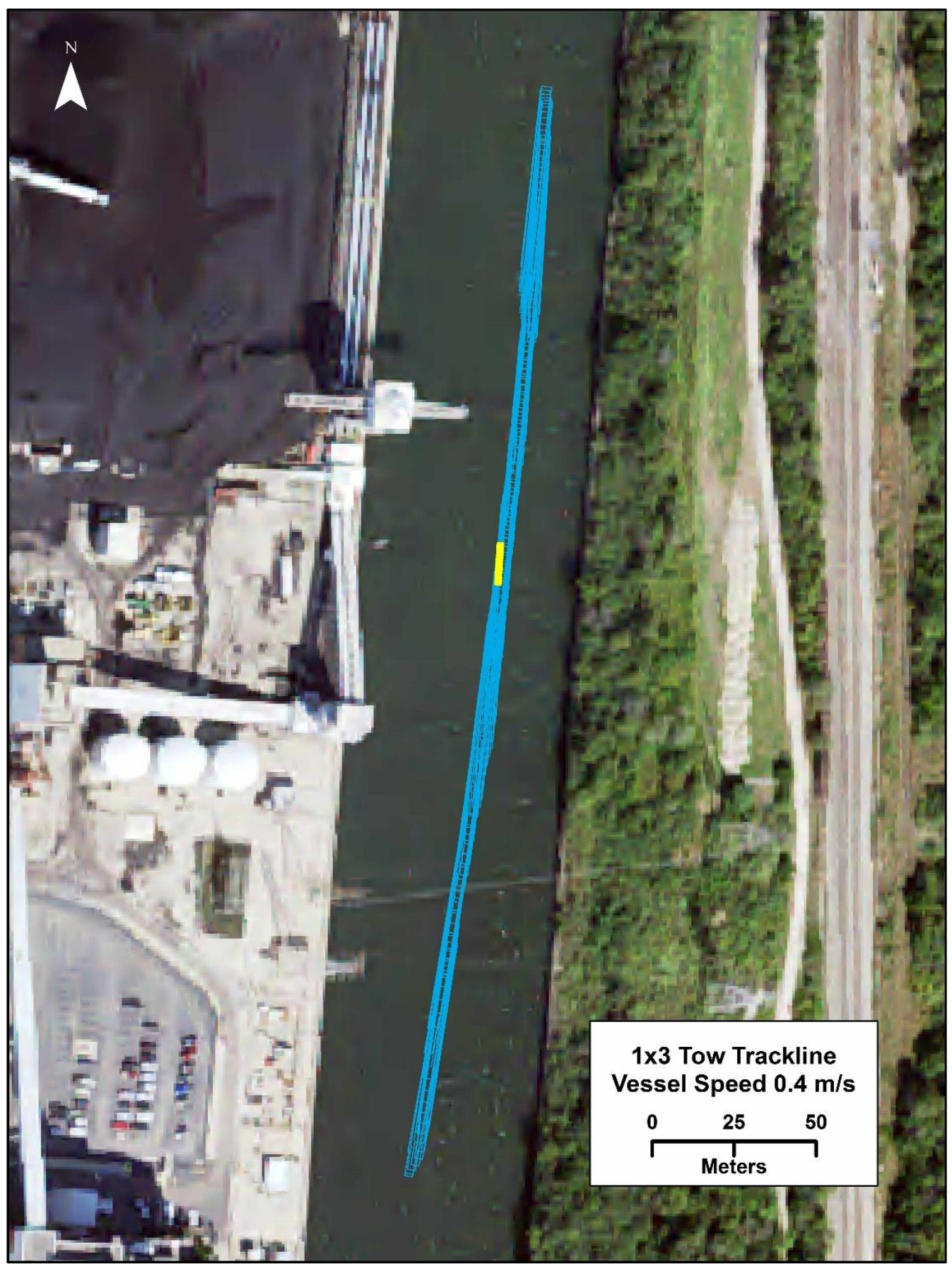


Figure 4-3. Vessel position showing the off-center approach and veering towards the east bank after passing over the jet manifold.

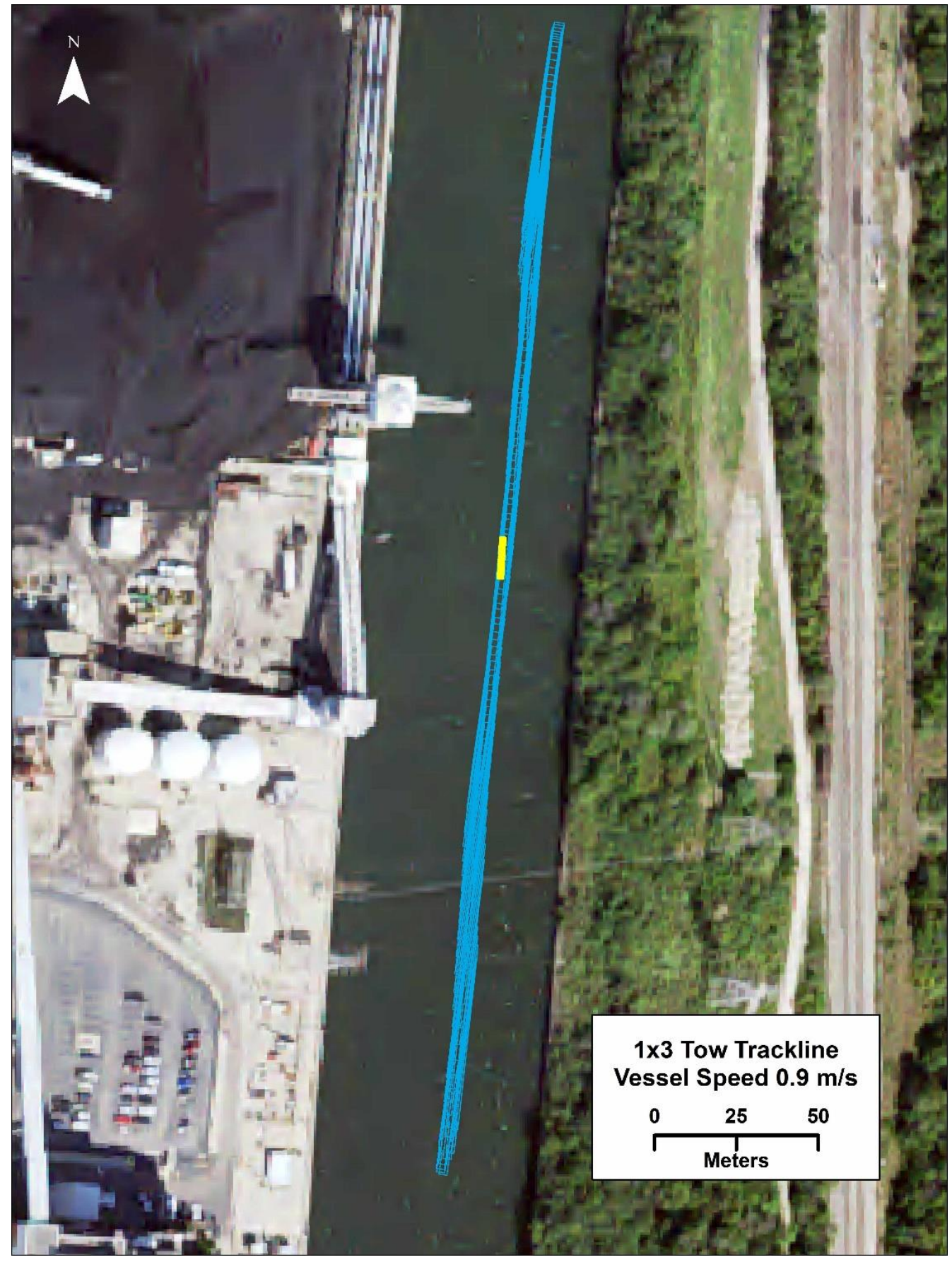


Figure 4-4. Tow tracks for the $2 \times 3$ barge configuration subdivided by vessel speed. (A) $0.4 \mathrm{~m} / \mathrm{s}$; (B) $0.9 \mathrm{~m} / \mathrm{s}$; and (C) $1.3 \mathrm{~m} / \mathrm{s}$.

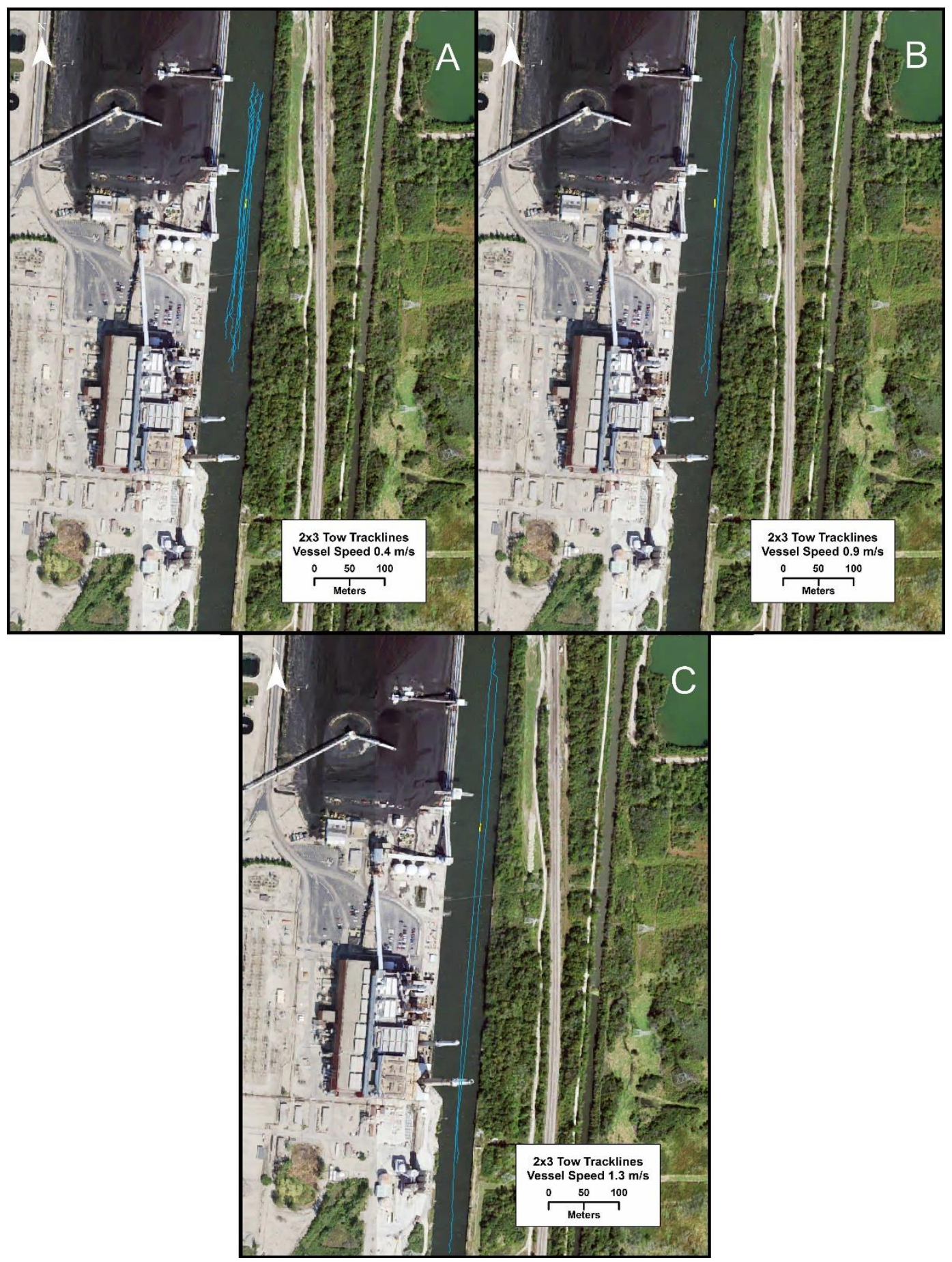


Figure 4-5. Tow tracks for the $1 \times 3$ barge configuration. (A) $0.4 \mathrm{~m} / \mathrm{s}$; (B) $0.9 \mathrm{~m} / \mathrm{s}$; (C) $1.8 \mathrm{~m} / \mathrm{s}$; and (D) $2.2 \mathrm{~m} / \mathrm{s}$.

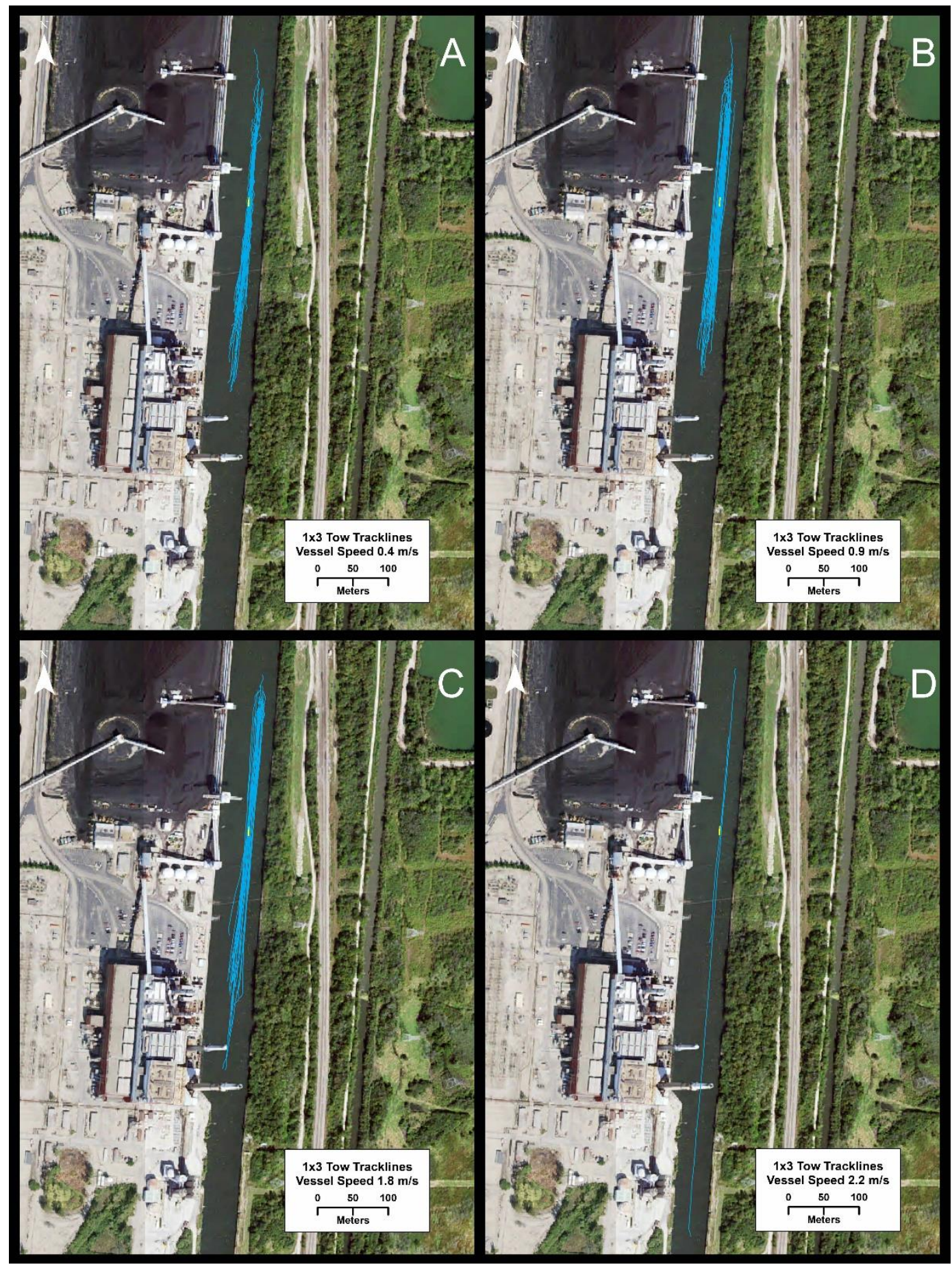

For the majority of the trials, the captain noted that the tow did not seem to respond in any significant way to the upward flow produced by the jets when passing over the manifold. While some maneuvering was required to maintain a straight path, it was unclear if the jets or the ambient currents 
caused the pilot to make small course adjustments. Another contributing factor that could affect tow maneuvering was a bend in the canal upstream of the test location. The pilot is very familiar with the CSSC and noted that the curvature produces cross-currents that push the bow of the tow off center of the canal. During normal operations the cross-current is not a concern, but during these controlled runs, in which maintaining a straight course is critical, the captain indicated that maneuverability is affected by the cross-current. Although not directly measured, the wind may also have played some factor as well. Wind speed and directional estimates are provide in Appendix A. These factors may have made it slightly more difficult for the tow to align with the manifold. If the captain had begun his run farther downstream of the jets, the vessel would probably not have had any issue lining up. For the earlier tests, it appeared as the jets were pushing the front of the flotilla towards the east bank, but it became apparent to the captain that the current coming around the bend played more of a role in pushing the flotilla.

After all tests were complete, a final questionnaire was given to the captain. Based on the questions, the pilot gave the following response: Question (1), the pilot stated that the maximum discharge that he can navigate through the canal is $198 \mathrm{~m} 3 / \mathrm{s}$, but he also explained that this can change from boat to boat and depends on the vessel's horsepower. Question (2), the pilot felt that no more than $1.8 \mathrm{~m} / \mathrm{s}$ would be the speed he would recommend during a slow discharge of the canal. Question (3), the pilot felt that $1.8 \mathrm{~m} / \mathrm{s}$, maybe slightly less, was a good speed through the upstream barrier to maintain navigation, but it also depended on the canal discharge or current coming through the barrier. Overall, the captain felt that the jets are a workable concept but a narrower channel or area would be more desirable. He felt a narrower section would allow for better control over the jets and recommended possibly installing jets in a navigation lock approach channel. $\mathrm{He}$ also reiterated that navigability is not affected by the jets. When asked if a total of 18 jets would adversely affect navigation, he said in his opinion that the increase in jets would not cause any effect on vessel maneuverability. He did state that increasing to 18 jets could deflect the tow slightly to port/starboard but the magnitude of the net lateral force should be so weak that a trained pilot could easily compensate via vessel maneuvering. If space allowed, he felt that concentrating the boat/tow through the center of the jets would not be an issue. 
At the conclusion of the study, the captain was asked "Do you think industry would have an issue lining up their tow over the jets?” He explained that more than likely they would have initial doubts about the process but would need to be informed on the importance of the jets and that communication between industry and the appropriate government agencies would need to take place. 


\section{Hydrodynamic Results}

\subsection{ADCP jet survey}

The ADCP survey results depict the depth-averaged current distribution in the vicinity of the manifold. The coordinate system is oriented with the canal such that the center of the jet manifold is at the origin and positive values are towards the upstream direction and the east bank. The case without jets shows an ambient current of approximately $0.25 \mathrm{~m} / \mathrm{s}$ flowing from north to south that is distributed across the width of the canal and approximately $50 \mathrm{~m}$ north and south of the manifold (Figure 5-1).

Currents are similar for the case of a $2.4 \mathrm{~m} / \mathrm{s}$ jet velocity, but there is a sharp deviation in the survey vessel track near the manifold. The survey vessel captain reports that the surface velocity induced by the jets tends to push the survey vessel away from the manifold so that velocities directly over the jets are not measured. This steering current generated by the manifold also occurred when the jet velocity was $3.7 \mathrm{~m} / \mathrm{s}$ (Figure $5-2$ ) as the survey vessel is pushed away from the manifold and the pilot makes a course correction to regain the cross-channel survey line. When the jet velocity is $4.9 \mathrm{~m} / \mathrm{s}$, the pilot is able to maneuver directly over the manifold, and the increase in magnitude and variability in the current is well illustrated. Even though the surveys do not capture the jet-induced flow at the lower jet velocities, the effect on small vessel maneuverability is clearly illustrated and tends to become more prevalent when the vessel is moving slowly and positioned within approximately $10 \mathrm{~m}$ of the manifold. 
Figure 5-1. Depth-averaged currents in the vicinity of the manifold obtained from the ADCP mounted on the MV Garcia. (A) Without the jets operating; (B) with the jet velocity of $2.4 \mathrm{~m} / \mathrm{s}$.

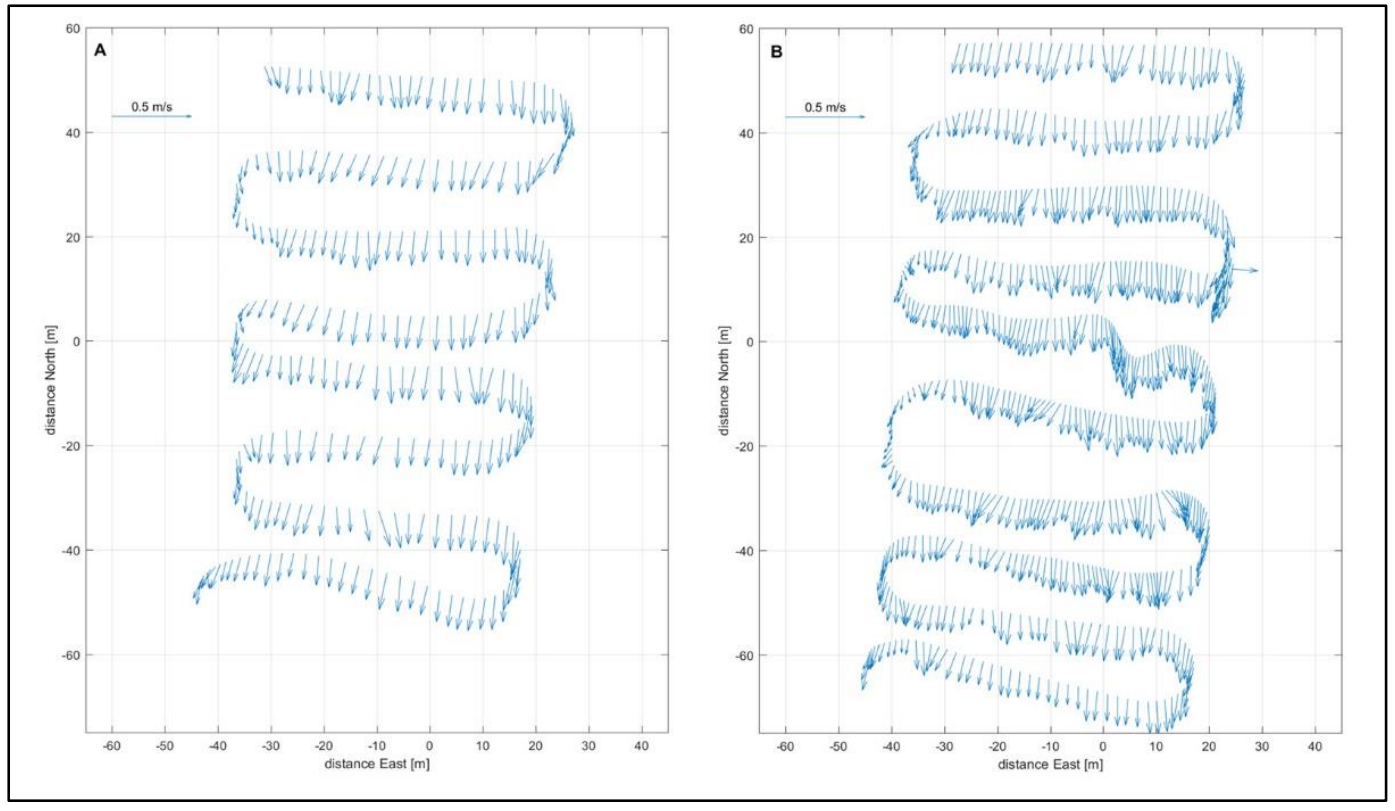

Figure 5-2. Depth-averaged currents for (A) jet velocity of $3.7 \mathrm{~m} / \mathrm{s}$ and (B) jet velocity of $4.9 \mathrm{~m} / \mathrm{s}$.

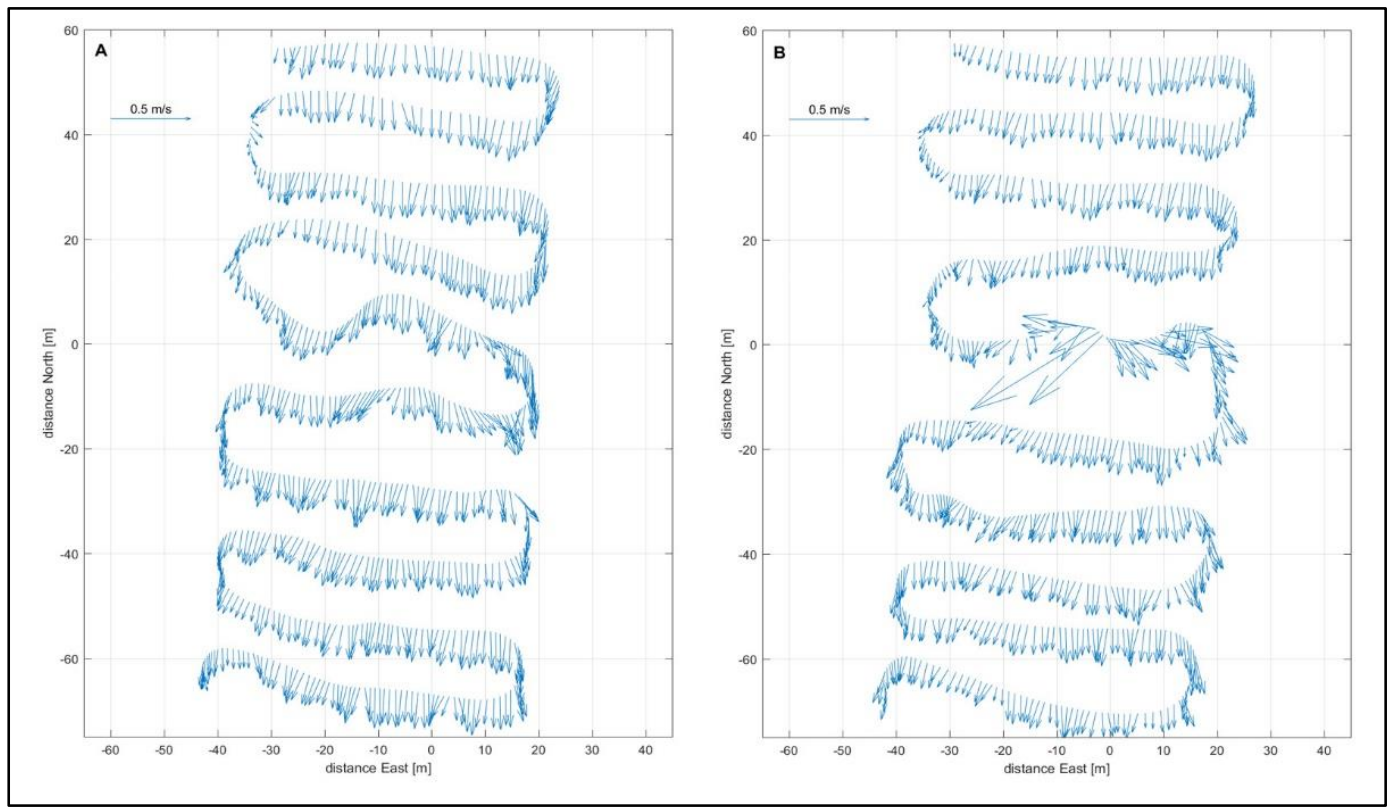

Vertical current profiles immediately upstream of the manifold indicate the spatial extent of the jets as a function of depth. The results represent the average current at each depth as the vessel traverses the canal approximately $20 \mathrm{~m}$ upstream of the manifold. In all cases, the current is positive, indicating downstream flow (Figure 5-3). Near the surface, where 
the jet influence is expected to be the greatest, the vertical profiles for the case without jets is similar to the cases with the lower two jet velocities ( 2.4 and $3.7 \mathrm{~m} / \mathrm{s}$ ). There is a noticeable reduction in velocity for the case with a $4.9 \mathrm{~m} / \mathrm{s}$ jet in the upper 3 to $4 \mathrm{~m}$ of the water column. Thus, the strongest jet does reduce the current somewhat, but it is not sufficient to cause a flow reversal.

Figure 5-3. Vertical profiles of the current near the manifold. Dashed line denotes standard error for the case without jets and provides a measure of the natural variability of the ambient current.

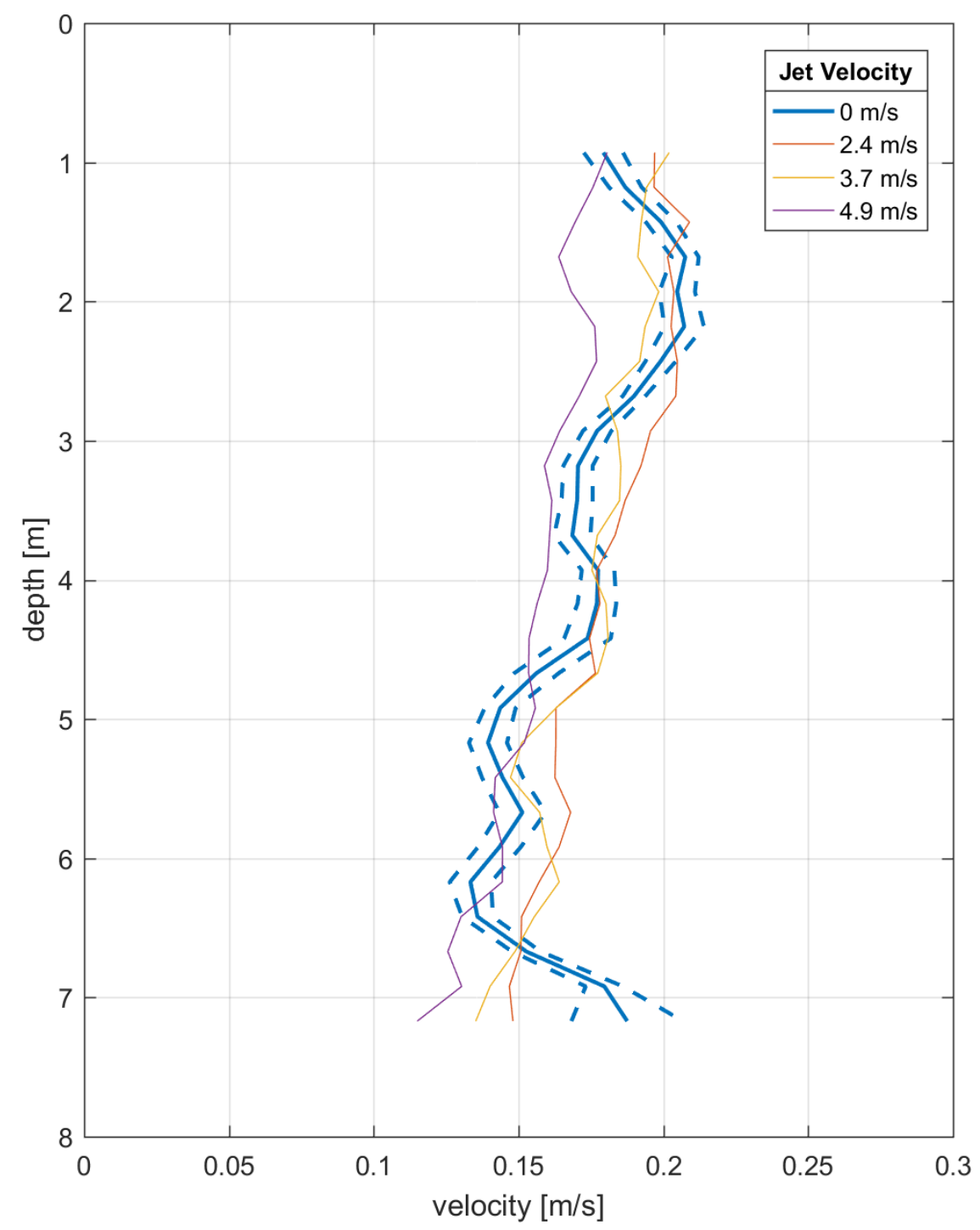




\subsection{ADCP wake-zone survey}

In addition to entrainment at the box-rake junction, a previous laboratory study (Bryant et al. 2016) showed that fish can be trapped in the space between the side of the towboat and the last barge. Current profiles in the region aft of the last barge and adjacent to the starboard side of the towboat reveal the current structure for this area and can be used to infer the likelihood of fish entrainment at full scale. The results indicate that depths shallower than the draft of the barge produce a streamwise current oriented in the direction of barge travel (Figure 5-4 A,C,E). The graphs are presented such that the ADCP measurements begin when the tow is $60 \mathrm{~m}$ downstream of the manifold and end when the tow has completed its north-bound run, which varies between 18 and $60 \mathrm{~m}$ upstream of the manifold. As the barge moves forward, eddies develop behind the aft barge producing a current that flows in the direction of the barge. There is a general transition in current magnitude between 2 and $3 \mathrm{~m}$ depth that corresponds to the draft of the barge. While the data indicate vertical variation in the wake boundary, the current below the barge depth is in general similar to the ambient current in the canal. The magnitude of the positive streamwise current tends to strengthen as the vessel speed increases. The relative magnitude and direction of the streamwise current does not seem affected by the presence of the jet, as conditions before and after the tow has passed over the manifold appear similar.

The cross-current (Figure 5-4 B,D,F) is generally weaker and more variable, but there are differences in the flow characteristics above and below the draft of the barge. Above the draft of the barge there are noticeable fluctuations in currents directed towards and away from the east bank, which is indicative of eddies being shed from the aft edge of the tow. The extremes between the positive and negative flows become more apparent as vessel speed increases. This is likewise due to the presence of more energetic eddies associated with a faster tow speed. Like the streamwise flow, the cross-stream does not appear to be affected by the jets. 
Figure 5-4. Vertical profiles of the current in the region between the aft barge and the starboard side of the towboat. A, C, and E give streamwise velocity; B, D, and F give cross-stream velocity. Vessel speeds (A-B) $0.57 \mathrm{~m} / \mathrm{s}$; (C-D) $0.49 \mathrm{~m} / \mathrm{s}$; and (D-E)

$1.6 \mathrm{~m} / \mathrm{s}$. The white areas denote poor data quality, typically over the jet array. The solid black line indicates the bottom of the canal.

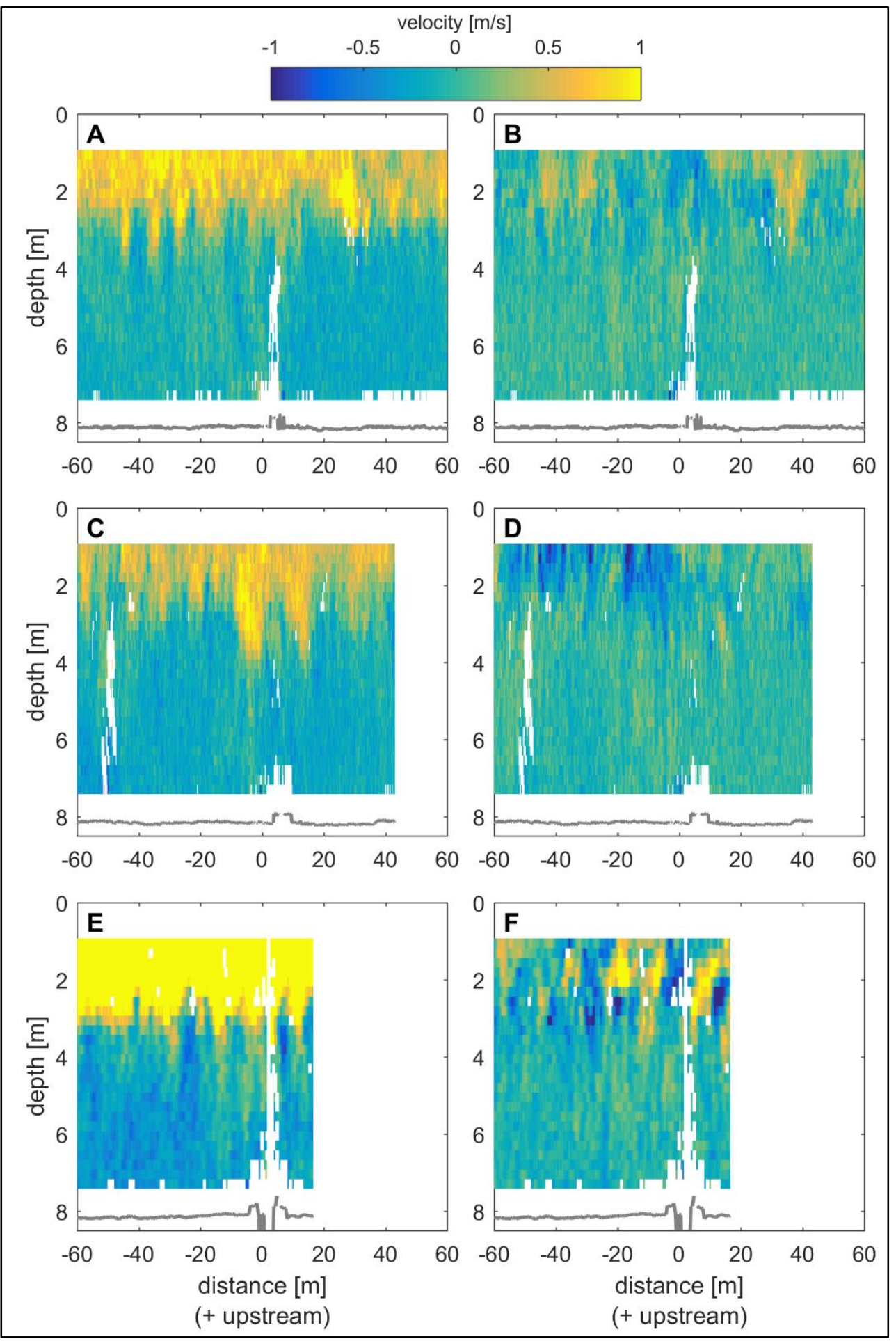


The depth-averaged currents over the upper $3 \mathrm{~m}$ of the water column provide a clearer perspective on the magnitude and frequency of the eddyinduced oscillations (Figure 5-5). There is a noticeable increase in the streamwise velocity as a function of tow speed. There is also considerable variability around the mean that increases with tow speed, but all flows for the higher two vessel speeds are directed upstream in the direction of tow travel. The cross-stream current shows similar variability in frequency but smaller overall amplitudes. Additionally, the cross-stream flows alternate between positive and negative values indicating a cycling of the current direction towards and away from the towboat. These patterns are indicative of eddy shedding behind the aft barge. Neither the streamwise nor cross-stream currents show any noticeable response to the jet.

Figure 5-5. (A) Streamwise and (B) cross-stream currents derived from averaging the ADCP profiles over the top $3 \mathrm{~m}$ of the water column. The zero crossing of the $x$-axis denotes when the ADCP passes over the manifold.

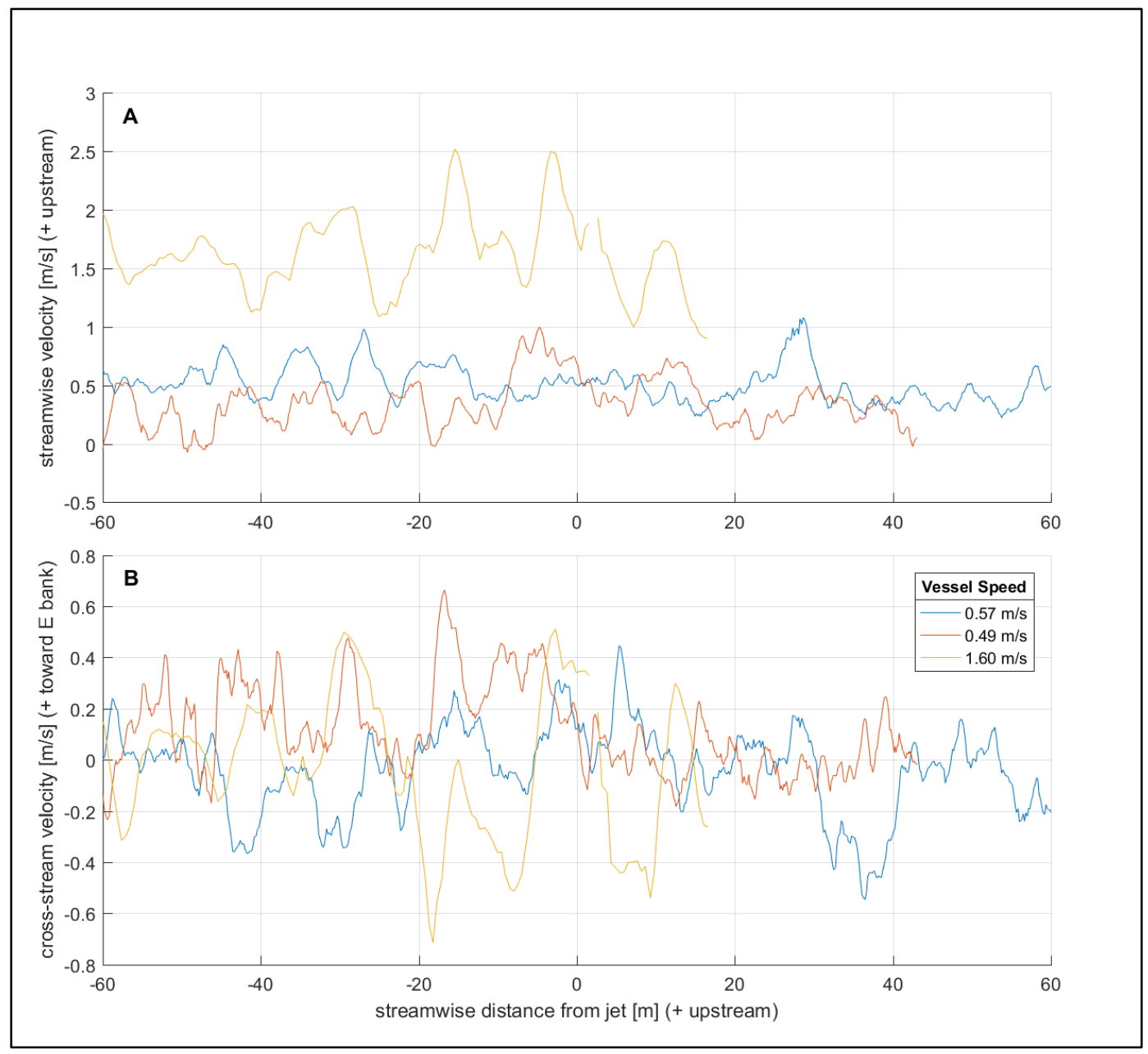




\subsection{ADV barge survey}

$\mathrm{ADV}$ results as the barge passes over the jet array are depicted in Figure 5-6 through Figure 5-8. The data are recorded as a time series, but integrating and vessel speed over time gives a spatial coordinate that represents the displacement of the ADV from a fixed reference point. This makes the results easier to interpret if the origin is placed at the point where the ADV is adjacent to the center of the manifold. Therefore, positive values denote distance from the jet center after the tow has passed over the jet manifold, and negative values denote the distance from the $\mathrm{ADV}$ to the jet center before the tow has passed over the manifold. Two ADVs were deployed in a vertical configuration with the upper ADV placed $1.0 \mathrm{~m}$ below the water surface and the lower ADV placed $2.0 \mathrm{~m}$ below the surface. The configuration is chosen to acquire current measurements at one-third and two-thirds the depth of the fully loaded barges.

\subsubsection{Exit velocity upper ADV}

The exit velocity for the slowest tow speed $(0.45 \mathrm{~m} / \mathrm{s})$ is depicted in Figure 5-6. Positive values denote flow away from the starboard side of the barge and represent conditions that would remove fish from the barge junction. The figure is divided into four panels, each representing the jet velocity for that particular trial. Trials with the same vessel speed and jet velocity are averaged to represent the variability associated with that particular set of conditions. The case with no jets (zero jet velocity) is also included as a baseline to quantify the flow variability due to the tow without jets. The figure indicates that only the 3.7 and $4.9 \mathrm{~m} / \mathrm{s}$ jet velocities produce a noticeable exit velocity that peaks after the tow has passed over the array. The maximum exit velocity occurs when the ADV has moved approximately $10 \mathrm{~m}$ beyond the center jet. As the tow continues to move away from the jet manifold, the velocity decreases, but the variability, as indicated by the width of the error bars, is larger compared to the exit velocity measured before the tow passes over the array. At the slowest tow speed, the jet manifold produces a noticeable exit velocity when the jet velocity exceeds $3.7 \mathrm{~m} / \mathrm{s}$. 
Figure 5-6. Exit velocity representing the flow perpendicular to the box-rake junction near the starboard side of the barge. Tow speed is $0.45 \mathrm{~m} / \mathrm{s}$. Positive values denote flow exiting the junction. The ADV is mounted on the vessel and is positioned $1 \mathrm{~m}$ below the water surface. The horizontal axis denotes the displacement of the ADV from the center of the jet manifold.

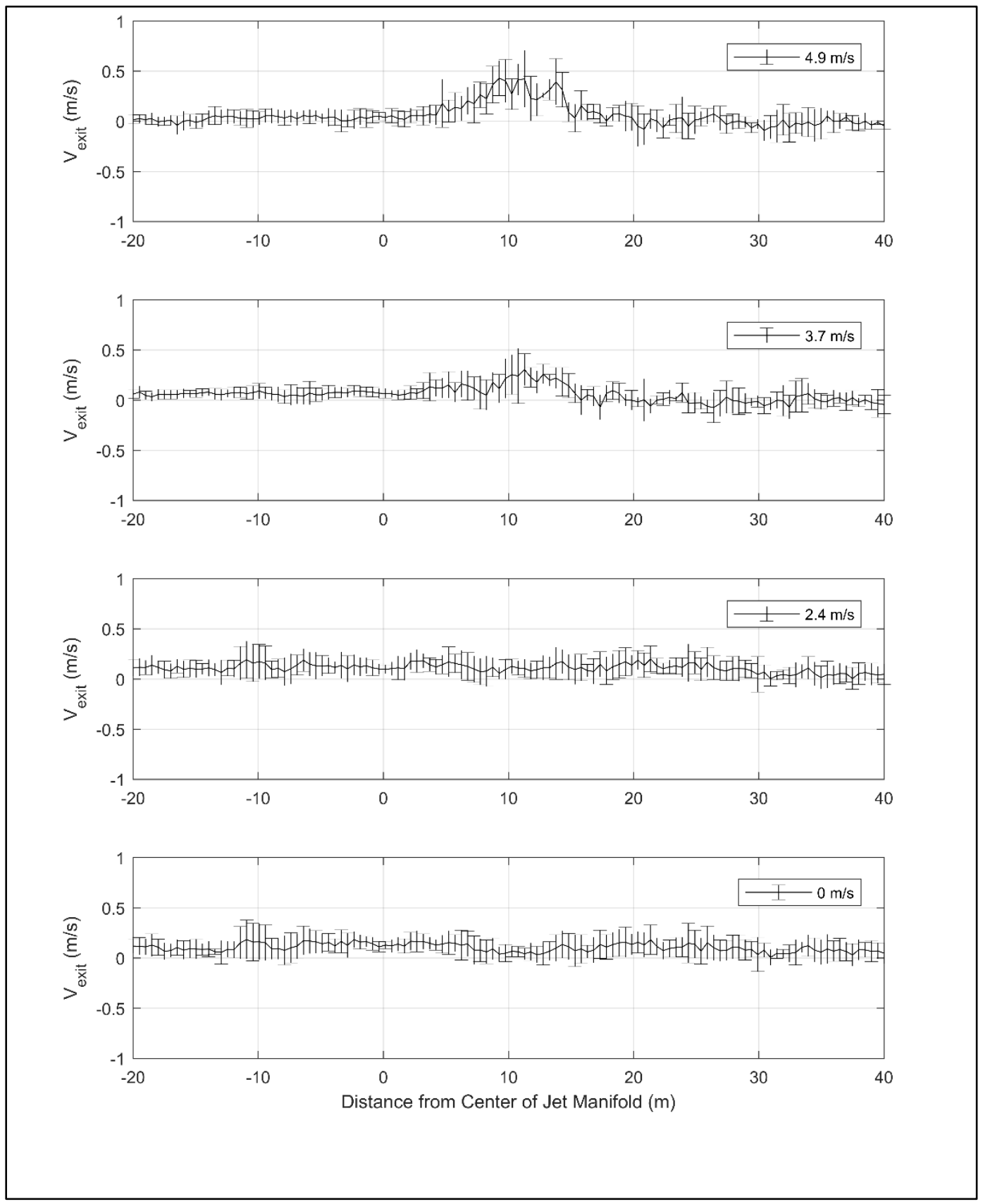

Figure 5-7 and Figure 5-8 depict the exit velocity for tow speeds of $1 \mathrm{~m} / \mathrm{s}$ and $2 \mathrm{~m} / \mathrm{s}$, respectively. For both vessel speeds, there does not appear to be a noticeable increase in the exit velocity after the tow passes over the jet manifold. The results do indicate an increase in flow variability, as measured by the length of the error bars after the tow has passed over the 
manifold. The larger error bars are likely due to increases in turbulent velocity fluctuations that are induced by the jets. For the two highest tow speeds, the jets tend to increase the turbulence but do not produce a significant exit velocity.

Figure 5-7. Exit velocity for the upper ADV with a tow speed of $1 \mathrm{~m} / \mathrm{s}$.

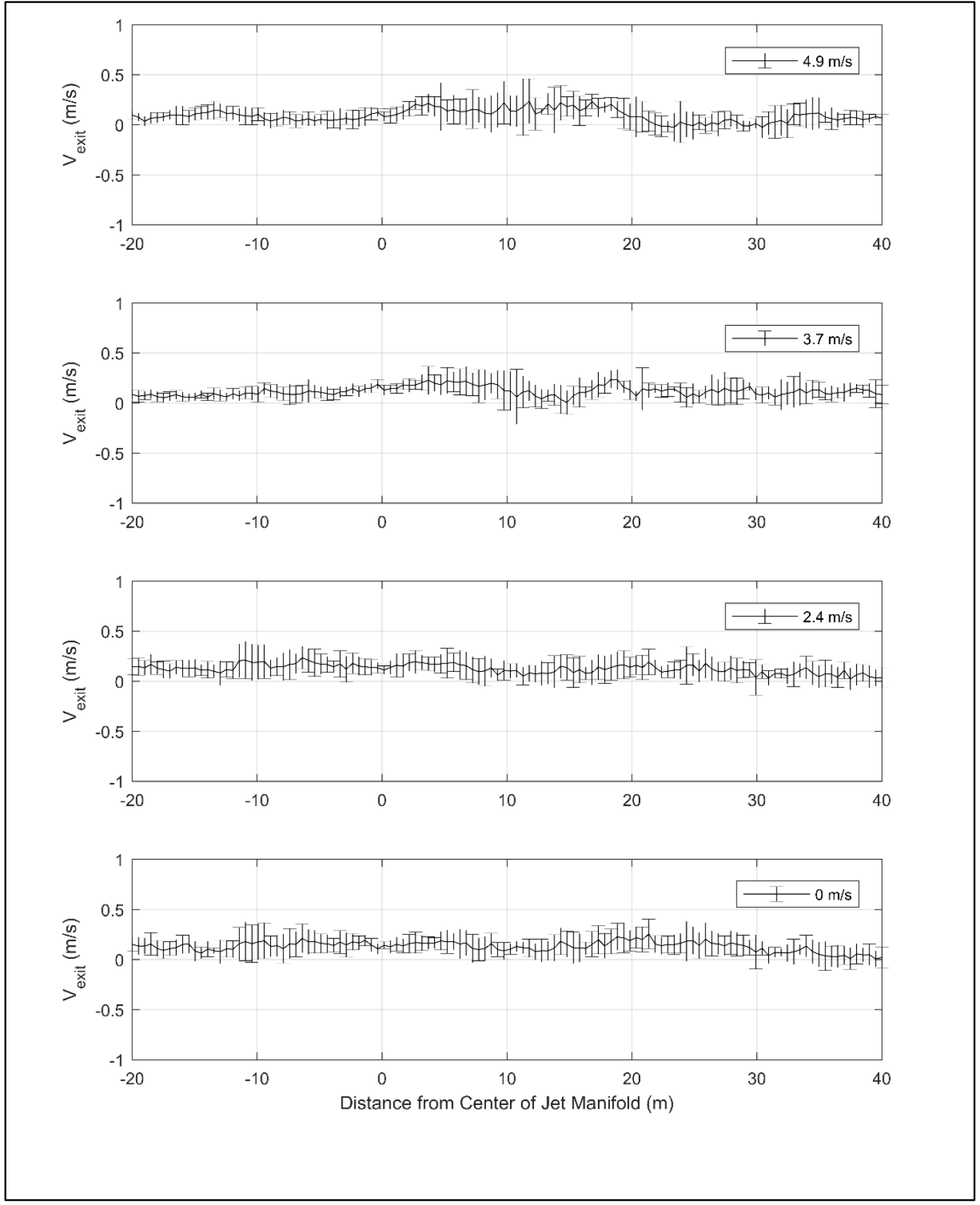


Figure 5-8. Exit velocity for the upper ADV with a tow speed of $2 \mathrm{~m} / \mathrm{s}$.

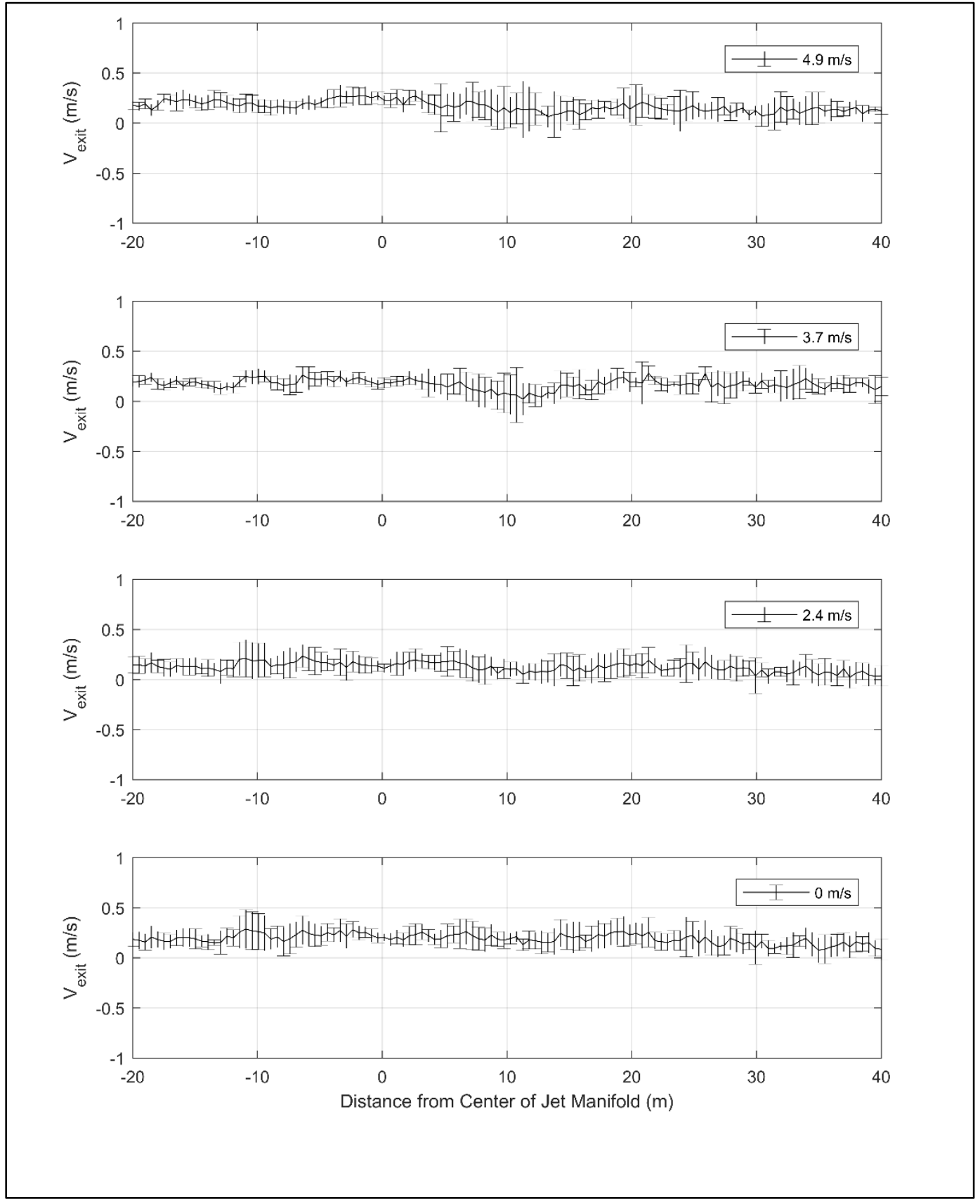

\subsubsection{Exit velocity lower ADV}

Figure 5-9 through Figure 5-11 depict the exit velocity measured from the lower ADV for each of the three tow speeds. The exit velocity for the slowest tow speed (Figure 5-9) does not show a clear increase in average velocity after the box-rake junction has passed over the jets. This is in contrast with the results from the upper ADV (Figure 5-6), which shows a clear increase in exit velocity for the two higher jet discharges after the tow 
has passed over the manifold. Likewise, there does not appear to be a noticeable increase in exit velocity for the two higher tow speeds (Figure 5-10, Figure 5-11) as measured by the lower ADV. This is similar to the results of the upper ADV, in which the higher tow speeds induce greater turbulence and reduce exposure time such that the flow induced by the jets is not as evident. Turbulence, as measured by the width of the error bars, does increase somewhat with jet velocity, but there is not a consistent trend between the magnitude of the velocity fluctuations and passage over the manifold.

Figure 5-9. Exit velocity measured from the lower ADV for a tow speed of $0.45 \mathrm{~m} / \mathrm{s}$.
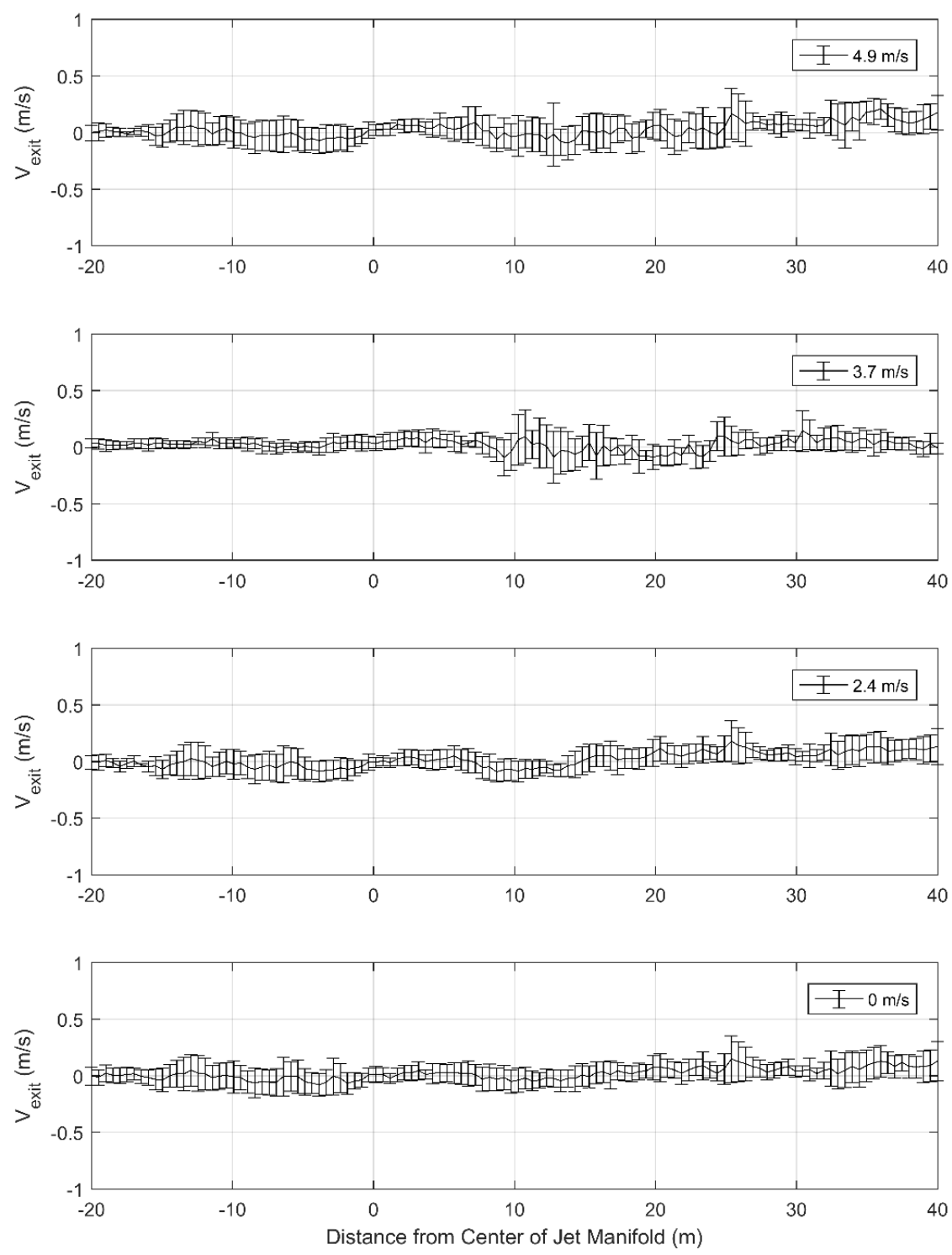
Figure 5-10. Exit velocity measured from the lower ADV for a tow speed of $1 \mathrm{~m} / \mathrm{s}$.
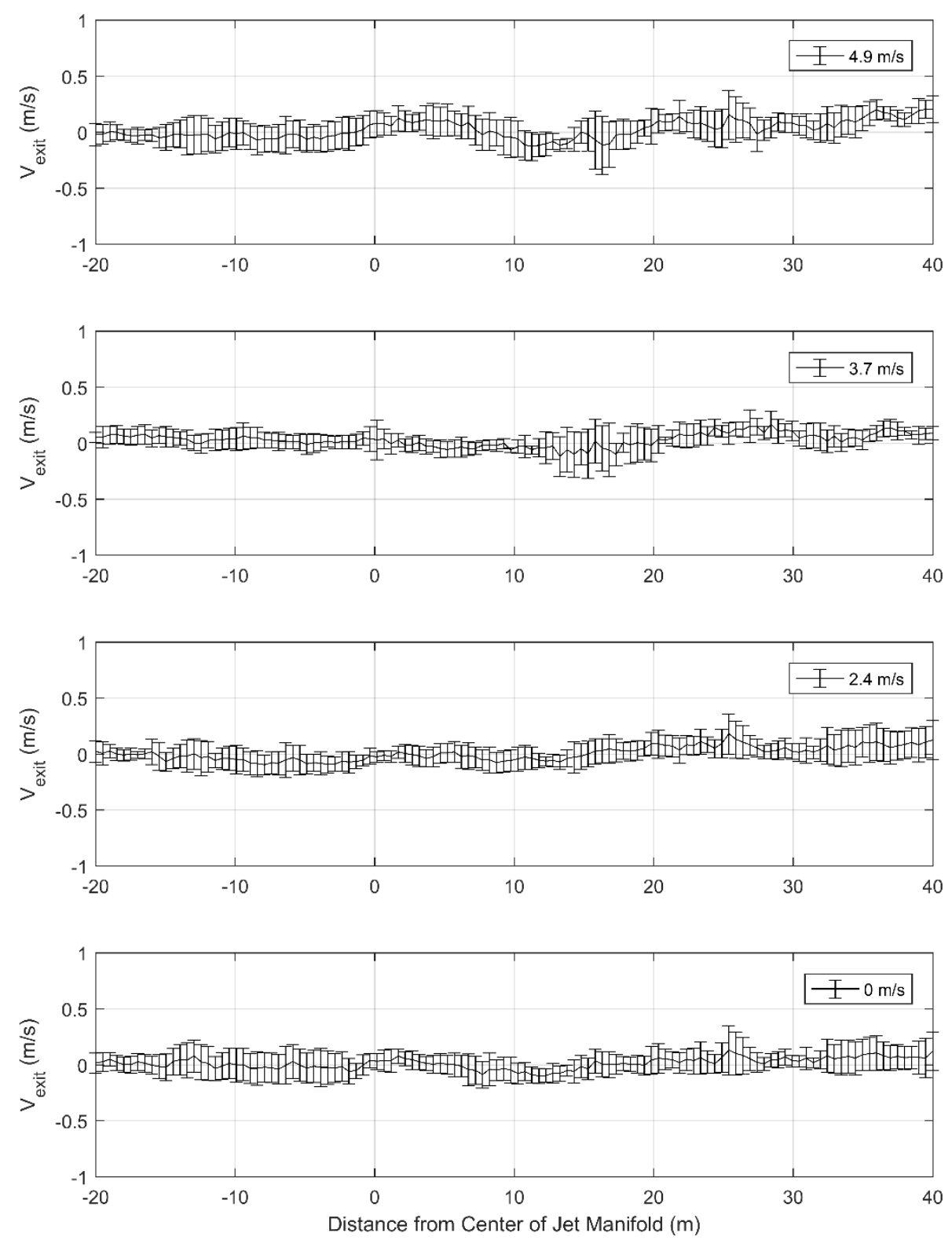
Figure 5-11. Exit velocity measured from the lower ADV for a tow speed of $2 \mathrm{~m} / \mathrm{s}$.
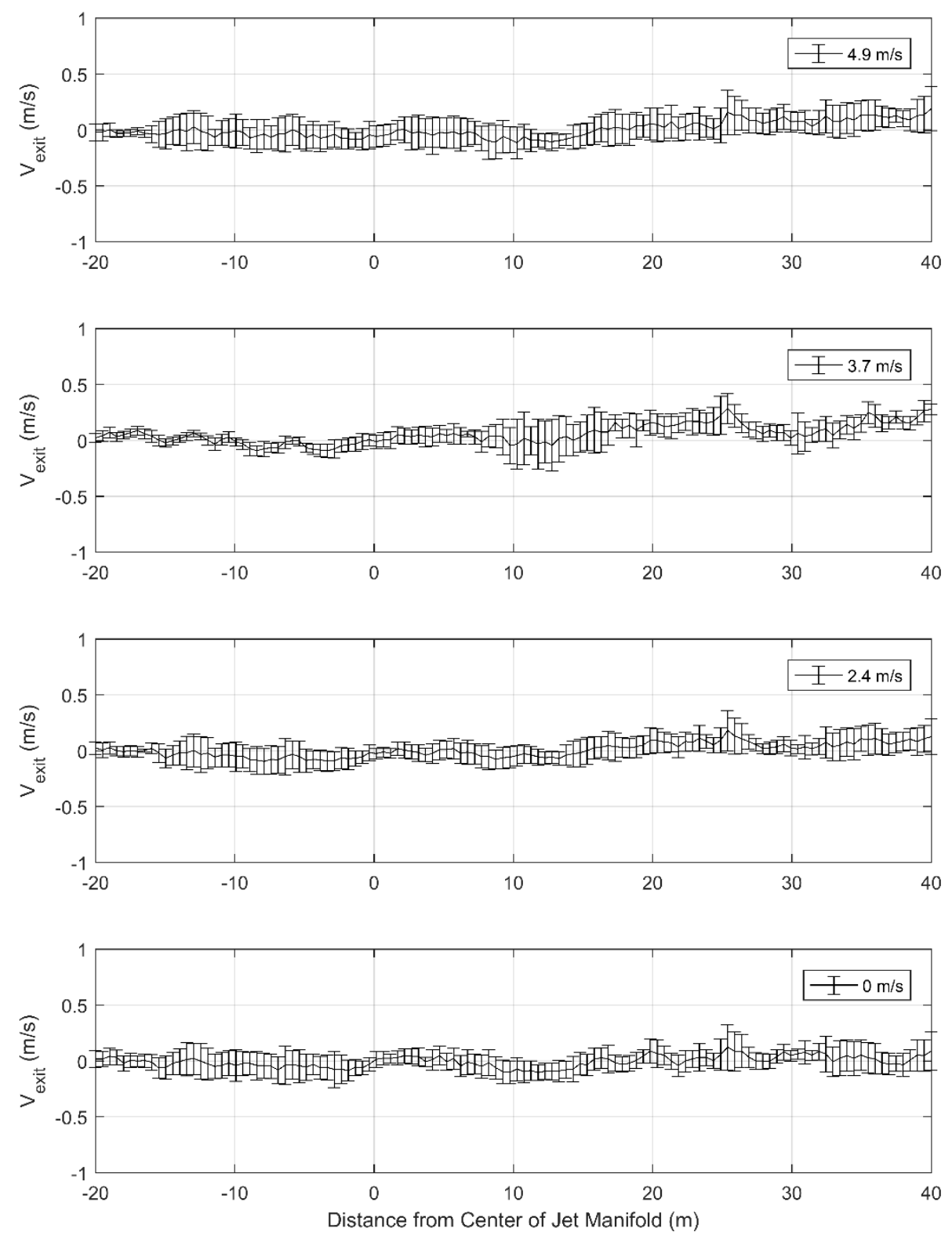

\subsubsection{Parcel displacement}

The exit velocity, flow perpendicular to the tow's direction measured within the rake to box junction, is a measure of the speed that a passive parcel could maintain during a tow passage over the jet manifold.

Integrating the measured exit velocity over time gives an estimate of parcel displacement. Establishing the timeframe in which the exit velocity acts on a parcel will constrain the total net distance a parcel is displaced. This can 
be used to compute net integrated displacement, which can be compared to the half width of the barge to identify the combination of vessel speeds and jet velocities required to remove immobilized fish from the box-rake junction. The ADV data indicate that the start time should be defined when the box-rake junction is directly over the center jet. From observations during the slowest tow speed, this is when the exit velocities start to become noticeable. In addition, the point where the rake junction is directly over the jets is easily identified using the GPS data. The end time is defined when the ADV has traveled $20 \mathrm{~m}$ away from the center jet. At this distance, the exit velocities become indistinguishable from the background velocities measured prior to the tow crossing over the jet manifold. These constraints limit the exposure time to when the jets produce velocities within the box-rake junction distinct from the flow induced by the moving tow.

The net parcel displacement as a function of jet velocity subdivided by vessel speed is depicted in Figure 5-12. With the exception of the highest tow speed, the average integrated distance does not exceed the half-width of the barge. Only the slowest tow speed coupled with the highest jet velocity has the capacity to consistently remove a parcel from the box-rake junction. The effect of increasing jet velocity on distance traveled is most pronounced at the lower two tow speeds primarily when the jet velocity exceeds $3 \mathrm{~m} / \mathrm{s}$ and the average integrated distance increases proportionately. For the highest tow speed, the average integrated distance is statistically independent of jet velocity. 
Figure 5-12. Net displacement due to the exit velocity as a function of the jet velocity. Legend denotes the three tow speeds in meters per second. The dashed line is the half-width of a single-wide standard barge. A parcel initially located at the center of the barge must travel $5.4 \mathrm{~m}$ before it is clear of the barge.

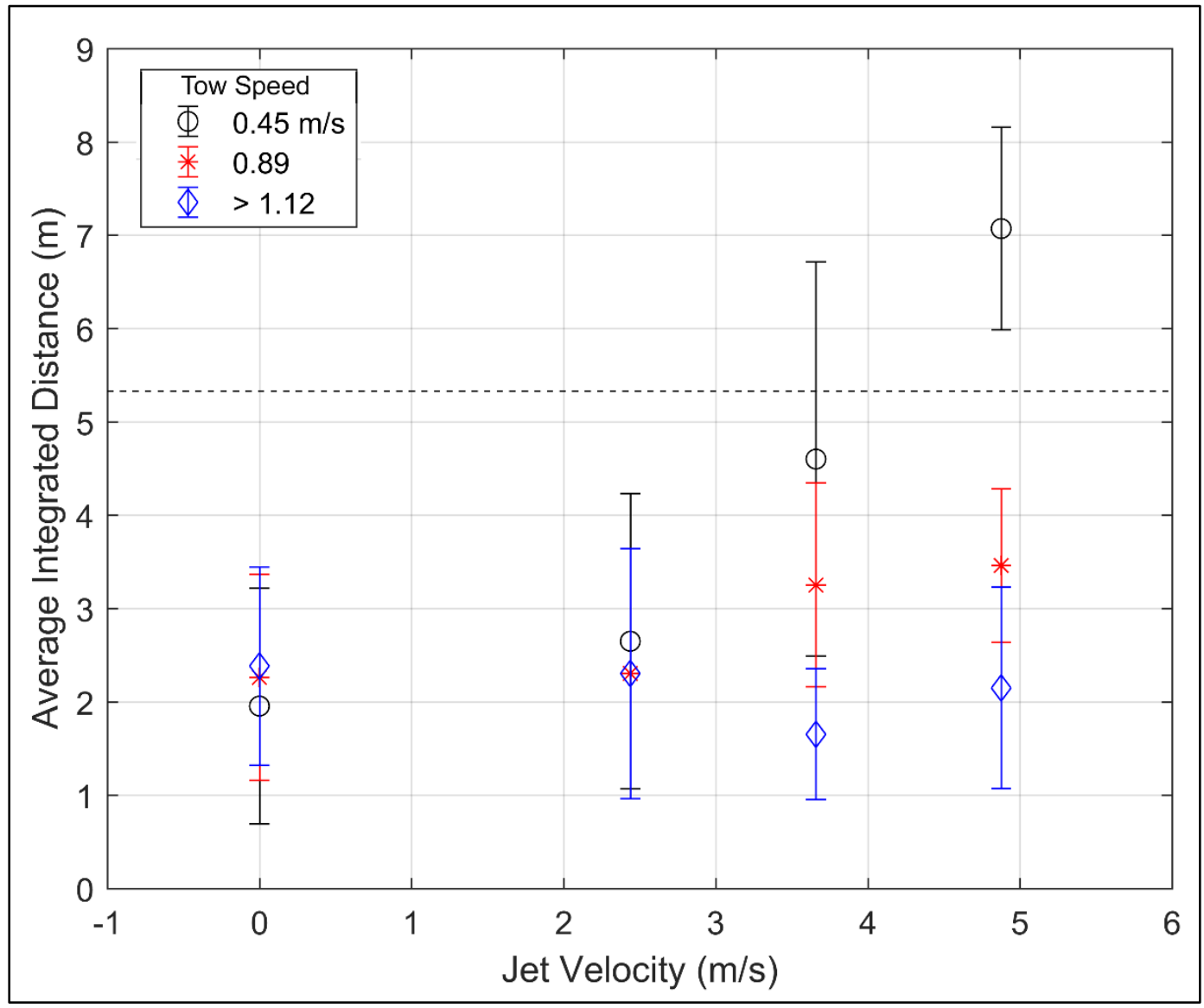

\subsubsection{Correlation with different metrics}

Vessel speed and jet velocity are the primary factors that control the magnitude of the velocities responsible for flushing, but there are several other variables and constraints that can influence the effectiveness of the jets at removing parcels. During the previous physical model tests, the sampling protocol was designed to optimize the flushing mechanism by ensuring that the center-line of the tow passed directly over the manifold. In addition, the tow pilot maintained an approach that was parallel to the long-axis of the canal and manifold. During the field study, the center-line of the tow was not aligned precisely over the manifold, and the tow sometimes approached at an acute angle. The vessel approach angle and lateral position when crossing the manifold are likely to be important in understanding the flushing dynamics. If the tow passes over the jet array at an angle, then the tow may produce a net cross flow within the box-rake 
junction independent of the jets. If the tow passes over the manifold with the center of the barge offset from the jet array, then the jets will be stronger on one side of the barge, also producing a bias flow within the box-rake junction. To investigate the potential effects of these other factors, a multi-linear regression analysis using variables that are suspected to have an influence over the flushing capacity of the jet system is presented to identify which combination of variables show the highest correlation. An important question is "How do different operational conditions influence the integrated average distance?" Variables that show a strong correlation with distance presumably have greater influence on the dynamical system and should be considered when formulating an operational manifold design.

The following variables are included in the regression analysis: (1) average exit velocity, (2) maximum exit velocity, (3) median exit velocity, (4) vessel speed, (5) jet velocity, (6) integrated average distance, (7) off center distance between the centerline of the barge and the jets, and (8) yaw the angular rate of turn of the tow as it passes over the jets. The correlation matrix including the trend line for the representative variables is depicted in Figure 5-13.

The first column of Figure 5-13 depicts the trend lines, correlation coefficient and $\mathrm{p}$-value for each of the variables plotted against integrated average distance. The first three variables (maximum/mean/median exit velocity) show a positive correlation indicating that the integrated distance increases with exit velocity. There is a negative correlation with vessel speed, indicating that the faster vessels trend with shorter integrated distance. The correlation with jet velocity and off-center distance is very weak; however, integrated distance would be expected to increase with jet velocity.

Given that the jet velocity distribution is clustered, the regression analysis is based on a narrow band of observations. A broader distribution of jet velocities would help with the interpretation of the regression analysis. Integrated distance is positively correlated with yaw, indicating that as the tow crosses the manifold while turning, a secondary cross-flow within the box-rake junction is established that augments the vertical jets to increase the magnitude of the exit velocity and thereby increase the integrated distance. 
Figure 5-13. Correlation matrix to determine relationships between variables that may influence flushing efficiency. Redline denotes the best fit based on linear regression analysis. Numeric values indicate $\mathrm{r}^{2}$ [p-value].

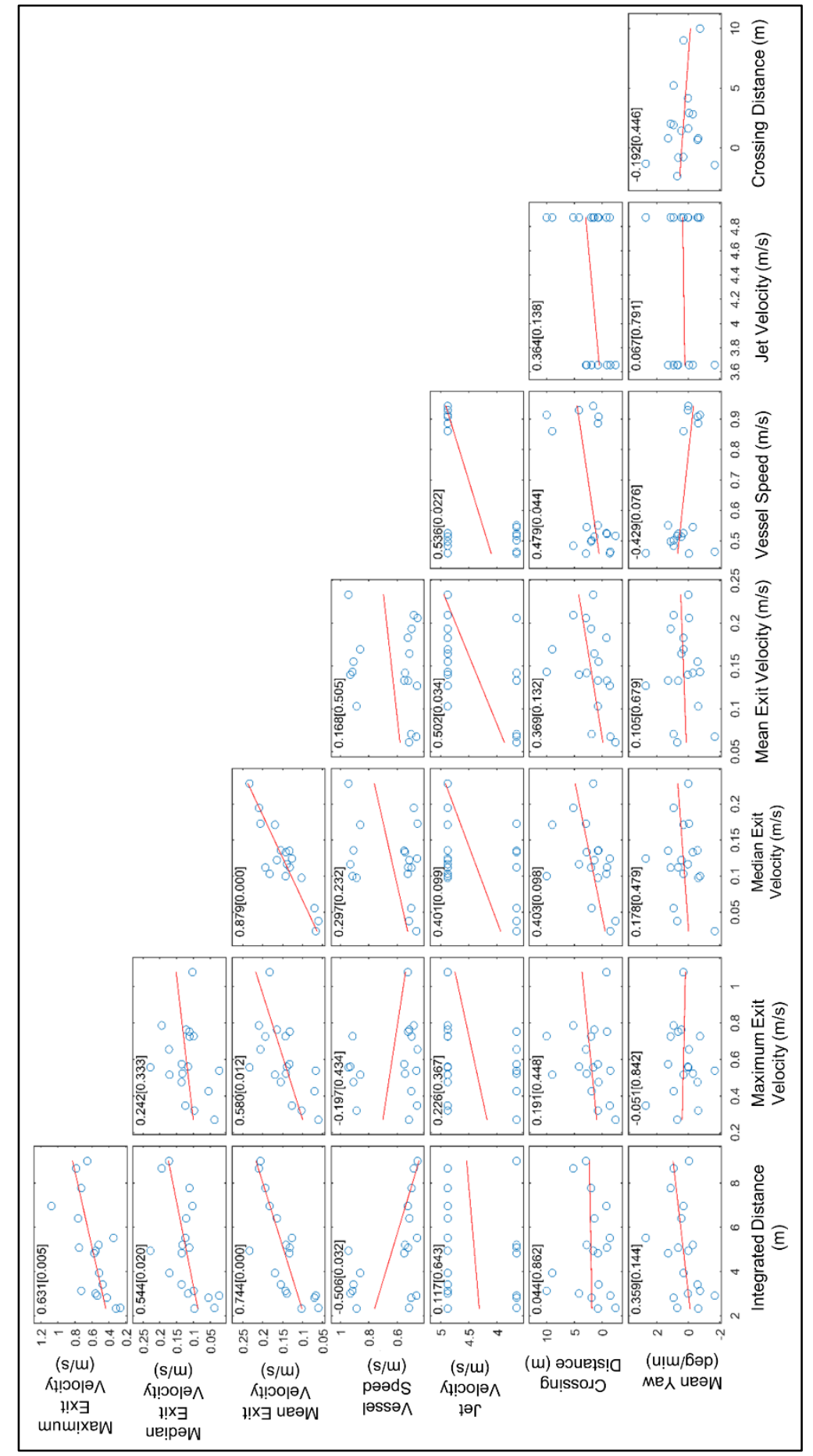




\subsection{Drifters}

Some of the orange drifter experiments were carried out concurrently with the ADV measurements, allowing an independent comparison between flushing effectiveness (drifters) and calculated displacement. The percentage of drifters flushed as the tow passes over the manifold can be used as a proxy to help gauge the jet's effectiveness at removing fish. The percentage of drifters that are flushed trends with the integrated distance (Figure 5-14). The higher the exit velocity the greater the net displacement and the largest number of tracers flushed. While the trends indicate an increase in flushing as vessel speed decreases, there is considerable scatter within individual trials. For example, the medium tow speed $(0.9 \mathrm{~m} / \mathrm{s})$ with the largest jet velocities did not flush the greatest number of drifters.

Figure 5-14. Integrated distance (displacement) and percentage of drifters flushed as a function of vessel speed. Legend denotes the two highest jet velocities. Dashed line is the half-width of a single-wide standard barge. The * denote percentage of drifters that were flushed, and open circles denote integrated distance.

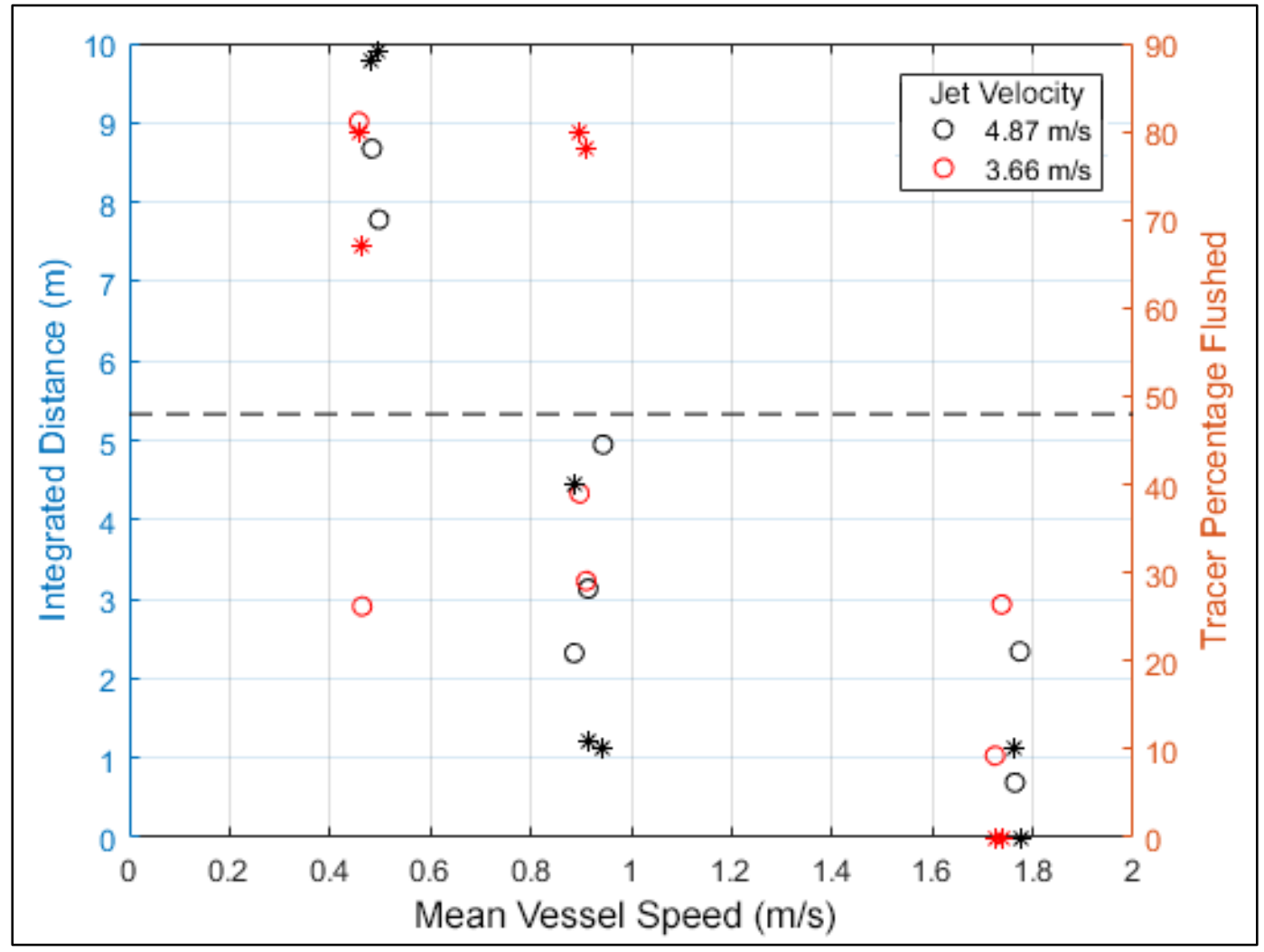




\section{Discussion}

\subsection{Navigation}

Navigation safety was the most important factor considered when planning and executing the field study. Based on the previous physical model results, it was determined that the range of jet velocities and the number of jets used in the field would not generate enough force to adversely affect vessel maneuverability. As a precaution, however, the first trial included the lowest jet velocity and higher tow speed so that the pilot would be in a better position to safely manage the effects of any lateral forces induced by the jets. The next two trials included increasing the jet velocities and varying tow speed. It turned out that the water jets were not strong enough to produce any noticeable force on the barges that would require the pilot to make sudden course corrections. During the 1.5-week testing period, the pilot completed 106 individual trials and did not report any significant issue in terms of the jet array interfering with navigability.

The field trials included a three-nozzle jet array whereas the physical model used a maximum of 18 jets. Eighteen nozzles increase the mass flux footprint so that the barges are subjected to a greater force distributed over a longer section of the flotilla. While the pilot could not test this case, based on his experience with three jets, he felt that a longer array would not present a navigation issue for commercial traffic in the CSSC. At this time no additional test with a longer jet array is planned. While a longer array would produce a greater force on the barges, commercial tows have a relatively high thrust capacity to ensure that the tow boat can maintain control of the barges. Given that the jet velocity is primarily vertical, the net lateral force is much weaker than the vertical velocities impinging the bottom of the barges. For fully loaded barges like those tested in the study, this is less of an issue because of the increased inertia. For empty or partially loaded barges the effects could be more evident, but in these cases the box-rake junction contains a much smaller volume of fluid due to the shallower draft, and the fish entrainment capacity is likely to be proportionally reduced. Future investigations should consider these factors, but based on the laboratory and field tests, including pilot input, a submerged water jet flushing system that does not interfere with navigation but is effective at removing fish seems feasible. 
The test plan called for an approach in which the long-axis of the tow is parallel to the long-axis of the manifold. In this way, the jets are parallel to the long-axis of the barges, which is the configuration used in the physical model experiments. Passage angle over the jets showed variability between trials. Part of the tendency to approach at a small angle may have been due to the downstream tow position at the beginning of each run. The requirement was for the tow to start a run far enough downstream of the manifold to ensure that it would obtain cruising speed before the first barge reached the manifold. Due to the greater mass, the tow had to start each trial with the $2 \times 3$ barge configuration farther downstream of the manifold than the $1 \times 3$ configuration. This distance was not measured for each trial, but judging from the position of the tow boat when the pilot started to move forward, the pilot was making slight course corrections to align the tow to pass over the manifold up until the leading barge reached the manifold. This sometimes caused the tow to pass over the manifold at a slight angle. If the tow had started farther downstream of the manifold, then it may have been easier to align the center of the tow directly over the manifold without producing any yaw. Note, however, that commercial tows deviate from a straight course that runs parallel to the canal walls and routinely make small course corrections that induce some yaw. For future evaluation of an operational system or continued testing of another jet array, the vessel track, including start and end points, should be determined during the planning phase.

\subsection{Hydrodynamics}

\subsubsection{ADCP}

The ADCP surveys of the canal and jet velocities indicated that the jets could affect the near-surface flow in a region that was approximately $10 \mathrm{~m}$ or less from the manifold. For distances greater than $10 \mathrm{~m}$, the results did not show any current patterns that would indicate variations beyond the ambient flow in the canal. For the two lower jet velocities, the approach vector for the MV Garcia showed strong deviations in the vicinity of the manifold indicative of the jet producing strong lateral flows at the surface. This caused the ADCP, which was mounted on the starboard side near the aft of the vessel, to fail to capture the jet velocities as the vessel was pushed laterally away from the manifold. For the highest jet velocity, the MV Garcia did pass directly over the manifold and captured an increased jet-induced flow. Jets may affect the 
maneuverability of smaller vessels, but the lateral extent of their influence is confined to about $10 \mathrm{~m}$ from the manifold.

Another concern is the placement of the jet manifold with respect to the location of the existing electric dispersal barriers. If the manifold is positioned too close to the barriers, then the issuing jets could force water upstream into the electric field, which is undesirable for a fish deterrent system. The vertical profiles indicated that the jets were incapable of producing flow reversals (flow directed upstream) at a distance of approximately $10 \mathrm{~m}$ upstream of the manifold. The ADCP measured the full water column to ensure that the flow at any depth did not produce negative currents. For the conditions tested, the results give an indication of how close the manifold could be positioned to the dispersal barriers without producing upstream flows that could penetrate the electric field. Note that under lower discharge conditions, the ambient current in the canal could be reduced to a point where the jets did produce a net upstream flow. This information should be considered in designing a larger scale operational system.

The ADCP survey that focused on the region adjacent to the starboard side of the towboat indicated a flow pattern that varied with depth. Above the draft of the barge, eddies appeared to be shed from the trailing edge of the barge as the flow expanded to fill the space between the barge and towboat. The ADCP was mounted in a region where the streamwise flow followed the tow (upstream) and increased with tow speed. The fact that the flow followed the tow indicated that fish caught in this region could be carried across the electric barrier. The ambient flow did not seem to respond to the jets, indicating that any jet deterrent system would need to be augmented if clearing fish in this region is of concern. Only one case for each of the tow speeds was investigated, and the tow was aligned to pass over the jets along the centerline, not offset to produce the strongest possible jet below the ADCP. As such, shifting the path of the tow so that the jets impinged directly on the area between the aft barge and starboard side of the towboat would disrupt the eddy field and possibly generate currents that could dislodge trapped fish. However, the jet would be less effective at clearing fish trapped in the box-rake junction, where the jet array should focus on the centerline of the barge.

Previous laboratory studies (Bryant et al. 2018) used an alternating jet array, in which the first jet was directed upstream and each subsequent jet 
was rotated in an alternating pattern to direct flow obliquely to the boxrake junction (Figure 6-1). By widening the angle, the maximum jet velocity rotates from a streamwise direction to a cross-stream direction. This provides a sweeping action that first forces fish away from the centerline of the tow and then rotates to direct the maximum flow towards the side of the barge. Such a system would deliver the required flow to remove fish from the box-rake junction and provide a strong lateral flow that could overcome the alternating cross-stream flow and force fish away from the towboat.

Figure 6-1. Manifold configuration for successful jet tests in the laboratory. The barge approaches from the top of the photograph. The nozzle angle increases in an alternating pattern along the manifold axis, thereby directing the flow farther from the centerline of the barge as it passes over the array.

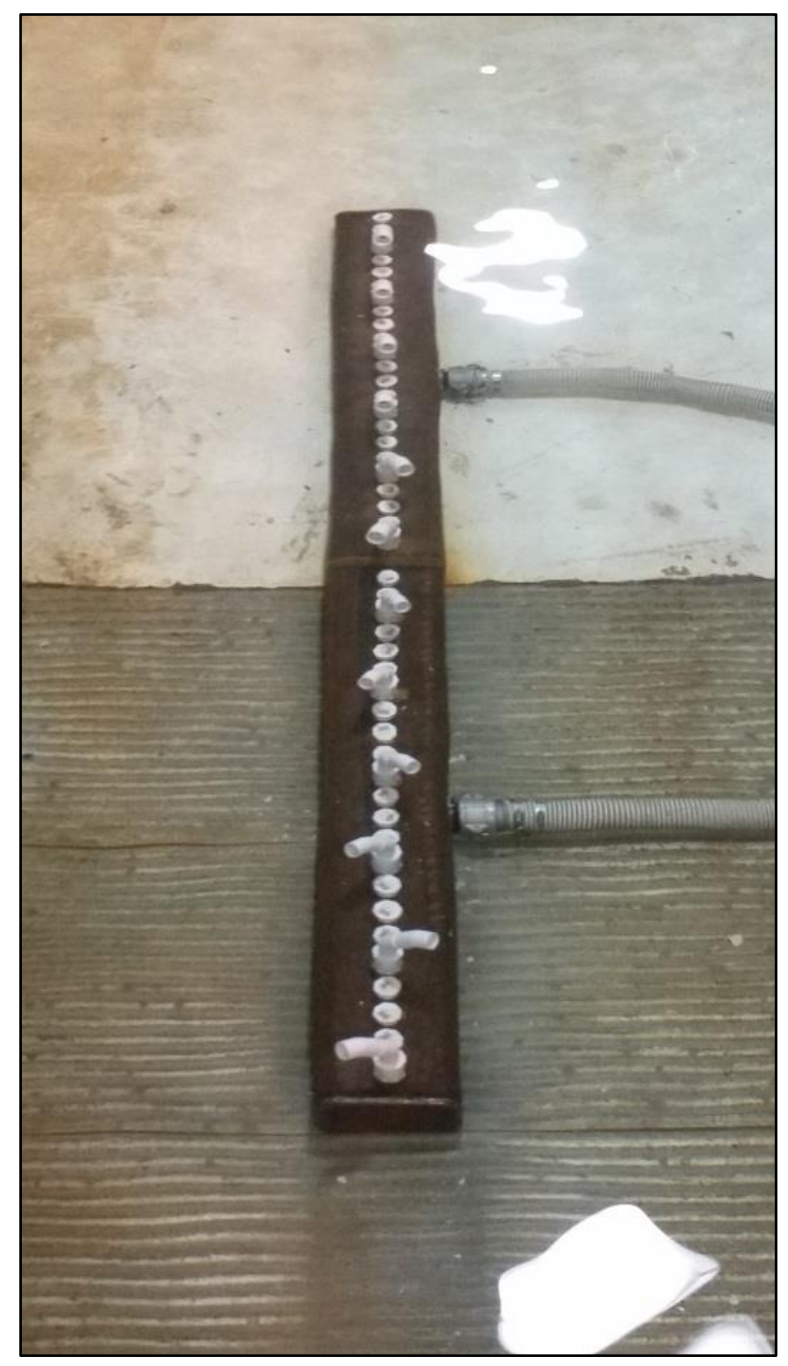




\subsubsection{ADV}

A pair of vertically mounted ADVs were deployed in the box-rake junction near the starboard edge of the barge to measure the jet-induced velocities. The ADVs were positioned at one-third and two-thirds the depth of the fully loaded barges to examine flow variability in the area influenced by the tow. Several trends were noted in the results: (1) exit velocity increased as jet velocity increased, (2) turbulence, as measured by the magnitude of velocity fluctuations, increased during jet passage, and (3) the magnitude of the exit velocity and turbulence due to the jets become less evident as tow speed increases.

The flow characteristics can be explained if the box-rake junction is viewed as a control volume in which flow entering one area is countered by flow exiting another area. For the cases studied here, the control volume consists of the recess space produced by a leading box barge connected to a trailing rake barge, with both barges at full draft $(2.8 \mathrm{~m})$. As the tow passes over the manifold, the issuing jets force water upward and impinge on the control volume from directly below the junction. As the jets reach the water surface, they are deflected laterally. Due to turbulent mixing, the flow is distributed horizontally and vertically so the jet becomes more diffuse. This results in a net outward flow on either side of the barge, as seen with the increase in exit velocity with increasing jet flow. Higher velocity jets produce stronger flows and greater fluctuations in the velocity components. This increases not only the average exit velocity, but the fluctuations around the mean due to turbulence generation.

The tendency for the jet-induced flow to become less distinctive as vessel speed increases is an indication of the increase in turbulence around the box-rake junction as the barges increase speed. In a frame of reference moving with the tow, the leading box barge configuration produces a sharp flow transition as fluid moves along the side and bottom of the barge to encounter the box-rake junction. The flow becomes detached and forms eddies and turbulence as it enters the box-rake junction. As tow speed increases, so does the energy in the detached flow, leading to stronger turbulence and more vigorous mixing. At the two higher vessel speeds, the magnitude of the tow-generated turbulence is on the order of the jetinduced turbulence, so it is not possible to distinguish the source of the turbulence in a velocity time series. The exit velocity is likewise overshadowed by the background velocity fluctuations produced by the faster moving vessel. For higher vessel speeds, the jets need to be stronger 
and/or longer to produce exit velocities sufficient to overcome the vesselgenerated turbulence and remove fish from the box-rake junction.

\subsection{Flushing effectiveness}

The flushing effectiveness was investigated using several techniques including tracers, integrated velocity exiting the box-rake junction, and visual observations of fish behavior and flow patterns. The tracer studies identified the combination of jet velocities and tow speeds that caused the greatest number of drifters to be ejected from the box-rake junction at the time of jet passage. The results indicated that the slower tow speeds and higher jet velocities were the most effective at removing tracers. At the slowest tow speed $(0.4 \mathrm{~m} / \mathrm{s})$, between $60 \%$ and $90 \%$ of all tracers were flushed from the junction with jet velocities of 3.7 and $4.9 \mathrm{~m} / \mathrm{s}$, respectively. At most, $28 \%$ were flushed at the same jet velocities but at a higher tow speed of $1.8 \mathrm{~m} / \mathrm{s}$. These findings are in agreement with previous laboratory work (Bryant et al. 2018). The laboratory study demonstrated model fish (passive tracers) were completely flushed under slower tow speeds $(1 \mathrm{~m} / \mathrm{s})$ and higher jet velocities with a 12-18 jet array. Although the absolute magnitudes of tracer removal were different for the much shorter, three-jet array applied in the field study, the general trends related to jet velocity and vessel speed are similar to the laboratory study. The higher jet velocities and the longer exposure time (slower vessel) produced the best flushing results for the conditions investigated in the field and the laboratory.

\subsubsection{Integrated distance}

Flushing effectiveness was also investigated by estimating the distance a passive parcel could be displaced from the box-rake junction as the tow passed over the jets. ADV exit velocities were measured and timeintegrated to produce a net lateral distance, which was compared to the width of the barge. Any integrated distance that was greater than half of the barge width was classified as a successful flushing combination of tow speed and jet velocity. The results indicated that the only cases that produced an average distance greater than the barge width was with a tow speed of $0.45 \mathrm{~m} / \mathrm{s}$ and jet velocity of $4.9 \mathrm{~m} / \mathrm{s}$. This combination represents the slowest tow speed and highest jet velocity, which is also in agreement with the laboratory results. 


\subsubsection{Air bubbles}

In addition to the water jets, air bubbles were intentionally introduced into the jet stream as a means to invoke behavioral changes that would keep fish from remaining in the box-rake junction. Air bubble curtains have been investigated as a supplementary means to keep fish from entering regions deemed hazardous, such as pump intakes, or from infiltrating new habitats as invasive species (Dawson et al. 2006). During some of the field trials, it was observed that the water jets did cause the fish (golden shiners) placed within the box-rake junction to leave, but after the vessel had passed over the jets, the fish returned. The behavioral pattern showed the fish exiting the box-rake junction during the jet passage but staying near the side of the barge and swimming into the boundary layer present along the hull. The fish would then swim along the side of the barge in the boundary layer and were observed to re-enter the box-rake junction. An illustration of this process is depicted in Figure 6-2.

Figure 6-2. Photograph depicting a fish swimming in the barge boundary layer near the box-rake junction. The dashed line denotes the general path the fish follow. They are initially forced out of the recess and then approach the side of the barge away from the junction. Then, they swim along the side of the barge in the boundary layer to return to the junction.

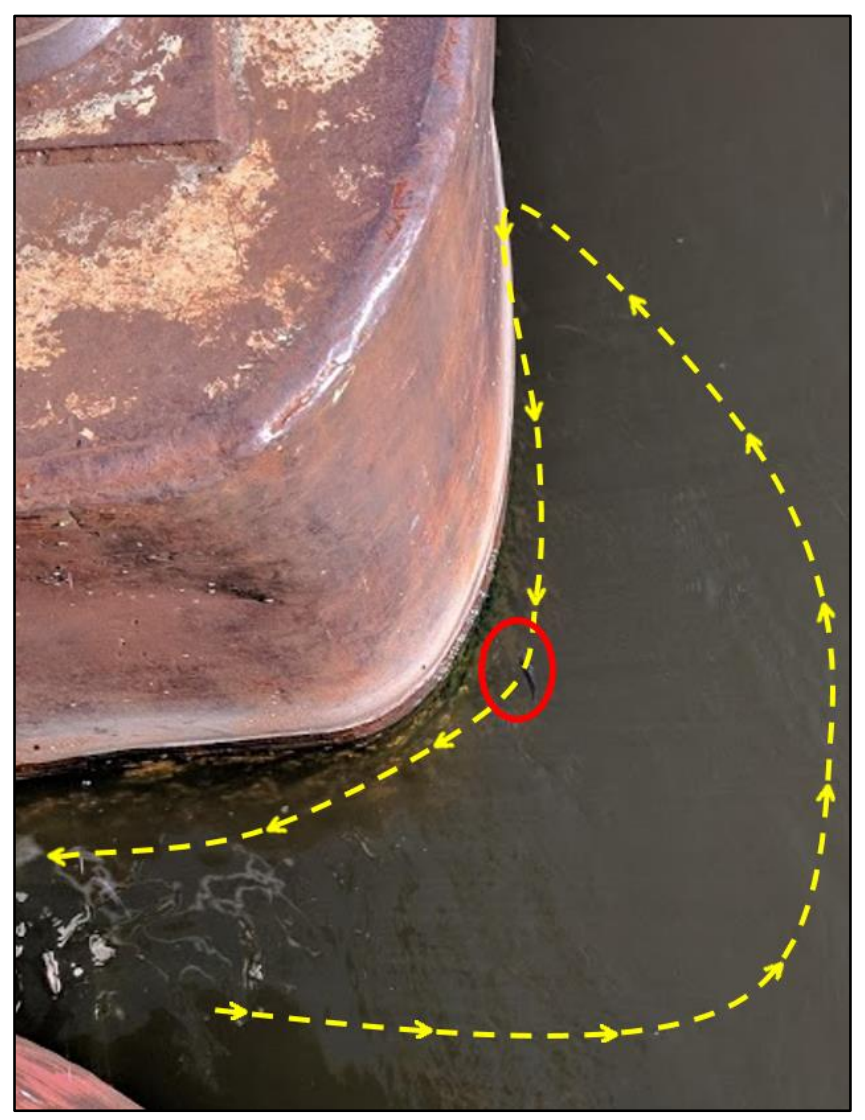


The fish behaved differently when the air bubbles were introduced. The fish were still ejected as the vessel passed over the jets, but fewer reentered the junction after the barge had progressed beyond the jets. The observational evidence suggested that the bubbles disrupted the swimming behavior of the fish, discouraging them from swimming alongside the barge and returning to the box-rate junction. After the bubbles exited the jet, their buoyancy forced them upward to impinge on the flat bottom of the barge. The buoyant force and movement of the vessel caused the bubbles to slide along the underside of the barge and then rise to the surface once they had cleared the edge (Figure 6-3). Buoyancy and boundary layer effects forced the bubbles to remain near the barge as they rose to the surface. This was a relatively slow process, so the bubbles continued to stream into the junction and the boundary layer alongside the barge well after the tow had passed over the manifold.

Figure 6-3. Photograph depicting air bubbles issuing from beneath the barge. Bubbles were seen rising to the surface along the hull for several minutes after the tow had cleared the manifold.

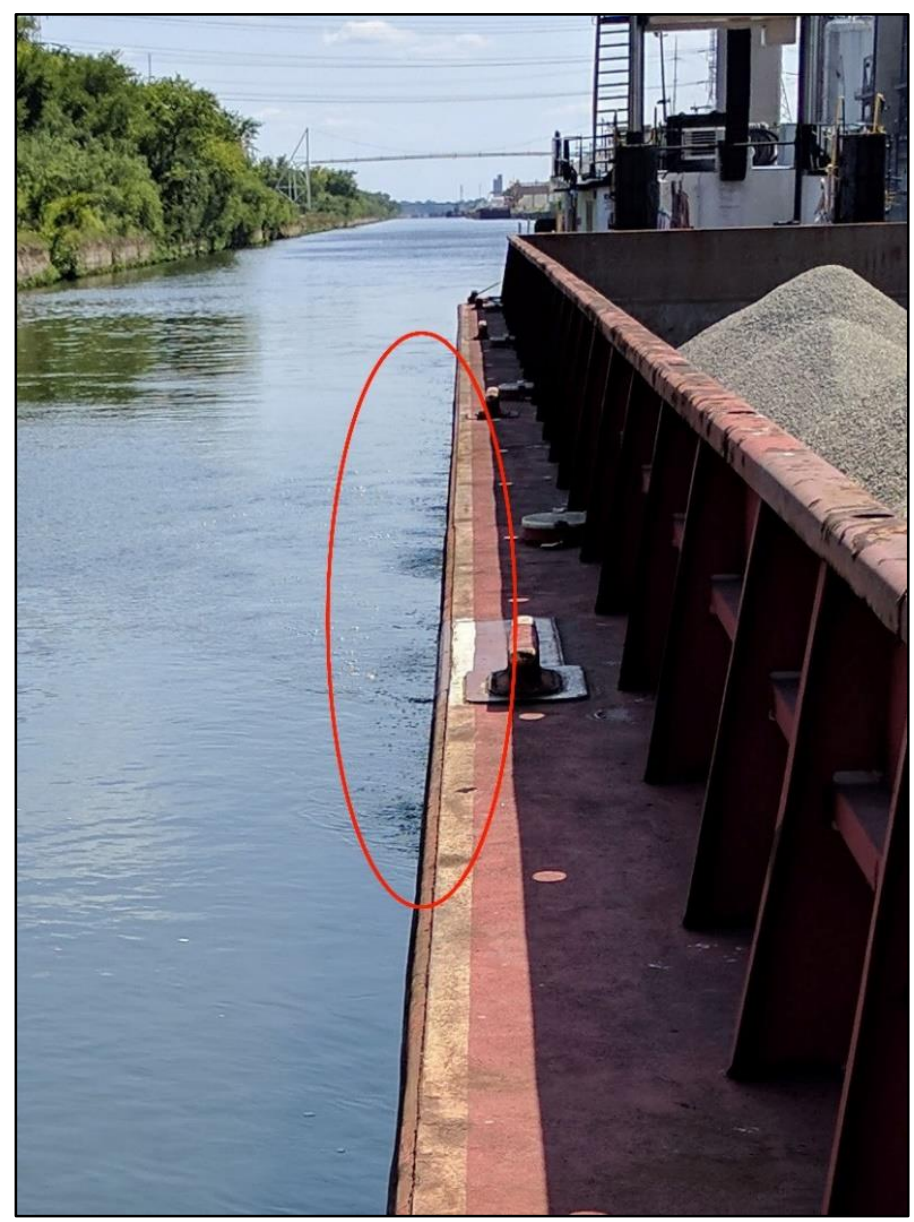


Based on anecdotal visual observations, the trials with air injection had fewer fish return to the boundary layer than trials with water jets alone. Thus, without air entrainment, ejected fish returned to the barge boundary layer and swam along the hull until they reached the box-rake junction and re-entered the void space. With air entrainment, ejected fish began to return to the barge boundary layer but were deterred from swimming alongside the hull due to the presence of the bubbles. These fish did not return to the box-rake junction and were presumed to remain away from the barge. Thus, the preferred habitat for recently ejected fish - the barge boundary layer - was not as attractive in the presence of air bubbles.

Fewer fish returning to the boundary layer meant fewer fish re-entering the box-rake junction. These results were mostly anecdotal and reflected visual observations of only fish that were visible from above the water surface. The total number of fish exhibiting this behavior was not quantified, only that some fish showed a response to the presence of the air bubbles that was not seen when the air bubbles were not present. Further quantitative studies of the behavioral response of juvenile carp or surrogates to bubbles is warranted to determine the effectiveness of air in reducing fish from returning to the box-rake junction.

\subsection{Recommendation for further study}

Jet array length - One of the tasks in a previous physical model study conducted at ERDC was to determine the number of jets needed to flush fish from the box-rake junction (Bryant et al. 2018). Three manifolds consisting of 12 nozzles each were constructed, and different combinations of jets were investigated until an optimal configuration was found that could flush all fish. It was determined that a jet manifold consisting of 18 nozzles with an individual spacing of $3 \mathrm{~m}$ was able to flush all fish for tow speeds $<1.1 \mathrm{~m} / \mathrm{s}$ and minimum discharge of $12.2 \mathrm{~m} 3 / \mathrm{s}$. Constructing an 18-nozzle manifold was impractical for the field test, so a smaller manifold consisting of 3 nozzles with a $3 \mathrm{~m}$ spacing was used to keep costs within project constraints. The smaller array was considered adequate for an initial field test, as the main focus was to demonstrate proof-of-concept for a future operational system.

Increasing the number of jets increases the exposure time, allowing the jet flow to impinge on the box-rake junction for a longer period, thereby increasing the flushing capacity. Future recommendations include constructing and deploying a jet manifold with a greater number of nozzle 
connections. Preliminary planning indicates a next phase in designing an operational system should include 9 to 12 jets as a minimum. Determining the logistical and resourcing requirements to construct a larger array is predicated on lessons already learned from this study, but the cost increase to go from 3 to 9 or 12 jets can be significant. The success of the initial field trial of a jet array provides valuable information on the resources required to build a larger system. The main additional costs would be for construction of the manifold, pump installation, additional plumbing, and deployment and recovery. However, expanding the number of jets is a primary requirement to further develop this technology.

Increase jet velocity - The maximum jet velocity obtained in the field $(4.8 \mathrm{~m} / \mathrm{s})$ was lower than the maximum velocity tested in the physical model study $(9 \mathrm{~m} / \mathrm{s})$. Due to mechanical issues, it was not possible to get higher discharge capacity from the pump array in the field, even though the initial plan was to produce maximum jet velocities that were closer to what was obtainable in the laboratory tests. Being able to control the magnitude of the jet velocities and to produce flows that are strong enough to remove fish is paramount to ensuring flushing system effectiveness, and any future study should set a goal to match the velocity tested in the physical model study.

Air entrainment - During the field study, the team added air to the jet flow to determine if the air release could be an effective measure to deter fish from remaining in the box-rake junction. Air was introduced into the system by slightly opening bleeder values on the discharge lines. The air concentration was not measured directly, so air entrainment levels were determined by noting the increase in bubbles at the surface. Anecdotal evidence during the experiment indicated that bubbles discourage fish from remaining near the barge where they can re-enter the box-rake junction. Using a controlled air delivery system and careful monitoring of fish behavior using a technology such as acoustic telemetry to see the degree to which the addition of air bubbles helps remove or deter fish would help to quantify the efficacy of air injection. Given that air can be easily incorporated into a water jet delivery system with minimal additional resource requirements, an air delivery system should be considered in future tests.

Tow conditions - The field tests were completed using six US standardsized barges and a $750 \mathrm{~kW}$ towboat designed for inland waterway 
operations. However, the field team witnessed a number of larger towboats operating in the canal. These larger vessels occupy a greater fraction of the canal width and possess greater thrust capacity. As such, the towboat used in the study does not represent the full contingent of commercial traffic operating in the CSSC. Furthermore, the purpose of this test was to evaluate jet performance under controlled conditions. This was motivated by the need to determine jet effectiveness while ensuring safe operations. The pilot was aware of the location of the jet manifold and was instructed to maintain specific speeds and approach vectors that aligned the center of the barge over the jet array. Commercial shipping practice in the CSSC does not adhere to the same maneuvering and speeds that were required to test the jet flushing system, so an operational system must be developed with these concerns in mind. Additional trials should also consider larger vessels with more thrust capacity, as these types of vessels traverse the CSSC routinely.

Reproduce more natural conditions for fish - The fish sampling methodology involved releasing live juvenile golden shiners into the boxrake junction just prior to the tow passing over the manifold. Once the tow passed over the jets, the engines were throttled down and the tow came to rest a few hundred meters beyond the manifold. Fish were then recovered from the recess to gauge the effectiveness of the jets by determining the difference between the number of fish released versus the number recaptured. Because the timing of jet passage is shortly after release, it is possible that the fish did not have enough time to acclimate. Their behavior as the tow passed over the jet array may not be representative of freely swimming fish that inhabit the CSSC.

Vary discharge conditions - For the majority of the trials, the canal discharge ranged between 40 and $51 \mathrm{~m} 3 / \mathrm{s}$. On the morning of 25 August, the discharge was increased to $139 \mathrm{~m} 3 / \mathrm{s}$ to accommodate testing under high discharge conditions. Discharge variability in the canal includes negative flows (flows towards Lake Michigan) to high discharge of $390 \mathrm{~m} 3 / \mathrm{s}$. Note that $95 \%$ of the time the discharge is less than $200 \mathrm{~m} 3 / \mathrm{s}$, with a mean of $45 \mathrm{~m} 3 / \mathrm{s}$ so that the testing conditions were representative of average conditions for the CSSC. However, increased discharge permits commercial traffic to have a slower speed over ground but still maintain vessel maneuverability. Thus, higher canal discharge would permit the tow to pass over the array at a slower speed without sacrificing maneuverability but increasing the exposure time and the potential to 
clear more fish. Additional testing would help determine if higher discharge conditions are more effective at removing fish from the box-rake junction. This should also include an analysis of discharge operational control measures to see how much flexibility the operators have in varying the discharge to assist in reducing fish entrainment. 


\section{Summary and Conclusions}

A previous physical model study (Bryant et al. 2016) demonstrated that commercial tows operating in confined channels produced secondary currents and forces that entrain and transport immobile fish. Based on these findings, a second laboratory study was carried out to investigate methodologies to remove entrained fish from the junction between adjacent barges (Bryant et al. 2018). This second study showed that an array of submerged water jets was effective at removing passive fish from the junction. At the request of the LRC, the ERDC was tasked to develop a prototype scale jet manifold and deploy it in the CSSC to conduct a field trial of the jet flushing system. The field test conditions were based on the laboratory results and included operating a $2 \times 3$ and $1 \times 3$ tow with live fish for different vessel speeds and jet velocities.

The major findings of the study are summarized as follows:

- Jets are most effective at slow tow speeds and high jet velocities - The flushing effectiveness was investigated using several techniques including tracers and integrated velocity exiting the box-rake junction. At the slowest tow speed $(0.4 \mathrm{~m} / \mathrm{s})$, between $60 \%$ and $90 \%$ of all tracers were flushed from the junction with jet velocities of 3.7 and $4.9 \mathrm{~m} / \mathrm{s}$, respectively. At most, $28 \%$ were flushed at the same jet velocities but at a higher tow speed of $1.8 \mathrm{~m} / \mathrm{s}$. Flushing effectiveness was also investigated by estimating the distance a passive parcel could be displaced from the box-rake junction as the tow passed over the jets. The results indicated that the only cases that produced an average distance greater than the barge width were with a tow speed of $0.45 \mathrm{~m} / \mathrm{s}$ and a jet velocity of $4.9 \mathrm{~m} / \mathrm{s}$. The results with both tracers and integrated distance indicated that the slower tow speeds and higher jet velocities were the most effective at removing tracers.

- Air entrainment may enhance jet effectiveness by inducing behavioral changes in the fish - Air bubbles were introduced into the jet stream as a means to invoke behavioral changes that would keep fish from remaining in the box-rake junction. Anecdotal observations suggest that the bubbles discouraged fish flushed from the barge junction from entering the barge boundary layer and returning to the box-rake junction. It is possible that an air injection system may discourage fish from remaining near the barge, making it less likely for them to become entrained in the box-rake junction. 
There are also several recommendations for further study based on lessons learned during the field trial and the resource constraints imposed by scaling up the physical model to prototype conditions. Recommendations that will likely improve the jet performance include a longer jet array and higher maximum jet velocities. The previous laboratory study used a maximum of 18 jets whereas the field study used three. Maximum jet velocity in the laboratory was $9 \mathrm{~m} / \mathrm{s}$, and in the field it was $4.8 \mathrm{~m} / \mathrm{s}$. Increasing both the jet velocity and the number of jets would likely be more effective at removing fish by increasing the maximum ejection force and the exposure time. The velocity data indicate that flushing is strongest near the water surface and much weaker near the bottom of the barge junction. Future studies should consider how the vertical distribution of velocity may affect fish retention and removal from the junction. Other recommendations based on the field trial include (1) a wider range of tows, to better represent the variability in commercial traffic, (2) a better representation of the natural conditions for the fish, which would allow them to acclimate to the box-rake junction before passing over the jet array, (3) varying the discharge in the canal, which may affect the jets overall effectiveness and alter the tow's speed over ground, thereby modulating the exposure time, and (4) exploring fish removal from the wake zone between the aft barge and the towboat. 


\section{References}

Bryant, Duncan, B., Stephen T. Maynord, Howard E. Park, Lauren Coe, Jarrell Smith, and Richard Styles. 2016. Navigation Effects on Asian Carp Movement Past Electric

Barrier, Chicago Sanitary and Ship Canal. ERDC/CHL TR-16-2. Vicksburg, MS: US Army Engineer Research and Development Center.

Bryant, D., C. Callegan, L. Coe, J. Smith, R. Styles, and C. Moore. 2018 Laboratory Study to Reduce the Transport of Asian Carp by Barges. ERDC/CHL TR-18-14. Vicksburg, MS: US Army Engineer Research and Development Center.

Chick, J. H., and M. A. Pegg. 2001. "Invasive Carp in the Mississippi River Basin,” Science 292: 2250-2251.

Davis, J. J., P. R. Jackson, F. L. Engel, J. Z. LeRoy, R. N. Neeley, S. T. Finney, and E. A. Murphy. 2016. "Entrainment, Retention, and Transport of Freely Swimming Fish in the Junction between Commercial Barges Operating on the Illinois Waterways." Journal of Great Lakes Research 42: 837-848.

Dawson, H. A., U. G. Reinhardt, and J. F. Savino. 2006. "Use of Electric or Bubble Barrier to Limit the Movement of Eurasian Ruffe (Gymnocephalus cernuus).” Journal of Great Lakes Research 32:40-49.

Goring, D. G., and V. I. Nikora. 2002. "Despiking Acoustic Doppler Velocimeter Data." Journal of Hydraulic Engineering 128(1): 117-126.

Wahl, T. L. 2003. Discussion of "Despiking Acoustic Doppler Velocimeter Data" by Derek G. Goring and Vladimir I. Nikora. Journal of Hydraulic Engineering 129(6): 484-487. 


\section{Appendix A: Test Matrix}

\begin{tabular}{|c|c|c|c|c|c|c|c|c|c|c|c|c|c|c|c|c|c|c|}
\hline $\begin{array}{l}\text { CHL Run } \\
\text { ID }\end{array}$ & Date/Time & $\begin{array}{c}\text { Run } \\
\text { Number }\end{array}$ & $\begin{array}{l}\text { Jet Exit } \\
\text { Velocity }\end{array}$ & Tow Speed & Tow & Tow Direction & Test & USFWS & Fin Clip & START & STOCK & $\begin{array}{l}\text { JET } \\
\text { PASS } \\
\end{array}$ & Test & Orange & Canal Discharge & Wind & $\begin{array}{l}\text { ADV } \\
\text { Data } \\
\end{array}$ & Jet Passage \\
\hline & & & $\mathrm{M} / \mathrm{S}$ & Target/Actual (M/S) & Configuration & US/DS & w/ Fish & Stock \# & & & & & w/ Oranges & Flushing & CMS & Speed/Direction & Yes/No & Location \\
\hline & $\begin{array}{l}8 / 21 / 1710: 00 \\
\text { AM }\end{array}$ & 1 & 2.44 & 0.45 & Light Boat & US & No & & & & & & No & $\begin{array}{l}\mathrm{RIP}=\text { remain in } \\
\text { pocket }\end{array}$ & 39.64352 & $n / a$ & No & $0 \%=$ Port \\
\hline & $8 / 21 / 17$ 10:30 & 2 & 3.66 & 0.45 & Light Boat & US & No & & & & & & No & $\begin{array}{c}\mathrm{UA}= \\
\text { unaccounted }\end{array}$ & 39.64352 & $n / a$ & No & $\begin{array}{c}100 \%= \\
\text { Starboard }\end{array}$ \\
\hline & $\begin{array}{c}8 / 21 / 17 \\
\text { AM }\end{array}$ & 3 & 4.88 & 0.45 & Light Boat & US & No & & & & & & No & $P=$ port & 39.64352 & $n / a$ & No & \\
\hline & $\begin{array}{l}8 / 21 / 17 \\
12: 00 P M\end{array}$ & 4 & 2.44 & $0.45 / 0.51$ & $2 \times 3$ & US & No & & & & & & No & $\mathrm{S}=$ starboard & 39.64352 & $n / a$ & No & \\
\hline & $\begin{array}{l}\text { 8/21/17 } \\
\text { 14:00PM }\end{array}$ & 5 & 3.66 & $0.45 / 0.51$ & $2 \times 3$ & US & No & & & & & & No & $J=$ iet & 39.64352 & $n / a$ & No & \\
\hline & $\begin{array}{l}8 / 21 / 17 \\
14: 30 P M\end{array}$ & 6 & 4.88 & $0.45 / 0.51$ & $2 \times 3$ & US & No & & & & & & No & $B=$ before jet & 39.64352 & $n / a$ & No & \\
\hline & $\begin{array}{l}1.50 / 17 \\
15: 00 P M\end{array}$ & 7 & 4.88 & $1.34 / 1.44$ & $2 \times 3$ & US & No & & & & & & No & $M=a f t e r$ jet & 39.64352 & $n / a$ & No & \\
\hline & $\begin{array}{l}8 / 21 / 17 \\
15: 30 \mathrm{PM}\end{array}$ & 8 & 4.88 & $0.45 / 0.51$ & $2 \times 3$ & DS & No & & & & & & No & & 39.64352 & $n / a$ & No & \\
\hline & $\begin{array}{l}8 / 21 / 17 \\
16: 00 P M\end{array}$ & 9 & 4.88 & $n / a$ & $2 \times 3$ & US & No & & & & & & No & & J0.0TOUL & $n / a$ & No & \\
\hline & $\begin{array}{c}\text { 8/22/2017 } \\
\text { 08:52AM }\end{array}$ & 1 & 2.44 & $0.45 / 0.51$ & $2 \times 3$ & us & No & & & & & & Yes & & 39.64352 & $n / a$ & No & \\
\hline & $\begin{array}{c}8 / 22 / 2017 \\
09: 15 A M\end{array}$ & 2 & 3.66 & $0.45 / 0.51$ & $2 \times 3$ & US & No & & & & & & Yes & & 39.64352 & $n / a$ & No & \\
\hline & $\begin{array}{c}\text { 8/22/2017 } \\
\text { 09:41AM }\end{array}$ & 3 & 4.88 & $0.45 / 0.51$ & $2 \times 3$ & US & No & & & & & & Yes & & 39.64352 & $n / a$ & No & \\
\hline 1 & $\begin{array}{c}8 / 22 / 2017 \\
14: 20 \mathrm{PM} \\
\end{array}$ & 4 & 4.88 & $0.45 / 0.51$ & $2 \times 3$ & US & Yes & 500 & Dorsal & 14:14:44 & $14: 16: 27$ & $14: 20: 30$ & No & & 39.64352 & $\begin{array}{c}4.47-6.71 \mathrm{~m} / \mathrm{s} \text {, } \\
\mathrm{W}\end{array}$ & No & $25 \%$ \\
\hline 2 & $\begin{array}{c}8 / 22 / 2017 \\
14: 42 \mathrm{PM} \\
\end{array}$ & 5 & 4.88 & $0.45 / 0.51$ & $2 \times 3$ & US & Yes & 300 & Top caudal & $14: 42: 56$ & $14: 43: 17$ & $14: 50: 02$ & No & & 39.64352 & $\begin{array}{c}4.47-6.71 \mathrm{~m} / \mathrm{s}, \\
\mathrm{W} \\
\end{array}$ & No & $35 \%$ \\
\hline 3 & $\begin{array}{c}/ 22 / 2017 \\
15: 10 \mathrm{PM}\end{array}$ & 6 & 4.88 & $0.45 / 0.51$ & $2 \times 3$ & US & Yes & 277 & $\begin{array}{l}\text { Bottom } \\
\text { caudal }\end{array}$ & $15: 08: 28$ & $15: 10: 26$ & $15: 15: 29$ & No & & 39.64352 & $\begin{array}{c}4.47-6.71 \mathrm{~m} / \mathrm{s} \\
\mathrm{W}\end{array}$ & No & $50 \%$ \\
\hline 4 & $\begin{array}{c}8 / 22 / 2017 \\
15: 40 P M \\
\end{array}$ & 7 & 4.88 & $0.89 / 0.89$ & $2 \times 3$ & US & Yes & 295 & Both caudal & & $15: 43: 00$ & $15: 45: 39$ & No & & 39.64352 & $\begin{array}{c}4.47-6.71 \mathrm{~m} / \mathrm{s}, \\
\mathrm{W} \\
\end{array}$ & No & $40 \%$ \\
\hline 5 & $\begin{array}{c}8 / 22 / 2017 \\
16: 15 \mathrm{PM}\end{array}$ & 8 & 4.88 & $0.89 / 0.93$ & $2 \times 3$ & US & Yes & 275 & Anal & $16: 17: 01$ & $16: 18: 20$ & $16: 21: 33$ & No & & 39.64352 & $\begin{array}{c}4.47-6.71 \mathrm{~m} / \mathrm{s}, \\
\mathrm{W}\end{array}$ & No & $40 \%$ \\
\hline 6 & $\begin{array}{c}\text { 8/22/2017 } \\
16: 45 \mathrm{PM}\end{array}$ & 9 & 4.88 & $0.89 / 0.93$ & $2 \times 3$ & US & Yes & 294 & Left pectoral & 16:46:33 & $16: 48: 19$ & $16: 50: 37$ & No & & 39.64352 & $\begin{array}{c}4.47-6.71 \mathrm{~m} / \mathrm{s}, \\
\mathrm{W}\end{array}$ & No & $35 \%$ \\
\hline 7 & $\begin{array}{c}8 / 22 / 2017 \\
17: 13 \mathrm{PM} \\
\end{array}$ & 10 & 4.88 & $1.79 / 1.54$ & $2 \times 3$ & US & Yes & 293 & $\begin{array}{c}\text { right } \\
\text { pectoral }\end{array}$ & $17: 18: 10$ & $17: 20: 45$ & $17: 21: 56$ & No & & 39.64352 & $\begin{array}{c}4.47-6.71 \mathrm{~m} / \mathrm{s}, \\
\mathrm{W}\end{array}$ & No & $75 \%$ \\
\hline 8 & $\begin{array}{c}8 / 23 / 2017 \\
09: 15 \mathrm{AM} \\
\end{array}$ & 1 & 4.88 & $0.45 / 0.46$ & $2 \times 3$ & US & Yes & 300 & $\begin{array}{c}\text { Bottom } \\
\text { caudal }+ \\
\text { Dorsal } \\
\end{array}$ & 9:12:42 & 9:16:45 & 9:21:22 & No & & 39.64352 & $<2.24 \mathrm{~m} / \mathrm{s}, \mathrm{N}$ & No & $25 \%$ \\
\hline 9 & $\begin{array}{c}\text { 8/23/2017 } \\
\text { 09:42AM }\end{array}$ & 2 & 4.88 & $0.45 / 0.51$ & $2 \times 3$ & US & Yes & 299 & $\begin{array}{l}\text { Both caudal } \\
\text { + dorsal }\end{array}$ & $9: 45: 25$ & 9:44:31 & $9: 48: 50$ & No & & 39.64352 & $<2.24 \mathrm{~m} / \mathrm{s}, \mathrm{N}$ & No & $50 \%$ \\
\hline 10 & $\begin{array}{c}\text { 8/23/2017 } \\
\text { 10:09AM }\end{array}$ & 3 & 4.88 & $0.45 / 0.54$ & $2 \times 3$ & US & Yes & 297 & $\begin{array}{l}\text { Anal + } \\
\text { Dorsal }\end{array}$ & $10: 16: 30$ & $10: 19: 02$ & $10: 23: 44$ & No & & 39.64352 & $<2.24 \mathrm{~m} / \mathrm{s}, \mathrm{N}$ & No & $50 \%$ \\
\hline 11 & $\begin{array}{c}8 / 23 / 2017 \\
10: 49 A M \\
\end{array}$ & 4 & 4.88 & $0.45 / 0.51$ & $2 \times 3$ & US & No & & & 10:50:00 & $10: 51: 27$ & 10:55:35 & Yes & 7PJ 2 UA 9 & 39.64352 & $<2.24 \mathrm{~m} / \mathrm{s}, \mathrm{NW}$ & No & $60 \%$ \\
\hline 12 & $\begin{array}{c}\text { 8/23/2017 } \\
11: 25 \mathrm{AM}\end{array}$ & 5 & 4.88 & $1.79 / 1.70$ & $2 \times 3$ & US & Yes & 297 & Dorsal & $11: 24: 21$ & 11:30:34 & 11:31:57 & Yes & 9J $1 \mathrm{RIP} 10$ & 39.64352 & $<2.24 \mathrm{~m} / \mathrm{s}, \mathrm{NW}$ & No & $50 \%$ \\
\hline 13 & $\begin{array}{c}8 / 23 / 2017 \\
14: 51 \mathrm{PM} \\
\end{array}$ & 6 & 4.88 & $0.45 / 0.46$ & $2 \times 3$ & US & Yes & 300 & $\begin{array}{l}\text { Upper } \\
\text { caudal }\end{array}$ & $14: 30: 21$ & $14: 43: 41$ & $14: 49: 24$ & No & & 39.64352 & $<2.24 \mathrm{~m} / \mathrm{s}, \mathrm{NW}$ & Yes & nd \\
\hline 14 & $\begin{array}{c}\text { 8/23/2017 } \\
\text { 15:10PM }\end{array}$ & 7 & 4.88 & $0.45 / 0.51$ & $2 \times 3$ & US & Yes & 300 & Caudal & $15: 09: 25$ & $15: 13: 44$ & $15: 18: 02$ & No & & 39.64352 & $\begin{array}{c}2.24-4.47 \\
\mathrm{~N}\end{array}$ & Yes & nd \\
\hline
\end{tabular}




\begin{tabular}{|c|c|c|c|c|c|c|c|c|c|c|c|c|c|c|c|c|c|c|}
\hline $\begin{array}{l}\text { CHL Run } \\
\text { ID }\end{array}$ & Date/Time & $\begin{array}{c}\text { Run } \\
\text { Number }\end{array}$ & $\begin{array}{l}\text { Jet Exit } \\
\text { Velocity }\end{array}$ & Tow Speed & Tow & Tow Direction & Test & USFWS & Fin Clip & START & STOCK & $\begin{array}{l}\text { JET } \\
\text { PASS } \\
\end{array}$ & Test & Orange & Canal Discharge & Wind & $\begin{array}{l}\text { ADV } \\
\text { Data } \\
\end{array}$ & Jet Passage \\
\hline 15 & $\begin{array}{c}\text { 8/23/2017 } \\
15: 39 \mathrm{PM}\end{array}$ & 8 & 4.88 & $0.45 / 0.51$ & $2 \times 3$ & US & Yes & 300 & Anal & $15: 40: 30$ & $15: 43: 25$ & $15: 47: 11$ & No & & 39.64352 & $\stackrel{2.24-4.47}{\mathrm{~N}} \mathrm{~m} / \mathrm{s}$ & No & nd \\
\hline 16 & $\begin{array}{c}8 / 23 / 2017 \\
16: 23 \mathrm{PM}\end{array}$ & 9 & 4.88 & $1.79 / 1.60$ & $2 \times 3$ & US & No & & & & & & No & & 39.64352 & $<2.24 \mathrm{~m} / \mathrm{s}, \mathrm{N}$ & No & nd \\
\hline 17 & $\begin{array}{c}\text { 8/24/2017 } \\
\text { 08:45AM }\end{array}$ & 1 & 4.88 & $0.45 / 0.51$ & $1 \times 3$ & US & Yes & 296 & Dorsal & 8:46:05 & 8:49:11 & 8:53:10 & No & & 39.64352 & $<2.24 \mathrm{~m} / \mathrm{s}$. NW & No & $90 \%$ \\
\hline 18 & $\begin{array}{c}\text { 8/24/2017 } \\
\text { 09:10AM }\end{array}$ & 2 & 4.88 & $0.89 / 0.72$ & $1 \times 3$ & US & Yes & 299 & Caudal & 9:12:01 & 9:13:02 & 9:16:03 & No & & 39.64352 & $<2.24 \mathrm{~m} / \mathrm{s}, \mathrm{NW}$ & No & $35 \%$ \\
\hline 19 & $\begin{array}{c}\text { 8/24/2017 } \\
09: 41 \mathrm{AM}\end{array}$ & 3 & 4.88 & $0.45 / 0.46$ & $1 \times 3$ & US & Yes & 300 & $\begin{array}{l}\text { Bottom } \\
\text { Caudal }\end{array}$ & 9:40:50 & 9:43:33 & 9:47:40 & No & & 39.64352 & $<2.24 \mathrm{~m} / \mathrm{s}, \mathrm{N}$ & No & $35 \%$ \\
\hline 20 & $\begin{array}{c}8 / 24 / 2017 \\
10: 09 \mathrm{AM}\end{array}$ & 4 & 4.88 & $0.45 / 0.60$ & $1 \times 3$ & US & Yes & 100 & Both Caudal & $10: 05: 20$ & 10:13:11 & $10: 14: 00$ & Yes & IOUA 10 & 39.64352 & $<2.24 \mathrm{~m} / \mathrm{s}, \mathrm{N}$ & No & $40 \%$ \\
\hline 21 & $\begin{array}{c}8 / 24 / 2017 \\
10: 33 \mathrm{AM}\end{array}$ & 5 & 4.88 & $0.89 / 0.98$ & $1 \times 3$ & US & Yes & 299 & Anal & 10:33:16 & $10: 36: 43$ & $10: 37: 31$ & No & & 39.64352 & $<2.24 \mathrm{~m} / \mathrm{s} . \mathrm{N}$ & No & $10 \%$ \\
\hline 22 & $\begin{array}{c}\text { 8/24/2017 } \\
11: 00 \mathrm{AM}\end{array}$ & 6 & 4.88 & $0.89 / 0.89$ & $1 \times 3$ & US & Yes & 300 & Unclipped & 10:57:08 & 11:01:14 & 11:01:54 & No & & 39.64352 & $<2.24 \mathrm{~m} / \mathrm{s} . \mathrm{N}$ & No & $30 \%$ \\
\hline 23 & $\begin{array}{c}8 / 24 / 2017 \\
11: 17 A M\end{array}$ & 7 & 4.88 & $0.89 / 0.85$ & $1 \times 3$ & US & Yes & 300 & $\begin{array}{c}\text { Dorsal + } \\
\text { Anal }\end{array}$ & $11: 17: 50$ & 11:21:25 & 11:22:14 & No & & 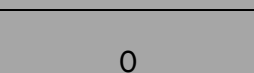 & $<2.24 \mathrm{~m} / \mathrm{s}, \mathrm{N}$ & No & $50 \%$ \\
\hline 24 & $\begin{array}{c}8 / 24 / 2017 \\
14: 13 P M\end{array}$ & 8 & 4.88 & $0.89 / 0.89$ & $1 \times 3$ & US & No & & 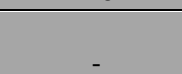 & $14 \cdot 14 \cdot 25$ & $14 \cdot 18 \cdot 16$ & $14 \cdot 19 \cdot 08$ & Yes & $119 \mathrm{RIP} 10$ & 0 & $<224 \mathrm{~m} / \mathrm{s} \mathrm{N}$ & No & $50 \%$ \\
\hline 25 & $\begin{array}{c}8 / 24 / 2017 \\
14: 34 \mathrm{PM}\end{array}$ & 9 & 4.88 & $1.79 / 1.80$ & $1 \times 3$ & US & No & & - & $14: 33: 45$ & $14: 36: 18$ & $14: 36: 42$ & Yes & 1ORIP 10 & 0 & $<224 \mathrm{~m} / \mathrm{s}$ & No & $30 \%$ \\
\hline 26 & $\begin{array}{l}8 / 24 / 2017 \\
14.53 \mathrm{PM}\end{array}$ & 10 & 488 & $1.79 / 1.75$ & $1 \times 3$ & US & Yes & 298 & Top caudal & $14: 52: 53$ & $14: 56: 09$ & $14: 56: 40$ & No & & 0 & $<224 \mathrm{~m} / \mathrm{s} \mathrm{N}$ & No & $40 \%$ \\
\hline 27 & $\begin{array}{l}8 / 24 / 2017 \\
15: 13 \mathrm{PM}\end{array}$ & 11 & 4.88 & $1.79 / 1.80$ & $1 \times 3$ & US & Yes & 299 & $\begin{array}{l}\text { Bottom } \\
\text { Caudal }\end{array}$ & $15: 12: 20$ & $15: 14: 44$ & $15: 15: 14$ & No & & 0 & $<2.24 \mathrm{~m} / \mathrm{s}, \mathrm{NE}$ & No & $50 \%$ \\
\hline 28 & $\begin{array}{l}8 / 24 / 2017 \\
15 \cdot 37 \mathrm{PM}\end{array}$ & 12 & 488 & $179 / 179$ & $1 \times 3$ & US & Yes & 299 & Both Caudal & $15: 37: 12$ & $15: 40: 26$ & $15: 40: 56$ & No & & 0 & $<224 \mathrm{~m} / \mathrm{s} N \mathrm{NF}$ & No & $50 \%$ \\
\hline $\begin{array}{r}28 \\
\text { (repeat) }\end{array}$ & $\begin{array}{l}8 / 25 / 2017 \\
08: 37 A M\end{array}$ & 1 & 4.88 & $0.89 / 0.94$ & $1 \times 3$ & US & Yes & 297 & Unclipped & $8: 35: 17$ & 8:39:33 & $8: 40: 17$ & No & & 39.64352 & $-5,-1,-1$, & No & $50 \%$ \\
\hline 29 & $\begin{array}{l}8 / 25 / 2017 \\
08: 58 \mathrm{AM}\end{array}$ & 2 & 4.88 & $0.89 / 0.93$ & $1 \times 3$ & US & Yes & 200 & Dorsal & $8: 58: 40$ & $9 \cdot 01 \cdot 36$ & $9 \cdot 02 \cdot 22$ & No & & & 0 & No & $40 \%$ \\
\hline 30 & $\begin{array}{c}8 / 25 / 2017 \\
09: 15 A M\end{array}$ & 3 & 4.88 & $0.89 / 0.94$ & $1 \times 3$ & US & Yes & 200 & $\begin{array}{l}\text { Upper } \\
\text { caudal }\end{array}$ & $9: 17: 30$ & 9:24:07 & $9: 25: 20$ & No & & & $<2.24 \mathrm{~m} / \mathrm{s}, \mathrm{E}$ & No & $50 \%$ \\
\hline 31 & $\begin{array}{c}8 / 25 / 2017 \\
\text { 09:50AM }\end{array}$ & 4 & 4.88 & $0.22 / 0.23$ & $1 \times 3$ & US & Yes & 195 & $\begin{array}{l}\text { Bottom } \\
\text { caudal }\end{array}$ & 9:48:30 & $10: 07: 26$ & $10: 10: 20$ & No & & 138.75232 & 0 & No & $50 \%$ \\
\hline 32 & $\begin{array}{c}8 / 25 / 2017 \\
10: 28 \mathrm{AM}\end{array}$ & 5 & 4.88 & $0.55 / 0.22$ & $1 \times 3$ & US & Yes & 197 & Both caudal & $10 \cdot 28 .-$ & $10 \cdot 39 \cdot 51$ & $10: 41: 50$ & No & & 13875232 & 0 & $\mathrm{No}$ & $n d$ \\
\hline 33 & $\begin{array}{c}8 / 25 / 2017 \\
11: 20 \mathrm{AM}\end{array}$ & 6 & $\sim 3.66$ & $0.89 / 0.89$ & $1 \times 3$ & US & Yes & 97 & Anal & $11: 24: 00$ & $11: 27: 42$ & 11:28:30 & No & & 39.64352 & 0 & No & $25 \%$ \\
\hline 34 & $\begin{array}{c}8 / 25 / 2017 \\
14: 20 \mathrm{PM}\end{array}$ & 7 & $\sim 3.66$ & $0.45 / 0.54$ & $1 \times 3$ & US & Yes & 93 & $\begin{array}{c}\text { Dorsal + top } \\
\text { caudal }\end{array}$ & $14: 21: 25$ & $14: 31$ & 14:32:15 & No & & 39.64352 & $<2.24 \mathrm{~m} / \mathrm{s}, \mathrm{E}$ & No & $50 \%$ \\
\hline 35 & $\begin{array}{c}8 / 25 / 2017 \\
14: 51 \mathrm{PM}\end{array}$ & 8 & $\sim 3.66$ & $1.79 / 1.79$ & $1 \times 3$ & us & Yes & 46 & $\underset{\substack{\text { Dorsal + } \\
\text { anal }}}{+}$ & $14: 50: 19$ & $14: 53: 16$ & $14: 54: 00$ & No & & 39.64352 & $<2.24 \mathrm{~m} / \mathrm{s}, \mathrm{E}$ & No & nd \\
\hline 36 & $\begin{array}{c}8 / 25 / 2017 \\
15: 14 \mathrm{PM}\end{array}$ & 9 & $\sim 3.66$ & 2.458 & $1 \times 3$ & US & No & & & & & & Yes & & 39.64352 & $<2.24 \mathrm{~m} / \mathrm{s}, \mathrm{NE}$ & No & $40 \%$ \\
\hline 37 & $\begin{array}{c}8 / 25 / 2017 \\
15: 31 \mathrm{PM}\end{array}$ & 10 & $\sim 3.66$ & $1.79 / 1.80$ & $1 \times 3$ & US & No & & & & & & Yes & 5PRPP 10 & 3964352 & $<224 \mathrm{~m} / \mathrm{s} . \mathrm{NF}$ & $\mathrm{No}$ & $50 \%$ \\
\hline 38 & $\begin{array}{l}8 / 25 / 2017 \\
15 \cdot 48 \mathrm{PM}\end{array}$ & 11 & $\sim 366$ & $0.89 / 0.93$ & $1 \times 3$ & us & $\mathrm{No}$ & & & & & & Yes & 4SI 6SRIP 10 & 3964352 & 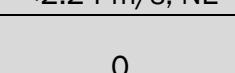 & No & $50 \%$ \\
\hline 39 & $8 / 25 / 2017$ & 12 & $\sim 366$ & $0.45 / 0.45$ & $1 \times 3$ & US & $\mathrm{No}$ & & & & & & Yes & $6 \mathrm{SI} 4 \mathrm{M} 10$ & 3964352 & $<224 \mathrm{~m} / \mathrm{s} \mathrm{NF}$ & $\mathrm{No}$ & $60 \%$ \\
\hline 40 & $\begin{array}{l}\text { 8.0.05/2017 } \\
\text { 08:53AM }\end{array}$ & 1 & 4.88 & $0.45 / 0.46$ & $1 \times 3$ & US & No & & & & & & Yes & $\begin{array}{l}2 \mathrm{~PB} 4 \mathrm{PJ} 3 \mathrm{SJ} \\
1 \mathrm{SM} 10\end{array}$ & 67.96032 & $2.24 \mathrm{II} / \mathrm{s}, \mathrm{NVL}$ & Yes & $40 \%$ \\
\hline 41 & $\begin{array}{c}\text { 8/28/2017 } \\
09: 13 \mathrm{AM}\end{array}$ & 2 & 4.88 & $0.89 / 0.93$ & $1 \times 3$ & US & No & & & & & & Yes & $\begin{array}{l}\text { 1PB 1PJ 1PM } \\
\text { 1SM 10 }\end{array}$ & 50.97024 & 0 & Yes & $50 \%$ \\
\hline 42 & $\begin{array}{c}\text { 8/28/2017 } \\
09: 27 \mathrm{AM}\end{array}$ & 3 & 4.88 & $1.79 / 1.80$ & $1 \times 3$ & US & No & & & & & & Yes & $\begin{array}{c}\text { 1SJ 5RIP 4 UA } \\
10\end{array}$ & 50.97024 & 0 & Yes & $50 \%$ \\
\hline 43 & $\begin{array}{c}\text { 8/28/2017 } \\
09: 46 \mathrm{AM}\end{array}$ & 4 & 4.88 & $0.45 / 0.51$ & $1 \times 3$ & US & No & & & & & & Yes & $\begin{array}{c}\text { 1PB 7PJ 1SJ } \\
\text { 1RIP 10 }\end{array}$ & 50.97024 & $<2.24 \mathrm{~m} / \mathrm{s}, \mathrm{s}$ & Yes & $50 \%$ \\
\hline
\end{tabular}




\begin{tabular}{|c|c|c|c|c|c|c|c|c|c|c|c|c|c|c|c|c|c|c|}
\hline $\begin{array}{l}\text { CHL Run } \\
\text { ID }\end{array}$ & Date/Time & $\begin{array}{c}\text { Run } \\
\text { Number }\end{array}$ & $\begin{array}{l}\text { Jet Exit } \\
\text { Velocity }\end{array}$ & Tow Speed & Tow & Tow Direction & Test & USFWS & Fin Clip & START & STOck & $\begin{array}{l}\text { JET } \\
\text { PASS }\end{array}$ & Test & Orange & Canal Discharge & Wind & $\begin{array}{l}\text { ADV } \\
\text { Data }\end{array}$ & Jet Passage \\
\hline 44 & $\begin{array}{c}\text { 8/28/2017 } \\
\text { 10:03AM }\end{array}$ & 5 & 4.88 & $0.89 / 0.89$ & $1 \times 3$ & US & No & & & & & & Yes & $\begin{array}{l}\text { 1SJ 3SM } \\
\text { 6SIP 10 }\end{array}$ & 50.97024 & $<2.24 \mathrm{~m} / \mathrm{s}, \mathrm{S}$ & Yes & $40 \%$ \\
\hline 45 & $\begin{array}{c}8 / 28 / 2017 \\
10: 20 \mathrm{AM}\end{array}$ & 6 & 4.88 & $1.79 / 1.80$ & $1 \times 3$ & US & No & & & & & & Yes & 1PB 7SRIP 10 & 50.97024 & $<2.24 \mathrm{~m} / \mathrm{s}$. SE & Yes & $40 \%$ \\
\hline 46 & $\begin{array}{c}8 / 28 / 2017 \\
10: 32 \mathrm{AM}\end{array}$ & 7 & 4.88 & $0.89 / 0.93$ & $1 \times 3$ & US & No & & & & & & Yes & $\begin{array}{l}\text { 1SJ 3JSM } \\
\text { 3SRIP } 10\end{array}$ & 50.97024 & 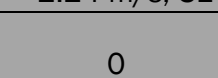 & Yes & $35 \%$ \\
\hline 47 & $\begin{array}{c}\text { 8/28/2017 } \\
10: 49 \mathrm{AM}\end{array}$ & 8 & $\sim 3.66$ & $0.45 / 0.46$ & $1 \times 3$ & US & No & & & & & & Yes & $8 \mathrm{SJ} 2 \mathrm{SM} 10$ & 50.97024 & 0 & Yes & $40 \%$ \\
\hline $48 \quad \longrightarrow$ & $\begin{array}{c}8 / 28 / 2017 \\
11: 06 \mathrm{AM}\end{array}$ & 9 & $\sim 3.66$ & $0.89 / 0.89$ & $1 \times 3$ & US & No & & & & & & Yes & $\begin{array}{l}\text { 8SJ 1SM } \\
\text { 1SRIP 10 }\end{array}$ & 50.97024 & $<2.24 \mathrm{~m} / \mathrm{s}, \mathrm{SE}$ & Yes & $50 \%$ \\
\hline 49 & $\begin{array}{c}\text { 8/28/2017 } \\
11: 24 \mathrm{AM}\end{array}$ & 10 & $\sim 3.66$ & $1.79 / 1.75$ & $1 \times 3$ & US & No & & & & & & Yes & 8 SRIP 2RIP 10 & 50.97024 & $<2.24 \mathrm{~m} / \mathrm{s}, \mathrm{SE}$ & Yes & $50 \%$ \\
\hline 50 & $\begin{array}{c}\text { 8/29/2017 } \\
\text { 08:30AM }\end{array}$ & 1 & $\sim 3.66$ & $0.45 / 0.51$ & $1 \times 3$ & US & Yes & 200 & Top caudal & 8:28:59 & 8:34:37 & 8:36:43 & No & & 39.64352 & 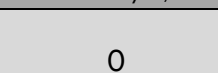 & Yes & $50 \%$ \\
\hline 51 & $\begin{array}{c}8 / 29 / 2017 \\
08: 48 A M\end{array}$ & 2 & $\sim 3.66$ & $0.89 / 0.93$ & $1 \times 3$ & US & Yes & 194 & $\begin{array}{l}\text { Bottom } \\
\text { caudal }\end{array}$ & 8:41:41 & 8:52:36 & 8:53:00 & No & & 39.64352 & 0 & Yes & $25 \%$ \\
\hline 52 & $\begin{array}{c}8 / 29 / 2017 \\
09: 05 A M\end{array}$ & 3 & $\sim 3.66$ & $1.79 / 1.79$ & $1 \times 3$ & US & Yes & 200 & Both caudal & 9:05:35 & $9: 08: 12$ & 9:08:43 & No & & 39.64352 & 0 & Yes & $30 \%$ \\
\hline 53 & $\begin{array}{c}\text { 8/29/2017 } \\
09: 19 A M\end{array}$ & 4 & $\sim 3.66$ & $n / a$ & $1 \times 3$ & US & Yes & 200 & Unclipped & 9:19:49 & $9: 23: 34$ & $9: 24: 24$ & No & & 39.64352 & 0 & Yes & $35 \%$ \\
\hline 54 & $\begin{array}{c}8 / 29 / 2017 \\
09: 33 A M\end{array}$ & 5 & $\sim 3.66$ & $0.89 / 0.89$ & $1 \times 3$ & US & Yes & 200 & Anal & $9: 34: 20$ & $9: 37: 04$ & 9:37:37 & No & & 39.64352 & 0 & Yes & $50 \%$ \\
\hline 55 & $\begin{array}{c}8 / 29 / 2017 \\
09: 50 A M \\
\end{array}$ & 6 & $\sim 3.66$ & $1.79 / 1.79$ & $1 \times 3$ & US & Yes & 200 & $\begin{array}{l}\text { Anal + } \\
\text { Bottom } \\
\text { caudal } \\
\end{array}$ & 9:53:32 & 9:56:36 & 9:56:56 & No & & 39.64352 & 0 & Yes & $50 \%$ \\
\hline 56 & $\begin{array}{c}8 / 29 / 2017 \\
10: 10 \mathrm{AM}\end{array}$ & 7 & $\sim 3.66$ & $n / a$ & $1 \times 3$ & US & No & & & $10: 09: 37$ & $10: 13: 47$ & $10: 14: 59$ & Yes & $\begin{array}{l}\text { 1PB 6PJ 1PM } \\
\text { 2PRIP } 10\end{array}$ & 39.64352 & 0 & Yes & $50 \%$ \\
\hline 57 & $\begin{array}{c}8 / 29 / 2017 \\
10: 24 \mathrm{AM}\end{array}$ & 8 & $\sim 3.66$ & $0.89 / 0.93$ & $1 \times 3$ & US & No & & & 10:24:04 & 10:26:45 & $10: 27: 23$ & Yes & $\begin{array}{c}\text { 1PB 7PJ 1SM } \\
\text { 1PRIP 10 }\end{array}$ & 39.64352 & $<2.24 \mathrm{~m} / \mathrm{s}$, & Yes & $40 \%$ \\
\hline 58 & $\begin{array}{c}8 / 29 / 2017 \\
10: 38 A M\end{array}$ & 9 & $\sim 3.66$ & $1.79 / 1.80$ & $1 \times 3$ & US & No & & & $10: 37: 41$ & - & $10: 40: 53$ & Yes & 3 SM 6SRIP 10 & 39.64352 & 0 & Yes & $50 \%$ \\
\hline 59 & $\begin{array}{c}8 / 29 / 2017 \\
10: 52 \mathrm{AM}\end{array}$ & 10 & 4.88 & $0.45 / 0.51$ & $1 \times 3$ & US & Yes & 197 & Dorsal & $10: 50: 03$ & $10: 55: 07$ & $10: 55: 47$ & No & & 39.64352 & 0 & Yes & $20 \%$ \\
\hline 60 & $\begin{array}{c}\text { 8/29/2017 } \\
11: 01 \mathrm{AM}\end{array}$ & 11 & 4.88 & $0.45 / 0.51$ & $1 \times 3$ & US & Yes & 205 & Top caudal & 11:01:40 & 11:05:44 & 11:06:27 & No & & 39.64352 & 0 & Yes & $50 \%$ \\
\hline 61 & $\begin{array}{c}8 / 29 / 2017 \\
11: 18 \mathrm{AM} \\
\end{array}$ & 12 & 4.88 & $0.89 / 0.98$ & $1 \times 3$ & US & Yes & 200 & $\begin{array}{l}\text { Bottom } \\
\text { caudal }\end{array}$ & 11:17:01 & 11:19:57 & 11:20:05 & No & & 39.64352 & 0 & Yes & $50 \%$ \\
\hline 62 & $\begin{array}{c}8 / 29 / 2017 \\
11: 31 \mathrm{AM} \\
\end{array}$ & 13 & 4.88 & $1.79 / 1.80$ & $1 \times 3$ & US & Yes & 200 & Both caudal & 11:31:55 & 11:34:44 & 11:34:57 & No & & 39.64352 & 0 & Yes & $50 \%$ \\
\hline 63 & $\begin{array}{c}\text { 8/29/2017 } \\
14: 15 \mathrm{PM}\end{array}$ & 14 & 4.88 & $0.45 / 0.51$ & $1 \times 3$ & US & Yes & 200 & Unclipped & $14: 14: 33$ & $14: 20: 08$ & 14:21:13 & No & & 39.64352 & 0 & Yes & $50 \%$ \\
\hline 64 & $\begin{array}{c}8 / 29 / 2017 \\
14: 30 P M\end{array}$ & 15 & 4.88 & $0.89 / 0.93$ & $1 \times 3$ & US & Yes & 200 & Anal & $14: 32: 00$ & $14: 34: 48$ & $14: 35: 08$ & No & & 39.64352 & 0 & Yes & $40 \%$ \\
\hline 65 & $\begin{array}{c}8 / 29 / 2017 \\
14: 46 \mathrm{PM} \\
\end{array}$ & 16 & 4.88 & $1.79 / 1.80$ & $1 \times 3$ & US & Yes & 200 & $\begin{array}{c}\text { Bottom } \\
\text { caudal + } \\
\text { anal } \\
\end{array}$ & 14:46:04 & 14:48:51 & 14:49:07 & No & & 39.64352 & 0 & Yes & $50 \%$ \\
\hline 66 & $\begin{array}{c}8 / 29 / 2017 \\
15: 00 P M\end{array}$ & 17 & 4.88 & $0.45 / 0.51$ & $1 \times 3$ & US & Yes & 200 & Dorsal & $14: 59: 41$ & 15:03:21 & 15:04:12 & No & & 39.64352 & 0 & Yes & $50 \%$ \\
\hline 67 & $\begin{array}{c}8 / 29 / 2017 \\
15: 16 \mathrm{PM}\end{array}$ & 18 & 4.88 & $0.89 / 0.89$ & $1 \times 3$ & US & Yes & 200 & Top caudal & $15: 15: 18$ & $15: 17: 59$ & $15: 18: 18$ & No & & 39.64352 & 0 & Yes & $60 \%$ \\
\hline 68 & $\begin{array}{c}8 / 29 / 2017 \\
15: 29 P M\end{array}$ & 19 & 4.88 & $1.79 / 1.80$ & $1 \times 3$ & US & Yes & 100 & $\begin{array}{l}\text { Bottom } \\
\text { caudal }\end{array}$ & $15: 29: 19$ & $15: 32: 15$ & 15:32:45 & No & & 39.64352 & 0 & Yes & nd \\
\hline 69 & $\begin{array}{c}\text { 8/29/2017 } \\
15: 42 P M\end{array}$ & 20 & 3.66 & $0.45 / 0.51$ & $1 \times 3$ & US & Yes & 100 & Both caudal & $15: 42: 55$ & $15: 46: 15$ & $15: 46: 50$ & No & & 39.64352 & $<2.24 \mathrm{~m} / \mathrm{s}, \mathrm{NE}$ & Yes & $60 \%$ \\
\hline 70 & $\begin{array}{c}8 / 29 / 2017 \\
15: 56 \mathrm{PM}\end{array}$ & 21 & 3.66 & $0.89 / 0.93$ & $1 \times 3$ & US & Yes & 100 & Unclipped & $15: 56: 58$ & $16: 00: 09$ & 16:00:37 & No & & 39.64352 & $<2.24 \mathrm{~m} / \mathrm{s}, \mathrm{NE}$ & Yes & $40 \%$ \\
\hline 71 & $\begin{array}{c}8 / 29 / 2017 \\
16: 12 \mathrm{PM}\end{array}$ & 22 & 3.66 & $1.79 / 1.80$ & $1 \times 3$ & US & Yes & 100 & Anal & $16: 12: 50$ & $16: 15: 20$ & $16: 15: 31$ & No & & 39.64352 & 0 & Yes & $50 \%$ \\
\hline
\end{tabular}




\begin{tabular}{|c|c|c|c|c|c|c|c|c|c|c|c|c|c|c|c|c|c|c|}
\hline $\begin{array}{l}\text { CHL Run } \\
\text { ID }\end{array}$ & Date/Time & $\begin{array}{c}\text { Run } \\
\text { Number }\end{array}$ & $\begin{array}{l}\text { Jet Exit } \\
\text { Velocity }\end{array}$ & Tow Speed & Tow & Tow Direction & Test & USFWS & Fin Clip & START & STOck & $\begin{array}{l}\text { JET } \\
\text { PASS }\end{array}$ & Test & Orange & Canal Discharge & Wind & $\begin{array}{l}\text { ADV } \\
\text { Data }\end{array}$ & Jet Passage \\
\hline 72 & $\begin{array}{c}8 / 29 / 2017 \\
16: 25 P M \\
\end{array}$ & 23 & 3.66 & $0.45 / 0.51$ & $1 \times 3$ & US & Yes & 100 & $\begin{array}{c}\text { Bottom } \\
\text { caudal }+ \\
\text { anal }\end{array}$ & $16: 25: 20$ & $16: 29: 45$ & $16: 30: 24$ & No & & 39.64352 & 0 & Yes & $30 \%$ \\
\hline 73 & $\begin{array}{l}8 / 29 / 2017 \\
16: 40 P M\end{array}$ & 24 & 3.66 & $0.89 / 0.93$ & $1 \times 3$ & US & Yes & 100 & Dorsal & $16: 39: 14$ & $16: 41: 51$ & $16: 42: 18$ & No & & 39.64352 & 0 & Yes & $50 \%$ \\
\hline 74 & $\begin{array}{l}8 / 29 / 2017 \\
16: 52 \mathrm{PM}\end{array}$ & 25 & 3.66 & $1.79 / 1.75$ & $1 \times 3$ & US & Yes & 100 & Top caudal & $16: 50: 00$ & $16: 54: 20$ & $16: 54: 33$ & No & & 39.64352 & 0 & Yes & nd \\
\hline 75 & $\begin{array}{l}8 / 29 / 2017 \\
17: 06 P M\end{array}$ & 26 & 3.66 & $0.45 / 0.51$ & $1 \times 3$ & US & ves & 100 & $\begin{array}{l}\text { Bottom } \\
\text { caudal }\end{array}$ & $17: 05: 55$ & $17: 10: 57$ & $17: 11: 40$ & No & & 39.64352 & 0 & Yes & $50 \%$ \\
\hline 76 & $\begin{array}{l}8 / 29 / 2017 \\
17: 21 \mathrm{PM}\end{array}$ & 27 & 3.66 & $0.89 / 0.93$ & $1 \times 3$ & US & Yes & 100 & both caudal & $17: 22: 17$ & $17: 24: 20$ & $17: 24: 42$ & No & & 39.64352 & 0 & Yes & $50 \%$ \\
\hline 77 & $\begin{array}{c}8 / 29 / 2017 \\
17: 36 \mathrm{PM}\end{array}$ & 28 & 3.66 & $1.79 / 1.82$ & $1 \times 3$ & US & Yes & 100 & Unclipped & $17 \cdot 35: 40$ & $17 \cdot 38: 35$ & $17: 38: 48$ & No & & 39.64352 & 0 & Yes & $40 \%$ \\
\hline 78 & $\begin{array}{l}8 / 30 / 2017 \\
08: 15 A M\end{array}$ & 1 & 0 & $0.45 / 0.51$ & $1 \times 3$ & US & Yes & 99 & Dorsal & $8 \cdot 14 \cdot 01$ & $8 \cdot 21 \cdot 03$ & $8 \cdot 22 \cdot 40$ & $\mathrm{No}$ & & 50.97024 & 0 & Yes & nd \\
\hline 79 & $\begin{array}{c}\text { 8/30/2017 } \\
08: 33 \mathrm{AM}\end{array}$ & 2 & 0 & $0.89 / 0.89$ & $1 \times 3$ & US & Yes & 100 & Top caudal & 8:33:13 & 8:36:41 & 8:36:59 & No & & 50.97024 & 0 & Yes & nd \\
\hline 80 & $\begin{array}{l}\text { 8/30/2017 } \\
\text { 08:49AM }\end{array}$ & 3 & 0 & $1.79 / 1.83$ & $1 \times 3$ & US & Yes & 100 & $\begin{array}{l}\text { Bottom } \\
\text { caudal }\end{array}$ & 8:49:- & 8:52:25 & 8:52:38 & No & & 50.97024 & 0 & Yes & nd \\
\hline 81 & $\begin{array}{c}\text { 8/30/2017 } \\
\text { 09:03AM }\end{array}$ & 4 & 0 & $0.45 / 0.45$ & $1 \times 3$ & US & Yes & 100 & Both caudal & 9:03:40 & 9:08:54 & 9:09:32 & No & & 5097024 & $<224 \mathrm{~m} / \mathrm{s} N \mathrm{~W}$ & Yes & nd \\
\hline 82 & $\begin{array}{l}\text { 8/30/2017 } \\
\text { 09:19AM }\end{array}$ & 5 & 0 & $0.89 / 0.89$ & $1 \times 3$ & US & Yes & 100 & Anal & 9:19:20 & 9:23:00 & $9: 23: 24$ & No & & 50.97024 & $<2.24 \mathrm{~m} / \mathrm{s}, \mathrm{NW}$ & Yes & nd \\
\hline 83 & $\begin{array}{l}\text { 8/30/2017 } \\
09: 34 A M\end{array}$ & 6 & 0 & $1.79 / 1.80$ & $1 \times 3$ & US & Yes & 99 & $\begin{array}{l}\text { Anal+bottom } \\
\text { caudal }\end{array}$ & 9:34:06 & $9: 37: 05$ & $9: 37: 28$ & No & & 50.97024 & $<224 \mathrm{~m} / \mathrm{s} N \mathrm{~W}$ & Yes & nd \\
\hline 84 & $\begin{array}{l}\text { 8/30/2017 } \\
\text { 09:49AM }\end{array}$ & 7 & 0 & $0.45 / 0.51$ & $1 \times 3$ & US & Yes & 100 & Unclipped & 9:47:26 & 9:52:14 & 9:53:15 & No & & 50.97024 & $<2.24 \mathrm{~m} / \mathrm{s}, \mathrm{NW}$ & Yes & nd \\
\hline 85 & $\begin{array}{l}8 / 30 / 2017 \\
09: 56 \mathrm{AM}\end{array}$ & 8 & 0 & $0.89 / 0.93$ & $1 \times 3$ & US & Yes & 100 & Dorsal & & 9:56:35 & & No & & 50.97024 & $<2.24 \mathrm{~m} / \mathrm{s}$. NW & Yes & nd \\
\hline 86 & $\begin{array}{l}8 / 30 / 2017 \\
10: 06 \mathrm{AM}\end{array}$ & 9 & 0 & $0.89 / 0.89$ & $1 \times 3$ & US & Yes & 100 & Top caudal & $10: 06: 23$ & $10: 08: 23$ & $10: 08: 44$ & No & & 50.97024 & $<2.24 \mathrm{~m} / \mathrm{s}, \mathrm{NW}$ & Yes & nd \\
\hline 87 & $\begin{array}{l}8 / 30 / 2017 \\
10: 11 \mathrm{AM}\end{array}$ & 10 & 0 & $0.89 / 0.89$ & $1 \times 3$ & US & Yes & 100 & $\begin{array}{l}\text { Bottom } \\
\text { caudal }\end{array}$ & & $10: 12: 02$ & $10: 13: 46$ & No & & 50.97024 & $<2.24 \mathrm{~m} / \mathrm{s} . \mathrm{N}$ & Yes & nd \\
\hline 88 & $\begin{array}{l}8 / 30 / 2017 \\
10 / 22 \mathrm{AM}\end{array}$ & 11 & 0 & $1.79 / 1.79$ & $1 \times 3$ & US & Yes & 100 & Both caudal & $10: 21: 30$ & $10: 24: 22$ & $10: 24: 38$ & No & & 50.97024 & $<2.24 \mathrm{~m} / \mathrm{s} . \mathrm{N}$ & Yes & $50 \%$ \\
\hline 89 & $\begin{array}{l}8 / 30 / 2017 \\
10: 38 \mathrm{AM}\end{array}$ & 12 & 2.44 & $0.45 / 0.45$ & $1 \times 3$ & US & Yes & 100 & Anal & $10: 35: 22$ & $10: 44: 22$ & $10: 45: 01$ & No & & 50.97024 & 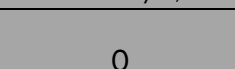 & $Y_{e s}$ & $50 \%$ \\
\hline 90 & $\begin{array}{c}8 / 30 / 2017 \\
10: 55 \mathrm{AM}\end{array}$ & 13 & 2.44 & $0.89 / 0.89$ & $1 \times 3$ & US & Yes & 100 & $\begin{array}{c}\text { Anal+bottom } \\
\text { caudal }\end{array}$ & $10: 55: 30$ & $10: 59: 53$ & 11:00:13 & No & & 50.97024 & 0 & Yes & $50 \%$ \\
\hline 91 & $\begin{array}{c}\text { 8/30/2017 } \\
11: 10 \mathrm{AM}\end{array}$ & 14 & 2.44 & $0.45 / 0.45$ & $1 \times 3$ & US & Yes & 100 & Unclipped & 11:11:01 & 11:15:34 & 11:16:30 & No & & 50.97024 & 0 & Yes & $50 \%$ \\
\hline 92 & $\begin{array}{c}\text { 8/30/2017 } \\
11: 26 \mathrm{AM}\end{array}$ & 15 & 2.44 & $0.89 / 0.89$ & $1 \times 3$ & US & Yes & 100 & Dorsal & $11: 26: 00$ & 11:29:26 & 11:29:42 & No & & 50.97024 & 0 & Yes & $50 \%$ \\
\hline 93 & $\begin{array}{c}8 / 30 / 2017 \\
11: 42 \mathrm{AM}\end{array}$ & 16 & 2.44 & $0.45 / 0.45$ & $1 \times 3$ & us & Yes & 100 & $\begin{array}{l}\text { Upper } \\
\text { caudal }\end{array}$ & $11: 42: 54$ & 11:49:41 & 11:50:29 & No & & 50.97024 & 0 & Yes & $50 \%$ \\
\hline
\end{tabular}




\section{Appendix B: Vessel Metrics for Each Test}

\begin{tabular}{|c|c|c|c|c|c|}
\hline Run ID & $\begin{array}{c}\text { Tow } \\
\text { Configuration }\end{array}$ & Speed $(\mathrm{m} / \mathrm{s})$ & $\begin{array}{l}\text { Heading } \\
\text { (degrees) }\end{array}$ & $\begin{array}{c}\text { Yaw } \\
\text { (degrees/minute) }\end{array}$ & $\begin{array}{l}\text { Crossing Distance } \\
\text { (m) }\end{array}$ \\
\hline 1 & '2×3' & 0.54 & 8.3 & 0.7 & -2.1 \\
\hline 2 & '2x3' & 0.50 & 9.0 & 4.3 & -3.9 \\
\hline 3 & '2x3' & 0.52 & 12.4 & -2.9 & 11.8 \\
\hline 4 & '2x3' & 0.99 & 11.1 & 0.1 & -0.2 \\
\hline 5 & '2x3' & 0.93 & 359.2 & -0.8 & -11.4 \\
\hline 6 & '2x3' & 0.92 & 7.6 & 1.9 & -2.7 \\
\hline 7 & '2x3' & 1.57 & 2.4 & 1.2 & -8.5 \\
\hline 8 & '2x3' & 0.48 & 10.0 & -0.1 & 4.4 \\
\hline 9 & '2x3' & 0.50 & 9.4 & 0.1 & 8.2 \\
\hline 10 & '2x3' & 0.52 & 7.9 & -0.2 & 3.6 \\
\hline 11 & '2×3' & 0.53 & 6.0 & -0.8 & 2.2 \\
\hline 12 & '2x3' & 1.65 & 6.0 & -2.3 & 1.7 \\
\hline 17 & '1x3' & 0.50 & 4.0 & -1.2 & 2.3 \\
\hline 18 & '1x3' & 0.66 & 13.2 & -0.6 & 11.5 \\
\hline 19 & '1×3' & 0.46 & 7.5 & -1.4 & 0.7 \\
\hline 20 & '1×3' & 0.43 & 7.7 & 3.2 & -0.5 \\
\hline 21 & '1x3' & 0.95 & 5.5 & 0.7 & -3.6 \\
\hline 22 & '1x3' & 0.92 & 5.8 & -0.4 & -1.1 \\
\hline 23 & '1x3' & 0.88 & 6.1 & -0.6 & 0.7 \\
\hline 24 & '1x3' & 0.91 & 6.8 & 0.2 & 2.3 \\
\hline 25 & '1x3' & 1.81 & 8.6 & 2.0 & 2.5 \\
\hline 26 & $' 1 \times 3 '$ & 1.76 & 5.8 & -0.8 & -0.8 \\
\hline 27 & '1x3' & 1.72 & 7.6 & 0.5 & 1.4 \\
\hline 28 & '1x3' & 1.77 & 5.4 & 0.8 & -4.7 \\
\hline 28 & '1×3' & 0.95 & 6.8 & -0.3 & 5.6 \\
\hline 29 & '1x3' & 0.93 & 9.8 & -0.7 & 10.0 \\
\hline 30 & '1x3' & 0.94 & 12.2 & -0.3 & 12.2 \\
\hline 31 & '1x3' & 0.25 & 6.6 & -0.6 & 0.8 \\
\hline
\end{tabular}




\begin{tabular}{|c|c|c|c|c|c|}
\hline Run ID & $\begin{array}{c}\text { Tow } \\
\text { Configuration }\end{array}$ & Speed $(\mathrm{m} / \mathrm{s})$ & $\begin{array}{l}\text { Heading } \\
\text { (degrees) }\end{array}$ & $\begin{array}{c}\text { Yaw } \\
\text { (degrees/minute) }\end{array}$ & $\begin{array}{l}\text { Crossing Distance } \\
\text { (m) }\end{array}$ \\
\hline 32 & '1x3' & 0.25 & 6.6 & -1.2 & 3.0 \\
\hline 33 & '1x3' & 0.89 & 6.5 & -1.1 & -0.5 \\
\hline 34 & '1x3' & 0.55 & 8.4 & 0.8 & 2.4 \\
\hline 35 & '1x3' & 1.78 & 8.9 & 1.6 & 2.3 \\
\hline 36 & '1x3' & 2.37 & 7.8 & -1.1 & -0.1 \\
\hline 37 & '1x3' & 1.74 & 4.5 & 1.9 & -4.1 \\
\hline 38 & '1x3' & 0.92 & 7.6 & -0.4 & 0.3 \\
\hline 39 & '1x3' & 0.53 & 7.4 & 0.4 & 0.8 \\
\hline 40 & '1x3' & 0.48 & 9.4 & 0.9 & 5.2 \\
\hline 41 & '1x3' & 0.91 & 9.8 & -0.7 & 10.0 \\
\hline 42 & '1x3' & 1.76 & 9.7 & 0.0 & 4.8 \\
\hline 43 & '1x3' & 0.50 & 7.3 & 1.1 & 2.0 \\
\hline 44 & '1x3' & 0.94 & 6.9 & 0.0 & 1.6 \\
\hline 45 & '1×3' & 1.77 & 6.2 & -0.9 & -1.2 \\
\hline 46 & '1x3' & 0.89 & 7.8 & -0.6 & 0.8 \\
\hline 47 & '1x3' & 0.46 & 6.5 & 0.0 & 2.9 \\
\hline 48 & '1x3' & 0.90 & 6.0 & -0.4 & 0.8 \\
\hline 49 & '1x3' & 1.72 & 5.6 & 0.4 & -1.9 \\
\hline 50 & '1×3' & 0.50 & 6.7 & 0.9 & 1.9 \\
\hline 51 & '1×3' & 0.89 & 8.8 & 0.3 & 3.1 \\
\hline 52 & '1x3' & 1.74 & 7.8 & -0.4 & 6.7 \\
\hline 53 & '1x3' & 0.52 & 6.3 & 0.7 & -0.8 \\
\hline 54 & '1×3' & 0.89 & 5.4 & 1.1 & -0.2 \\
\hline 55 & '1x3' & 1.75 & 8.0 & 0.4 & 1.5 \\
\hline 56 & '1x3' & 0.46 & 4.1 & -1.7 & -1.4 \\
\hline 57 & '1x3' & 0.91 & 8.5 & 3.2 & -2.2 \\
\hline 58 & '1x3' & 1.74 & 8.1 & -0.3 & 3.4 \\
\hline 59 & '1x3' & 0.46 & 9.1 & 2.7 & -1.3 \\
\hline 60 & '1x3' & 0.53 & 4.8 & 0.3 & -0.8 \\
\hline 61 & '1x3' & 0.93 & 8.3 & 0.0 & 4.2 \\
\hline 62 & '1×3' & 1.75 & 9.2 & 0.6 & 4.2 \\
\hline
\end{tabular}




\begin{tabular}{|c|c|c|c|c|c|}
\hline Run ID & $\begin{array}{c}\text { Tow } \\
\text { Configuration }\end{array}$ & Speed $(\mathrm{m} / \mathrm{s})$ & $\begin{array}{l}\text { Heading } \\
\text { (degrees) }\end{array}$ & $\begin{array}{c}\text { Yaw } \\
\text { (degrees/minute) }\end{array}$ & $\begin{array}{l}\text { Crossing Distance } \\
\qquad(\mathrm{m})\end{array}$ \\
\hline 63 & '1x3' & 0.48 & 7.6 & -1.6 & 2.0 \\
\hline 64 & '1x3' & 0.91 & 7.3 & -0.6 & 0.7 \\
\hline 65 & '1x3' & 1.75 & 9.6 & -2.4 & 5.2 \\
\hline 66 & '1x3' & 0.51 & 8.4 & 0.5 & 1.4 \\
\hline 67 & '1x3' & 0.86 & 13.1 & 0.3 & 9.0 \\
\hline 68 & '1x3' & 1.76 & 9.3 & 0.2 & 0.3 \\
\hline 69 & '1x3' & 0.55 & 9.1 & -0.3 & 2.8 \\
\hline 70 & '1x3' & 0.95 & 8.8 & 1.7 & 1.2 \\
\hline 71 & '1x3' & 1.78 & 8.3 & -1.3 & 1.9 \\
\hline 72 & '1x3' & 0.52 & 7.4 & 0.7 & -2.4 \\
\hline 73 & '1x3' & 0.93 & 6.7 & 1.9 & -2.0 \\
\hline 74 & '1x3' & 1.67 & 9.9 & -4.6 & 2.9 \\
\hline 75 & '1x3' & 0.55 & 7.9 & 1.3 & 0.8 \\
\hline 76 & '1x3' & 0.90 & 8.3 & -0.4 & 4.9 \\
\hline 77 & '1x3' & 1.74 & 4.1 & -0.2 & -4.8 \\
\hline 78 & '1x3' & 0.51 & 3.9 & 0.3 & -3.7 \\
\hline 79 & '1×3' & 0.93 & 8.4 & -1.0 & 3.3 \\
\hline 80 & '1x3' & 1.76 & 10.9 & 0.1 & 7.8 \\
\hline 81 & '1x3' & 0.49 & 7.4 & -0.2 & 1.7 \\
\hline 82 & '1×3' & 0.90 & 5.9 & 0.9 & -1.5 \\
\hline 83 & '1×3' & 1.72 & 6.0 & 1.6 & -3.7 \\
\hline 84 & '1x3' & 0.49 & 7.7 & 0.8 & 0.9 \\
\hline 86 & '1x3' & 0.95 & 5.7 & -1.3 & -6.8 \\
\hline 88 & '1x3' & 1.74 & 6.4 & 2.5 & -1.9 \\
\hline 89 & '1×3' & 0.51 & 7.2 & -2.1 & 1.9 \\
\hline 90 & '1x3' & 0.90 & 6.6 & -0.8 & -1.1 \\
\hline 91 & '1x3' & 0.49 & 6.2 & -0.6 & 1.8 \\
\hline 92 & '1x3' & 0.87 & 7.4 & 0.5 & 0.8 \\
\hline 93 & '1x3' & 0.48 & 5.3 & 0.3 & -4.7 \\
\hline
\end{tabular}




\section{Unit Conversion Factors}

\begin{tabular}{|l|l|l|}
\hline Multiply & \multicolumn{1}{|c|}{ By } & To Obtain \\
\hline cubic feet & 0.02831685 & cubic meters \\
\hline degrees (angle) & 0.01745329 & radians \\
\hline feet & 0.3048 & meters \\
\hline inches & 0.0254 & meters \\
\hline kip & 4448.221 & Newtons \\
\hline pound (force) & 4.44822 & Newtons \\
\hline ton & 8896.44 & Newtons \\
\hline
\end{tabular}




\section{Acronyms and Abbreviations}

\begin{tabular}{ll} 
ADCP & acoustic Doppler current profiler \\
ADV & acoustic Doppler velocimeters \\
AIS & Automatic Identification System \\
CAWS & Chicago Area Waterway System \\
CHL & Coastal and Hydraulics Laboratory \\
CSSC & Chicago Sanitary and Ship Canal \\
ERDC & US Army Engineer Research and Development Center \\
GPS & Global Positioning System \\
HDP & high density polyethylene \\
Hz & hertz \\
kg & kilogram \\
km & kilometer \\
kW & kilowatt \\
LPMS & Lock Performance Monitoring System \\
LRC & US Army Engineer District, Chicago \\
m & meter \\
m/s & meter per second \\
m3/s & cubic meter per second \\
ms & millisecond \\
MVR & US Army Engineer District, Rock Island \\
STD & standard deviation \\
USACE & US Army Corps of Engineers \\
USFWS & US Fish and Wildlife Service \\
USGS & US Geological Survey \\
volt/cm & volt per centimeter \\
\hline
\end{tabular}




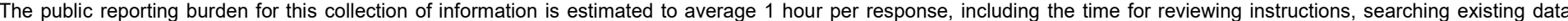

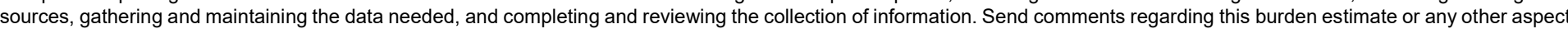

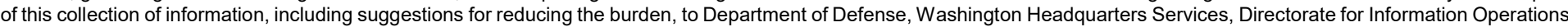

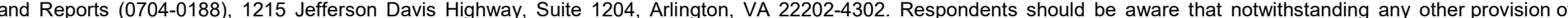
law, no person shall be subject to any penalty for failing to comply with a collection of information if it does not display a currently valid OMB control number.

PLEASE DO NOT RETURN YOUR FORM TO THE ABOVE ADDRESS.

\begin{tabular}{l|l|l}
\hline $\begin{array}{l}\text { 1. REPORT DATE } \\
\text { November } 2019\end{array}$ & $\begin{array}{l}\text { 2. REPORT TYPE } \\
\text { Final Report }\end{array}$ & 3. DATES COVERED (FrOm - To)
\end{tabular}

\section{TITLE AND SUBTITLE}

Prototype Test of a Water Jet System to Mitigate the Transport of Asian Carp by Barges 5a. CONTRACT NUMBER

5b. GRANT NUMBER

5c. PROGRAM ELEMENT NUMBER

5d. PROJECT NUMBER

W81G6672098667

5e. TASK NUMBER

5f. WORK UNIT NUMBER

8. PERFORMING ORGANIZATION REPORT NUMBER

ERDC/CHL TR-19-20

3909 Halls Ferry Road

Vicksburg, MS 39180-6199

9. SPONSORING/MONITORING AGENCY NAME(S) AND ADDRESS(ES)

US Army Corps of Engineers, Chicago District

10. SPONSOR/MONITOR'S ACRONYM(S)

USACE LRC

111 North Canal Street, Suite 600

Chicago, IL 60606-7206

11. SPONSOR/MONITOR'S REPORT NUMBER(S)

\section{DISTRIBUTION/AVAILABILITY STATEMENT}

Approved for public release; distribution is unlimited.

\section{SUPPLEMENTARY NOTES}

\section{ABSTRACT}

The potential migration of Asian carp through the Illinois River, Des Plaines River, and Chicago Area Waterway System is one risk factor facing the Great Lakes today. In an effort to mitigate this risk, the US Army Corps of Engineers has installed a series of electric dispersal barriers within the Chicago Sanitary and Ship Canal (CSSC) near Romeoville, IL, to deter fish from using the canal as a pathway to enter the Great Lakes. Previous laboratory studies have shown that tows produce residual currents and forces that can entrain and potentially transport fish across the barrier. The US Army Engineer Research and Development Center was tasked by US Army Corps of Engineers, Chicago District, to investigate mitigation measures to remove entrained fish from the recesses between barges. A full-scale prototype jet manifold was constructed and tested in the CSSC to determine the degree to which the jets could dislodge or remove fish during passage. Similar to previous laboratory studies, the jets were most effective for slow tow speeds $(<1$ meter per second $[\mathrm{m} / \mathrm{s}])$ and higher jet velocities $(4.9 \mathrm{~m} / \mathrm{s})$. For higher vessel speeds, the barges passed more quickly over the array, which reduced the exposure time and the number of tracers flushed.

\section{SUBJECT TERMS}

Barges, Bighead carp—Migration, Introduced aquatic organisms, Nonindigenous pests, Silver Carp-Migration, Water jets, Waterways

\section{SECURITY CLASSIFICATION OF:}

\begin{tabular}{|l|c|l|}
\hline a. REPORT & b. ABSTRACT & c. THIS PAGE \\
Unclassified & Unclassified & Unclassified \\
& & \\
\hline
\end{tabular}

17. LIMITATION OF ABSTRACT

SAR
18. NUMBER OF PAGES

84 19a. NAME OF RESPONSIBLE PERSON Duncan B. Bryant

19b. TELEPHONE NUMBER (Include area code) 601-634-3898 